\title{
Qualifications of Candle Filters for Combined Cycle Combustion Applications
}

\section{Final Report}

\author{
REPORTING PERIOD:
}

FROM: October 1, 2003 THROUGH: August 31, 2008

Principal Authors:

Jenny Tennant, Project Manager

Tomasz Wiltowski, Principal Investigator

Report Issued: November 2008

DOE Award Number: DE-FC26-03NT41839

Submitted by:

Southern Illinois University - Carbondale

Carbondale, IL 62901 


\section{DISCLAIMER}

This report was prepared as an account of the work sponsored by an agency of the United States Government. Neither the United States Government nor any agency thereof, nor any of their employees, makes any warranty, express or implied, or assumes any legal liability or responsibility for the accuracy, completeness, or usefulness of any information, apparatus, product, or process disclosed, or represents that its use would not infringe privately owned rights. Reference herein to any specific commercial product, process or service by trade name, trademark or manufacturer, or otherwise does not necessarily constitute or imply its endorsement, recommendation, or favoring by the United States Government or any agency thereof. The views and opinions of authors expressed herein do not necessarily state or reflect those of the United States Government or any agency thereof. 


\begin{abstract}
The direct firing of coal produces particulate matter that has to be removed for environmental and process reasons. In order to increase the current advanced coal combustion processes, under the U.S. Department of Energy's auspices, Siemens Westinghouse Power Corporation (SWPC) has developed ceramic candle filters that can operate at high temperatures. The Coal Research Center of Southern Illinois University (SIUC), in collaboration with SWPC, developed a program for long-term filter testing at the SIUC Steam Plant followed by experiments using a single-filter reactor unit. The objectives of this program funded by the U.S. Department of Energy were to identify and demonstrate the stability of porous candle filter elements for use in high temperature atmospheric fluidized-bed combustion (AFBC) process applications. These verifications were accomplished through extended time slipstream testing of a candle filter array under AFBC conditions using SIUC's existing AFBC boiler. Temperature, mass flow rate, and differential pressure across the filter array were monitored for a duration of 45 days. After test exposure at SIUC, the filter elements were characterized using Scanning Electron Microscopy and BET surface area analyses. In addition, a single-filter reactor was built and utilized to study long term filter operation, the permeability exhibited by a filter element before and after the slipstream test, and the thermal shock resilience of a used filter by observing differential pressure changes upon rapid heating and cooling of the filter. The data acquired during the slipstream test and the post-test evaluations demonstrated the suitability of filter elements in advanced power generation applications.
\end{abstract}




\section{TABLE OF CONTENTS}

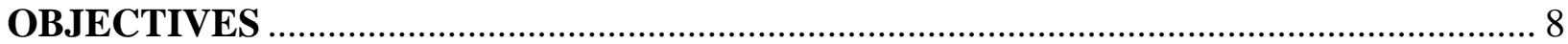

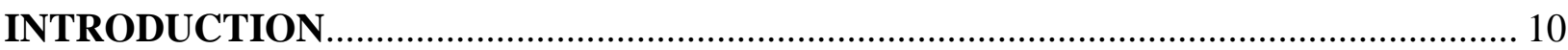

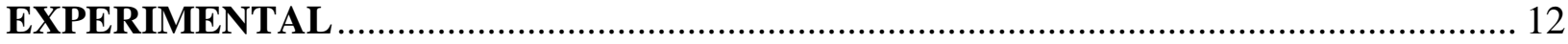

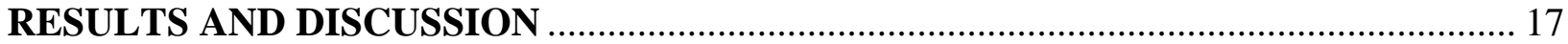

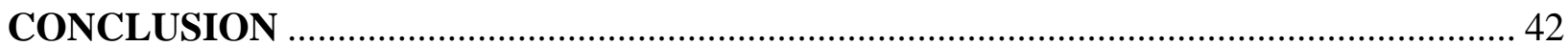

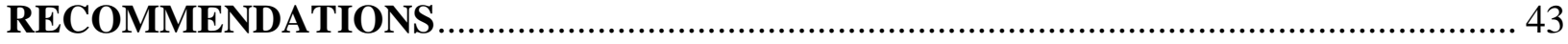

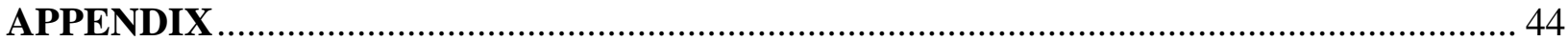




\section{LIST OF FIGURES}

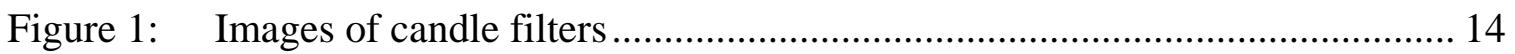

Figure 2: Image of filters mounted in slipstream vessel............................................. 15

Figure 3: Drawing of single-filter reactor............................................................. 15

Figure 4: (top) Controller box, differential pressure meter and solenoid valves;

(bottom) Reactor and furnace ......................................................................... 16

Figure 5: Shake-down data for pressure drop across the slipstream ............................. 18

Figure 6: Shake-down data for flow rate through the slipstream ................................. 18

Figure 7: Complete differential pressure profile for the slipstream test........................ 19

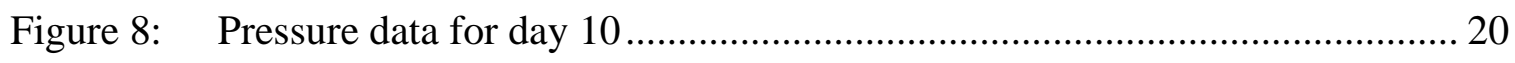

Figure 9: $\quad$ Pressure data for day 20 .................................................................... 20

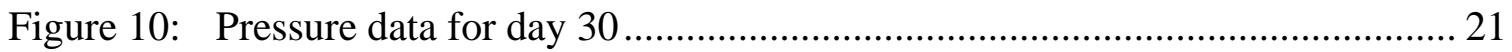

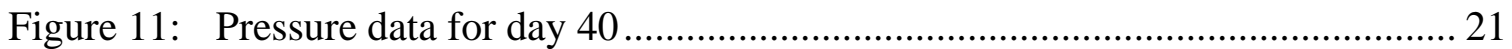

Figure 12: Photo of the rings of the new (right) and used (left) filter ............................. 22

Figure 13: Scanning electron micrograph of the fresh filter (x250).............................. 23

Figure 14: Scanning electron micrograph of the used filter (x250) ............................... 24

Figure 15: Scanning electron micrograph of the fresh filter (x1000)............................. 24

Figure 16: Scanning electron micrograph of the used filter (x1000) ............................. 25

Figure 17: Plot of pressure drop across a new filter verses air flow rate at different temperatures................................................................................................ 30

Figure 18: Plot of pressure drop across a used filter verses air flow rate at different temperatures.......................................................................................... 31

Figure 19: Plot of pressure drop across new and used filters verses temperature........... 31

Figure 20: Thermal shock (used filter, air only, flow=14 L/min) .................................. 32

Figure 21: Used filter with $14 \mathrm{~L} / \mathrm{min}$ air and $0.3-0.35 \mathrm{~g} / \mathrm{min}$ flyash ............................. 33

Figure 22: Used filter with $14 \mathrm{~L} / \mathrm{min}$ air, $0.3-0.35 \mathrm{~g} / \mathrm{min}$ flyash, and $0.7 \mathrm{~L} / \mathrm{min}$ steam . 34

Figure 23: Pictures of the filter loaded with flyash after being subjected to an air/flyash/steam mixture for nearly 130 hours................................................ 35

Figure 24: Thermal shock (used filter with flyash caked on, air flow=14 L/min) ......... 36

Figure 25: Used filter with $17.8 \mathrm{~L} / \mathrm{min}$ air, $0.3-0.35 \mathrm{~g} / \mathrm{min}$ flyash, and $0.9 \mathrm{~L} / \mathrm{min}$ steam

Figure 26: Thermal shock (used filter with flyash caked on, air flow=17.8 L/min) ...... 37

Figure 27: “Single Filter” operation 1-30 days 
Figure 28: “Single Filter” operation 31-60 days

Figure 29: “Single Filter” operation 61-91 days

Figure 30: “Single Filter” operation 92-115 days

Figure 31: “Single Filter” operation 116-170 days

Figure 32: “Single Filter” operation 171-220 days

Figure 33: “Single Filter” operation 221-276 days

\section{LIST OF TABLES}

Table 1: Current approaches to hot gas particulate removal ..................................... 10

Table 2: $\quad$ The permeability $(\beta)$ values for fresh and 45 days used (before and after

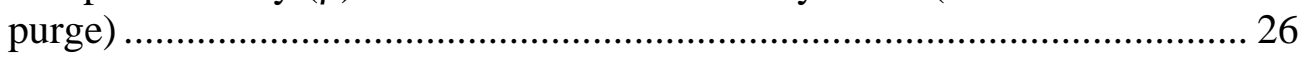

Table 3: $\quad$ BET measurement of the fresh filter (adsorption) ..................................... 27

Table 4: $\quad$ BET measurement of the fresh filter (desorption) ..................................... 27

Table 5: $\quad$ BET measurement of the fresh filter (surface area summary) ...................... 28

Table 6: $\quad$ BET measurement of the filter after 45 days (adsorption).......................... 28

Table 7: $\quad$ BET measurement of the filter after 45 days (desorption)........................... 29

Table 8: $\quad$ BET measurement of the filter after 45 days (surface area summary) ......... 29 


\section{EXECUTIVE SUMMARY}

Responding to Area of Interest 1, "Combustion Systems" and Subtopic 1 - Advanced Filtration, Southern Illinois University and Siemens Westinghouse Power Corporation (SWPC) proposed and completed a multi-year program to verify suitability of newly developed, but heretofore unqualified, hot gas filtration media to support commercial adoption of Pressurized Fluidized Bed Combustion (PFBC), Advanced PFBC, and hybrid gasification/combustion cycles. The program demonstrated the long term reliability and robustness of these filter media and filter systems under conditions typical of AFBC applications, capabilities of the filtration systems to clean gaseous products to levels suitable for introduction to a gas turbine. The filters performance long-term tests were accompanied by additional experiments in which the permeability of the filter, BET surface areas, SEM surface morphology, permeability, pressure drop, and thermal shock resistance were determined.

The Solicitation called for qualification of filter media and systems in a temperature range of $600{ }^{\circ} \mathrm{F}$ to $1200{ }^{\circ} \mathrm{F}$, however, this work demonstrated the feasibility of hot gas filtration at a higher temperature regime of $1550{ }^{\circ} \mathrm{F}$ to $1650{ }^{\circ} \mathrm{F}$. Application of hot gas filtration at this higher temperature regime will further enhance the power plant system efficiency and increase the financial payback of the new technology. The program produced data on filter system life that will support an investment decision for power plants utilizing the advanced combustion concepts. From this verification of suitability of filter systems and filter media at higher temperature regimes, plant operating efficiencies, emissions and availabilities should be considerably improved over that of PFBC systems using cyclones for gas cleaning.

Issues related to hot gas filtration at temperatures of $\sim 870{ }^{\circ} \mathrm{C}\left(\sim 1600{ }^{\circ} \mathrm{F}\right)$ were identified through conduct of this program (i.e., physical integrity of the elements; bowing, stability of the filter matrix, etc.). The long-term viability (i.e., $>8,000$ hours of service life) of currently existing filter elements in advanced, high temperature, AFBC environments were identified. Cost and risk factors were reduced through slipstream testing, minimizing potential downtime during operation in pilot and demonstration plant test facilities with elements that have shown both acceptable performance and life (i.e., particle collection efficiency: $>99.999 \%$; retention of gas flow resistance: $10 \mathrm{ft} / \mathrm{min}$ at 1 atm pressure; >8000 hrs service operation) under slipstream, AFBC test conditions.

Ceramic filters used in hot flue gas cleaning applications were tested in the slipstream long-term operation (Steam Plant-SIUC) and also tested in the different experiments using a so called "single-filter" unit located in the SIUC Coal Development Park. The slipstream test indicated no changes in the differential pressure between the cleaning air pulses, and upon visual inspection of the filters after the test, no cracks, bends, or other defects were found. It was concluded that pulsing the air in the reverse direction sufficiently breaks off the filter cake and restores the original permeability of the filters. The thermal shock experiments in the single-filter reactor indicated that rapid cooling and heating in the temperature range of $180{ }^{\circ} \mathrm{F}-1500{ }^{\circ} \mathrm{F}$ did not result in detrimental effects 
on the filter. The filters maintained functionality throughout all of the efforts in this work.

\section{OBJECTIVES}

The overall objectives of this effort were (1) to identify and demonstrate the stability of porous candle filter elements for use in high temperature $\left(\sim 870^{\circ} \mathrm{C}, \sim 1600^{\circ} \mathrm{F}\right)$, pressurized fluidized-bed combustion (PFBC) process applications, (2) to define their overall reliability and life based on long-term testing, (3) use comparative analyses (SEM, BET, etc.) of the filters before and after testing to explain the likely sources of failure, and lastly, (4) to examine by experimentation the thermal shock resistance exhibited by the filters in order to predict the effects of operational mishaps. These objectives were primarily accomplished through a 45 day slipstream testing of a twelve candle filter element array under atmospheric fluidized-bed combustion (AFBC) conditions at Southern Illinois University Carbondale (SIUC) followed by the "Single-filter" system operation for 276 days.

The process of obtaining the permits (both air and construction) from the Illinois Environmental Protection Agency was completed. All the necessary forms including additional forms IEPA requested were submitted, and reviewed and approved by the IEPA personnel.

SIUC AFBC testing was conducted in collaboration with the Siemens Westinghouse Power Corporation, Science and Technology Center (SWPC STC). The conceptual and detailed equipment design of the twelve candle filter array system was the responsibility of SWPC. This included design of the vessel and internals, and of the pulse cleaning skid. SIUC provided the overall plant and test site engineering, and was responsible for the design and modification to the AFBC equipment to provide the slipstream of flue gas. SIUC designed and procured the inlet hot gas ducting, inlet ash removal equipment, outlet gas ducting, filter vessel drain, solids handling and disposition equipment, instrumentation and electrical power, compressed air, and other auxiliaries required for operation of the $>815-870^{\circ} \mathrm{C}\left(>1500-1600^{\circ} \mathrm{F}\right)$ particulate removal filter system. After completion of the slipstream test, post-test filter analyses were conducted by SIUC. Scanning Electron Microscopy was conducted at SIUC's IMAGE Center and BET surface area analysis was conducted at the Illinois Coal Development Park (ICDP) in Carterville, IL. The single-filter reactor system (for permeability, back-pressure, and thermal shock tests) was also designed and constructed at ICDP by SIUC staff.

The work was divided into seven major tasks, thus the result section is reported according to the task structure below:

Task 1 - Filter System Conceptual Design

Task 2 - Filter Facility and Equipment Detailed Design

Task 3 - Equipment Procurement and Installation

Task 4 - AFBC Filtration Testing

Task 5 - Filter Performance and Materials Assessment 
Task 6 - Thermal Shock Tests in a Single-Filter Reactor

Task 7. “Single Filter” Long Term Experiments 


\section{INTRODUCTION}

There are several techniques available for hot gas particulate removal. Table 1 lists all of these techniques (Mitchell, S.C., 1997, "Hot gas particulate filtration", IEA Coal Research, report IEACR/95, London). Filter systems are the main alternative for ESP flue gas cleaning. Filter systems offer very high collection efficiencies of typically above $99 \%$, over rather large size ranges. They have the advantage over ESPs in that the electrical resistivity of the particles does not play any role, making them competitive for high-resistivity ashes. In the filter systems, gases (and also liquids) are separated from dispersed particles by passing it through a fabric or ceramic filter "medium" with a large surface area. Particles that are not able to penetrate the medium will be retained on its surface, forming the so called "filter cake". Generally, this filter cake is equally important to the actual filtration process as the medium.

Table 1: $\quad$ Current approaches to hot gas particulate removal

\begin{tabular}{|c|c|c|c|c|c|c|}
\hline Device & Capture mechanism & Rejection mechanism & $\begin{array}{l}\text { Pressure } \\
\text { drop }\end{array}$ & $\begin{array}{l}\text { Flow } \\
\text { capacity }\end{array}$ & $\begin{array}{l}\text { Particle } \\
\text { removal }\end{array}$ & Status \\
\hline Cyclones & Inertial concentration & $\begin{array}{l}\text { Gravity flow of fly ash } \\
\text { (continuous) }\end{array}$ & High & Moderate & Moderate & Commercial \\
\hline $\begin{array}{l}\text { Electrostatic } \\
\text { precipitators }\end{array}$ & $\begin{array}{l}\text { Particle charging and } \\
\text { migration to plates }\end{array}$ & $\begin{array}{l}\text { Mechanical rapping of } \\
\text { plates (intermittent) }\end{array}$ & Very low & Moderate & Moderate & Pilot scale \\
\hline Bag filters & Cake formation & $\begin{array}{l}\text { Back pulse with clean } \\
\text { gas (intermittent) }\end{array}$ & Low & Moderate & High & $\begin{array}{l}\text { Demonstration } \\
\text { scale planned }\end{array}$ \\
\hline Granular beds filters & Impact/diffusion & $\begin{array}{l}\text { Gravity flow of granules; } \\
\text { granule cleaning (intermittent) }\end{array}$ & Moderate & Low & High & $\begin{array}{l}\text { Demonstration } \\
\text { scale planned }\end{array}$ \\
\hline Metallic filters & Cake formation & $\begin{array}{l}\text { Back pulse with clean gas } \\
\text { (intermittent) }\end{array}$ & Moderate & High & High & $\begin{array}{l}\text { Demonstration } \\
\text { scale planned }\end{array}$ \\
\hline Rigid barrier filters & Cake formation & $\begin{array}{l}\text { Back pulse with clean gas } \\
\text { (intermittent) }\end{array}$ & Moderate & High & Very high & Commercial \\
\hline
\end{tabular}

Filtration of ash from advanced high temperature PFBC systems requires operation of filter vessel and porous elements at temperatures $>815-870^{\circ} \mathrm{C}\left(>1500-1600^{\circ} \mathrm{F}\right)$. Limited, long-term, field experience has been demonstrated at either PFBC pilot-scale or demonstration sites to date (Coors alumina/mullite candles: 2166 PCFBC hrs; Pall 326 and Schumacher FT20 clay bonded silicon carbide elements: 1035 PCFBC hrs) for PCFBC systems operating temperatures of $700-750^{\circ} \mathrm{C}\left(1290-1380^{\circ} \mathrm{F}\right)$. In order to fully qualify a filter element for extended, high temperature PFBC operation (i.e., 8,000$\left.16,000 \mathrm{hrs}(1-2 \mathrm{yrs}) ;>815-870^{\circ} \mathrm{C}\left(>1500-1600^{\circ} \mathrm{F}\right)\right)$, demonstration of the performance of the filter element (component and material) in an ash-containing environment, in the presence of volatile species (i.e., alkali; sulfur; etc.) emitted during coal processing is essential. Understanding the cleanability, as well as complete barrier filtration characteristics of fine particulates by the porous filter elements in these environments is also necessary. Defining the response of the filter material and overall physical integrity 
of the component is additionally required. Accomplishing these objectives at a reduced operating cost, in comparison to operation of a filter vessel at either a full pilot-scale or demonstration plant, is warranted through the use of a small array of candle filters exposed to an existing AFBC test facility slipstream.

Available literature reports a number of the new developments and operations of hot gas filtration systems, as well as in the development and assessment of ceramic and metal filter elements. As temperatures in advanced PFBC systems approach and/or exceed $870^{\circ} \mathrm{C}\left(1600^{\circ} \mathrm{F}\right)$, oxide-based ceramic filters have been considered as the materials of choice. During this time, SWPC addressed the development and transitioning of porous Coors, Blasch, and Ensto monolithic alumina/mullite filter materials to that of the more robust, thermal shock/fatigue tolerant, continuous fiber reinforced ceramic composite (CFCC) and filament wound, oxide-based elements manufactured by McDermott, Techniweave, 3M, and DuPont. SWPC also addressed the issue of long-term viability of the variously aged elements through a series of bench-scale, accelerated life, test campaigns, in which as-manufactured and field serviced-aged elements were shown to remain intact after $\sim 21,200-32,700$ hours of simulated, $815^{\circ} \mathrm{C}\left(\sim 1500^{\circ} \mathrm{F}\right)$, PFBC operation. Testing included exposure of the monolithic oxide- and non-oxide-based filter elements, and advanced second-generation oxide-based CFCC and filament wound candles to steady state, accelerated pulse cycling, and thermal transient conditions. In the proposed program, long-term exposure at high temperature in the presence of ash particulates and volatile alkali and sulfur species, is the criteria by which the filter element(s) will be judged as suitable for high temperature, PFBC, field-service operation.

Siemens Westinghouse and others have previously identified and successfully demonstrated candidate filter media and filter systems for utilization in PFBC systems at temperatures to $1400^{\circ} \mathrm{F}$. This prior work was performed at a Siemens Westinghouse facility in Pittsburgh, PA as well as the TIDD PFBC demonstration site in Brilliant $\mathrm{OH}$ and at a large PFBC test facility in Finland. The program incorporated that same methodology into a newly configured AFBC test facility at SIUC so that the filter media and filtration system could be validated in a higher temperature regime (up to $1700^{\circ} \mathrm{F}$ ). The utilization of proven methodologies with a new test facility using an accessible slipstream in a commercial FBC in this program suggests successful validation of this critical enabling technology at minimal programmatic risk.

The program produced continuous, long-term filter exposure test data applicable to PFBC using a very cost-effective AFBC slipstream test facility. The ceramic filter candles that were tested represent a new generation of ceramic materials having the potential to be more durable than previous tested ceramic filter elements. The test data provided experimental evidence of the merits of the hot gas filter for PFBC systems and will promote further demonstration of the technology.

Provided that the filter vessel were continually operated at $\sim 845-870^{\circ} \mathrm{C}\left(\sim 1550-1600^{\circ} \mathrm{F}\right)$ with continued feeding of ash fines to and removal of fines from the filter, performance of the hot gas filtration system is deemed to be feasible. Successful and continued operation of the slipstream unit followed by the "single filter" system experiments, 
determined the impact on the mechanical integrity of the filter elements that are housed in the filter array. The success of this research proved that these filters can operate in the full scale system for the long term application.

\section{EXPERIMENTAL}

\section{$\underline{\text { Overview of SIUC Steam Plant }}$}

The slipstream for testing the filters was taken from the AFBC at the SIUC's steam plant. The SIUC steam plant presently uses four different boilers to produce the steam required to heat/cool the campus buildings. \#2 and \#3 boilers are 1960 vintage traveling grate stoker boilers that had an initial rating of 80,000 lbs per hour each and have since been downgraded to a maximum $60,000 \mathrm{lb} / \mathrm{hr}$. A Nebraska gas boiler with a rating of approximately $120,000 \mathrm{lb} / \mathrm{hr}$ is used when problems are experienced with the other units or have boilers shut down for preventative maintenance.

The primary boiler is labeled Unit 5 and is a Circulating Fluidized Bed Boiler with a maximum steam output of 102,000 lb/hr. The "CFB" was put into service in 1997 and, for the most part, has been a truly trouble free unit with very low maintenance costs and high availability. The fuel for the CFB is purchased locally and is brought to the plant sized at 2" x 0". At the inlet to the plant the fuel is crushed down to $1 / 2$ " to $3 / 4$ " for delivery into a silo which holds a 27 hour supply. To lower the emissions of unwanted gases leaving the plant the CFB uses limestone as a dry scrubbing agent. The limestone is mixed in the furnace with incoming coal and the calcium in the limestone chemically reacts with the sulfur in the coal to remove much of the $\mathrm{SO}_{2}$ produced. The operating permit requires a minimum of $90 \%$ of the sulfur to be scrubbed from the coal fed into the boiler and we generally run with a 92\% removal rate. The CFB output is also used to drive a small turbine which allows the plant to produce a maximum of 3.14 mega watts when the boiler is at full steam load. The turbine is not a condensing turbine which means that the steam inlet pressure is at approximately 650 psig and at the turbine outlet near 150 psig steam is seen which is further regulated down to the 135 psig required by the steam lines that trail out onto the campus.

These coal fired units all burn coal supplied by local Southern Illinois coal mines. Fuel is presently purchased from Phoenix Coal Company near Du Quoin, a distance of only 25 miles. The ash removed is taken back to the mine for reclamation. In addition, some of the flyash is used by a local company in the production of materials such as blocks, mine tunnel supports, and other items.

\section{$\underline{\text { Experimental Apparatus }}$}

First, the design of the flue gas slipstream for the University Steam Plant boiler was conceptualized. The draft conceptual design (3 views) is provided in the Appendix. BRiC Engineering Company (Bellville, IL) prepared the draft final of the slipstream system together with the filter vessel. The filter housing was manufactured by the 
Siemens Westinghouse Power Corporation's contractor: George Marker \& Sons, Inc, Mckeenport, PA.

Figure 1 shows the images of the new candle filters that were manufactured for this project. Figure 2 shows the 12-filter array mounted in the vessel. More images of the vessel can be found in the Appendix. Figures 3 and 4 present the images of the "singlefilter" diagram of the reactor and the system setup, respectively. As shown in Figure 4, a programmable logic controller obtained from Micrologix was used to control the inlet and outlet valve positions as well as record the data (temperature and differential pressure) for the single-filter reactor. 

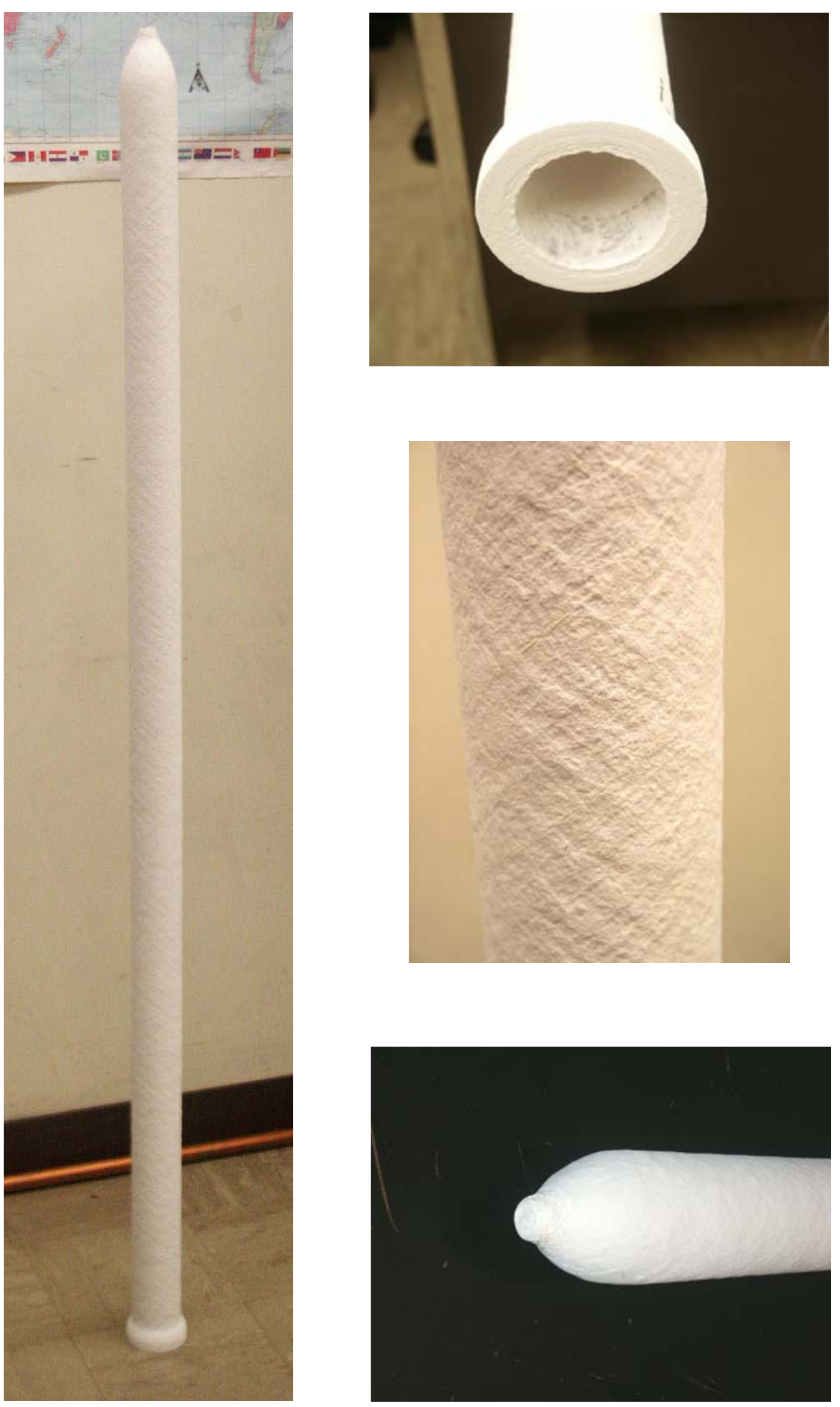

Figure 1: $\quad$ Images of candle filters 


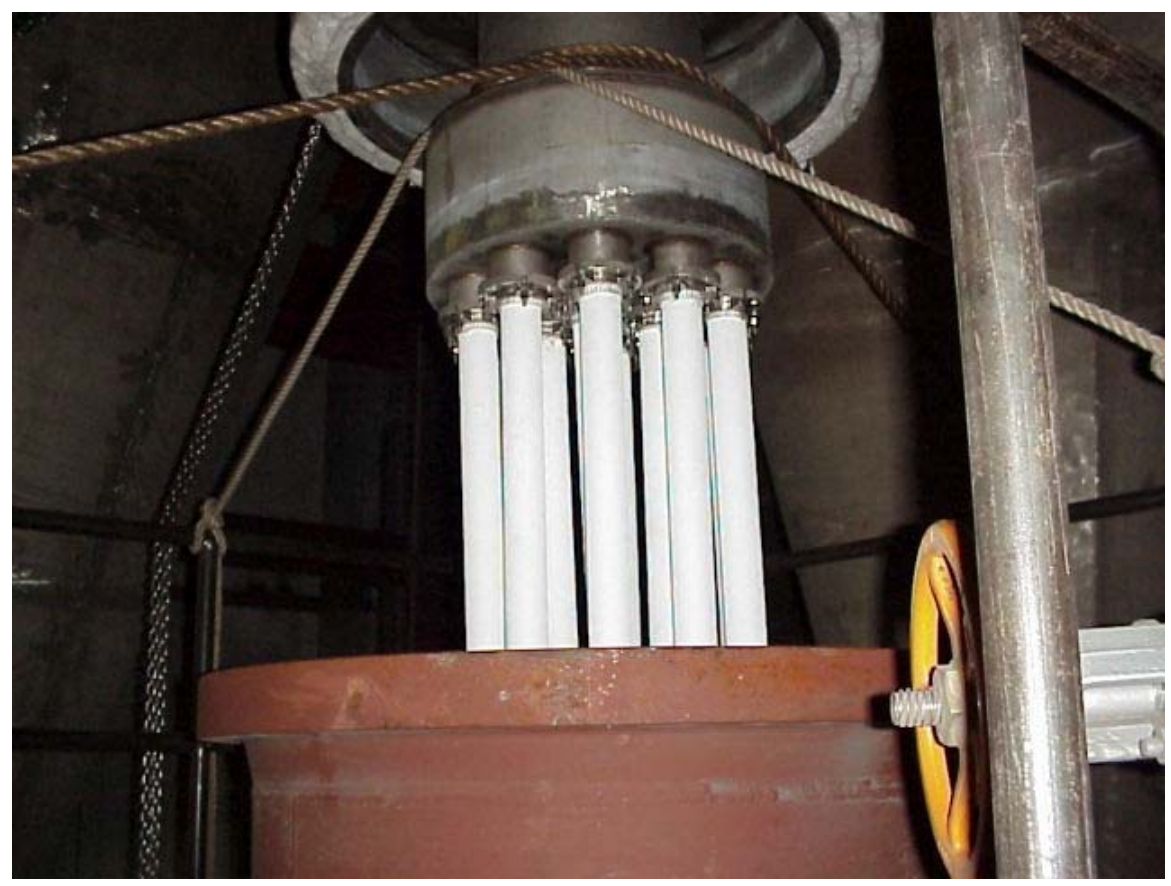

Figure 2: $\quad$ Image of filters mounted in slipstream vessel

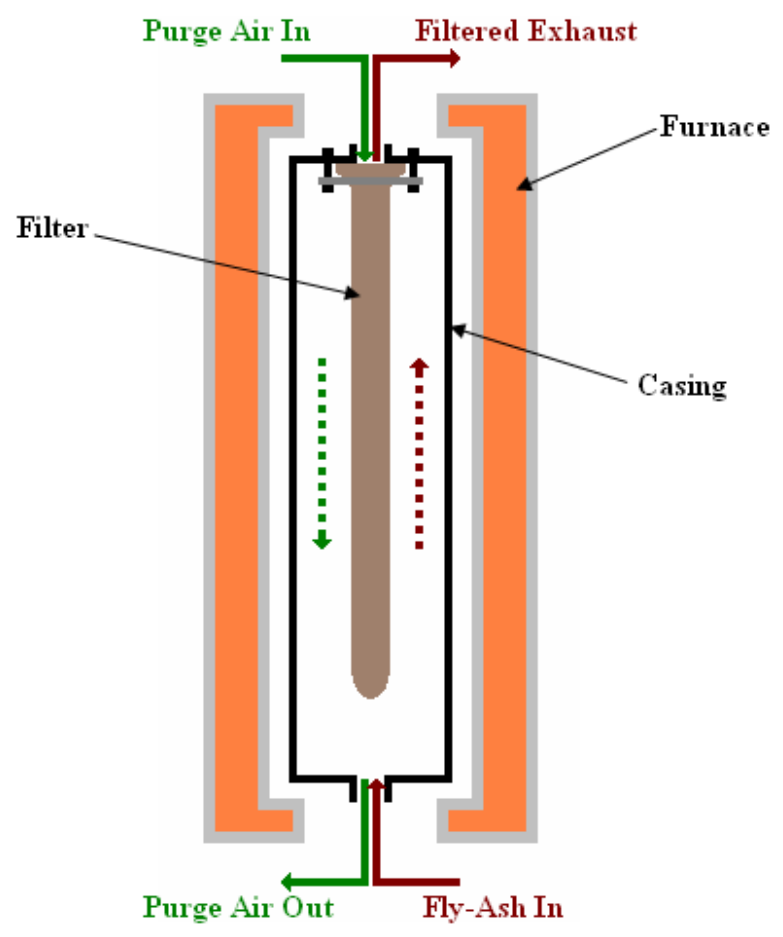

Figure 3: Drawing of single-filter reactor 


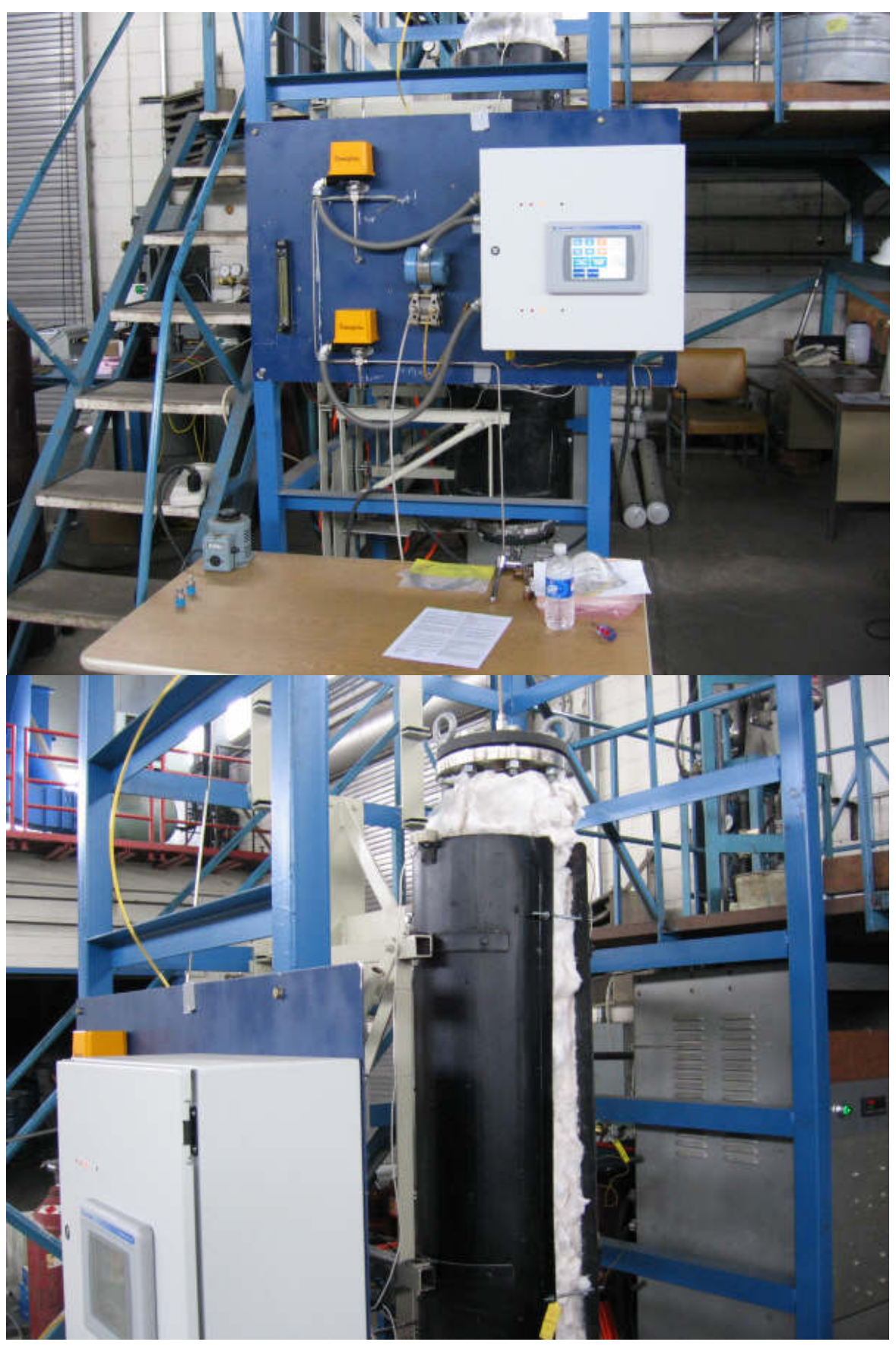

Figure 4: (top) Controller box, differential pressure meter and solenoid valves; (bottom) Reactor and furnace 


\section{RESULTS AND DISCUSSION}

\section{Task 1 — Filter System Conceptual Design}

The filter equipment (vessel, internals, pulse gas skid) were conceptually designed, and integrated with the design of the AFBC slipstream facility to satisfy space, cost, and auxiliaries constraints (inlet gas ducting, outlet gas ducting, ash handling system; fans, heat exchangers, valves and controls; auxiliaries).

\section{Task 2 - Filter Facility and Equipment Detailed Design}

Detailed design of the equipment components were completed (refractory-lined, carbonsteel vessel with trace heating of vessel wall; tube sheet supporting 12 filter candles on two plenums; inlet gas shroud; pulse gas control skid with manual pulse timer; internals maintenance support frame, slipstream ducting, fan, heat exchanger, valves and instrumentation).

\section{Task 3 - Equipment Procurement and Installation}

The designed test equipment and other purchased items (i.e., candle filters, failsafe/regenerators, gaskets, etc.) were procured. The candle filters were fabricated using vacuum winding by BWX Technologies Inc. They were comprised of Nextel 610 alumina fiber, Saffle chopped fiber, and an alumina bond. Shipment of all the equipment was direct to the test site. The equipment was installed at the test site, and the existing AFBC equipment was modified as needed to accept the slipstream system.

\section{Task 4 - AFBC Filtration Testing}

Twelve, $1.5 \mathrm{~m}$ candle filters were installed in the filter vessel. Elements selected for installation were based on (1) technology requirements; (2) availability of suppliers to support this effort; and (3) element cost and delivery schedule. Based on the anticipated extended operating time in the high temperature $\left(>815-870^{\circ} \mathrm{C}\right.$; $\left.>1500-1600^{\circ} \mathrm{F}\right)$, AFBC gas environment, advanced second-generation, porous, oxide-based elements were SWPC's recommended filter materials of choice. Monolithic, oxide and nonoxide-based, porous filter materials were ranked as secondary materials of choice, while porous, commercial metal, advanced alloys, and/or intermetallics were considered as unlikely candidate materials for extended use in high temperature, AFBC, filtration applications.

After installation of the elements into the filter array, the test facility was operated for a period of 45 days removing AFBC ash particulates. Figure 5 and Figure 6 provide the shake-down data on pressure drop and flow rate variations during initial operation of the filters, respectively. The data shown is that of a one day period. 


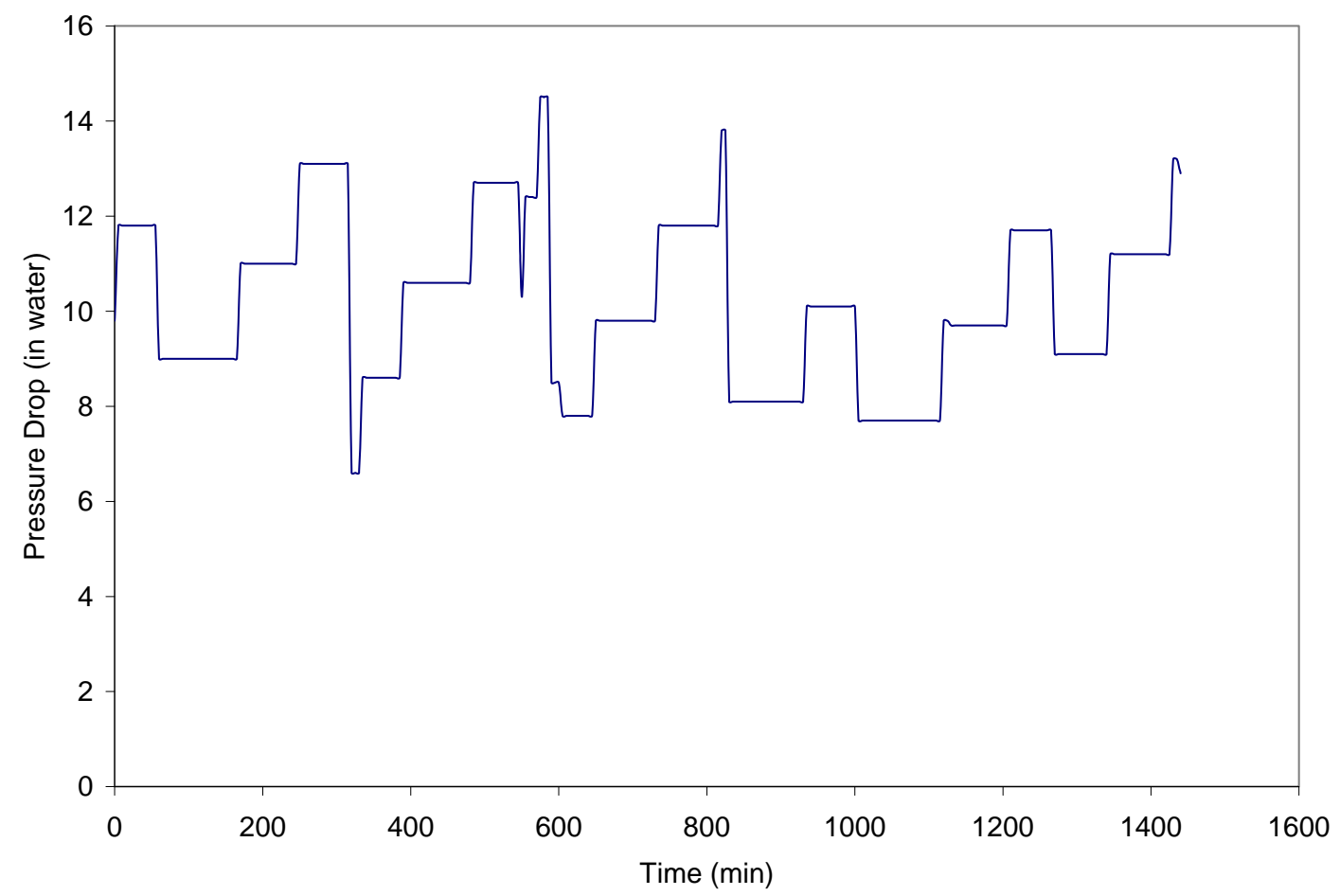

Figure 5: $\quad$ Shake-down data for pressure drop across the slipstream

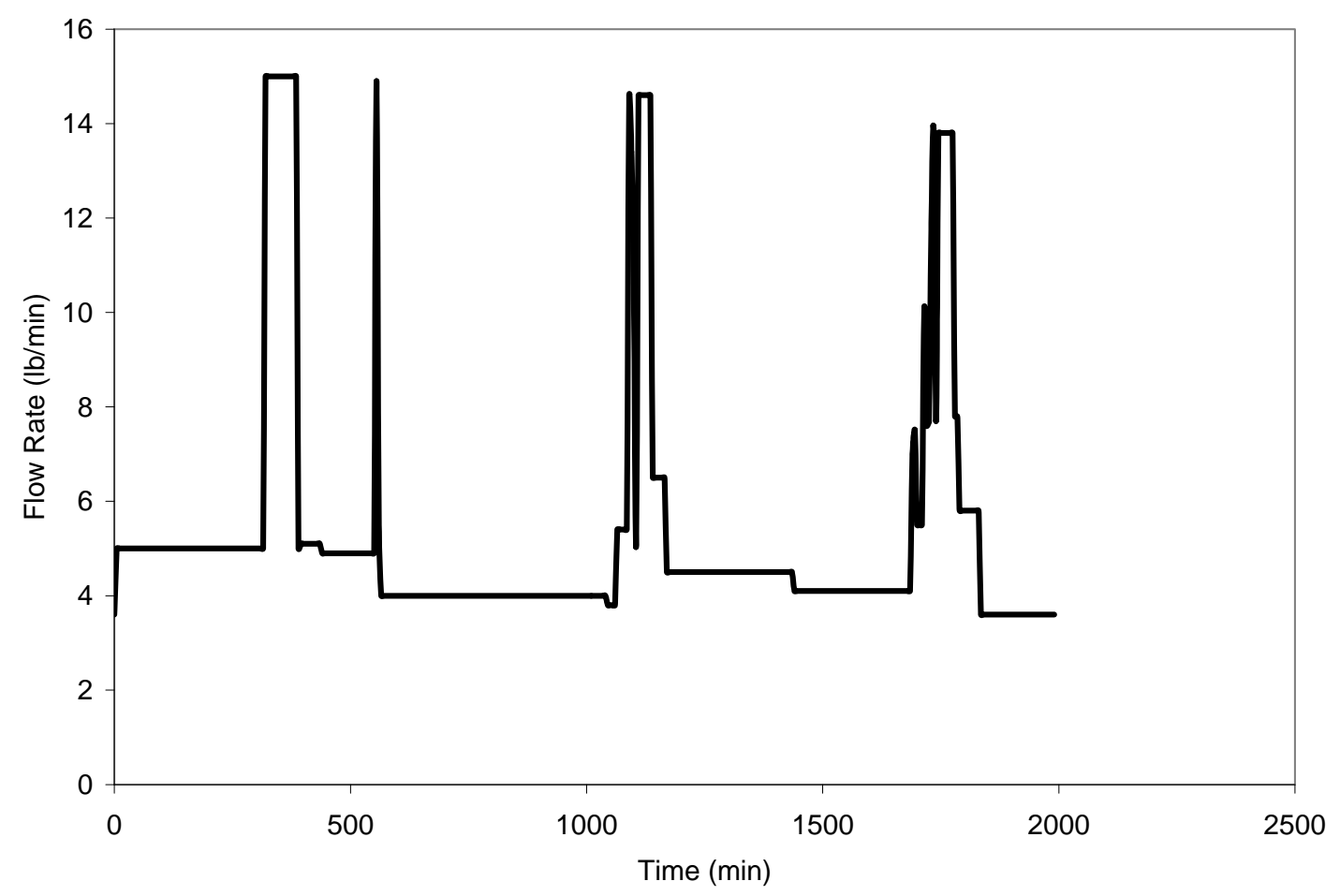

Figure 6: Shake-down data for flow rate through the slipstream 
After the first few days of operation in the slipstream, the intricacies of the system were worked out. A complete differential pressure profile verses time is shown in Figure $\mathbf{7}$. The reason for the scattered data points was the air pulsing for cleaning the filters. The lower data points indicate a clean filter vessel. As the flyash begins to collect, the differential pressure increased until the next clean air pulse. This cycle was continued throughout the duration of the test. This is more clearly seen in Figures 8, 9, 10, and 11, which show the differential pressure profiles verses time for days $10,20,30$, and 40 , respectively.

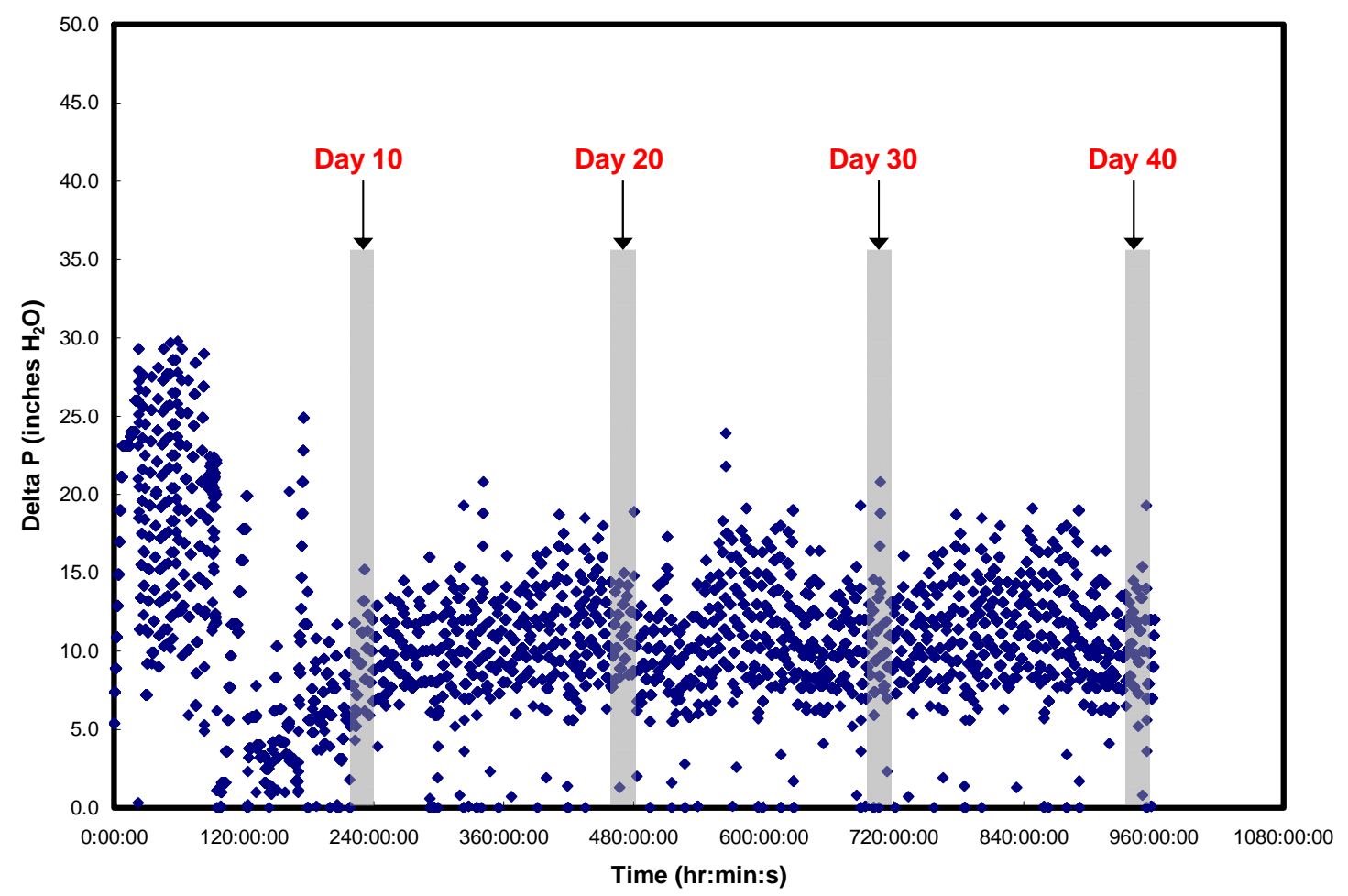

Figure 7: $\quad$ Complete differential pressure profile for the slipstream test 


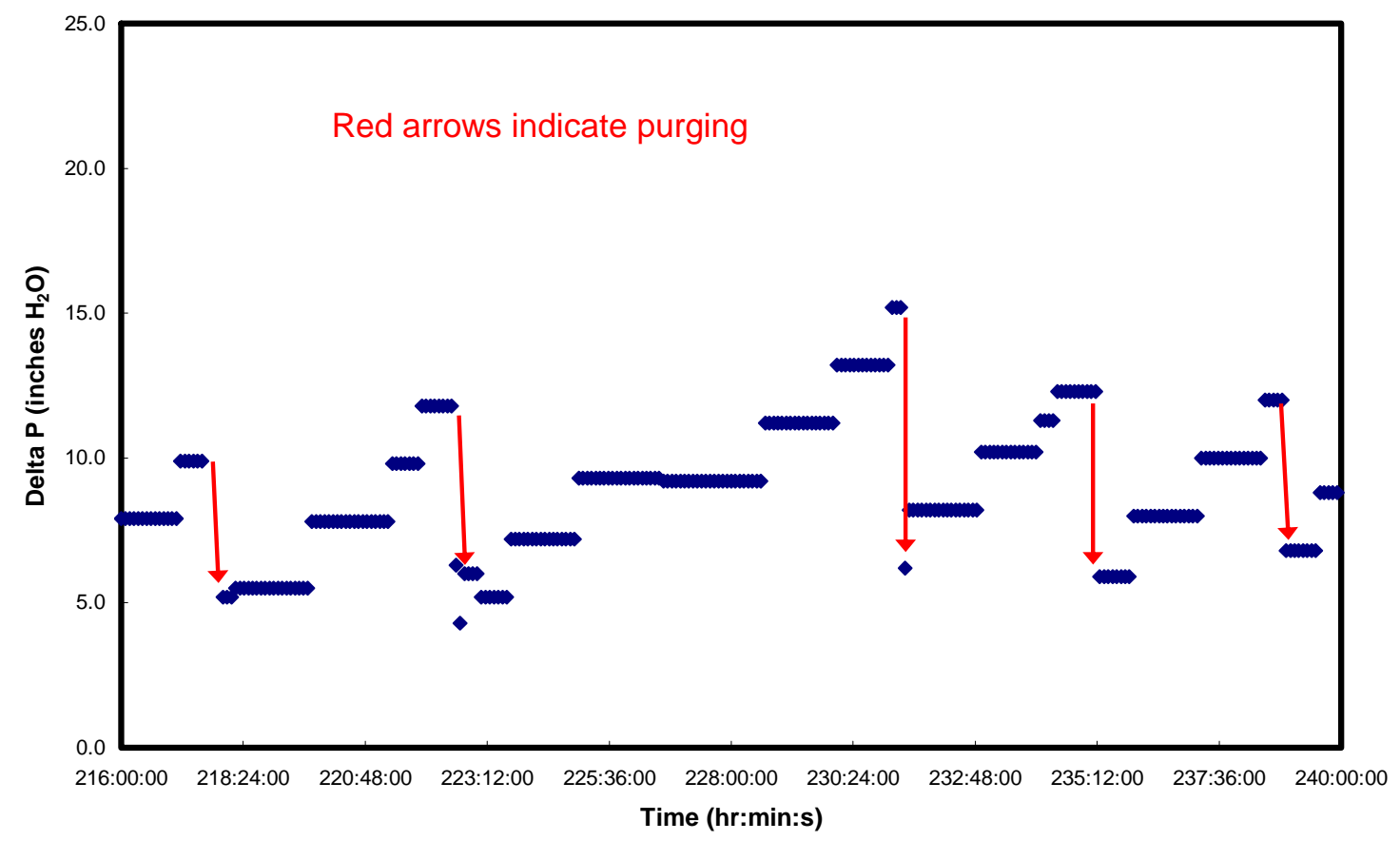

Figure 8: $\quad$ Pressure data for day 10

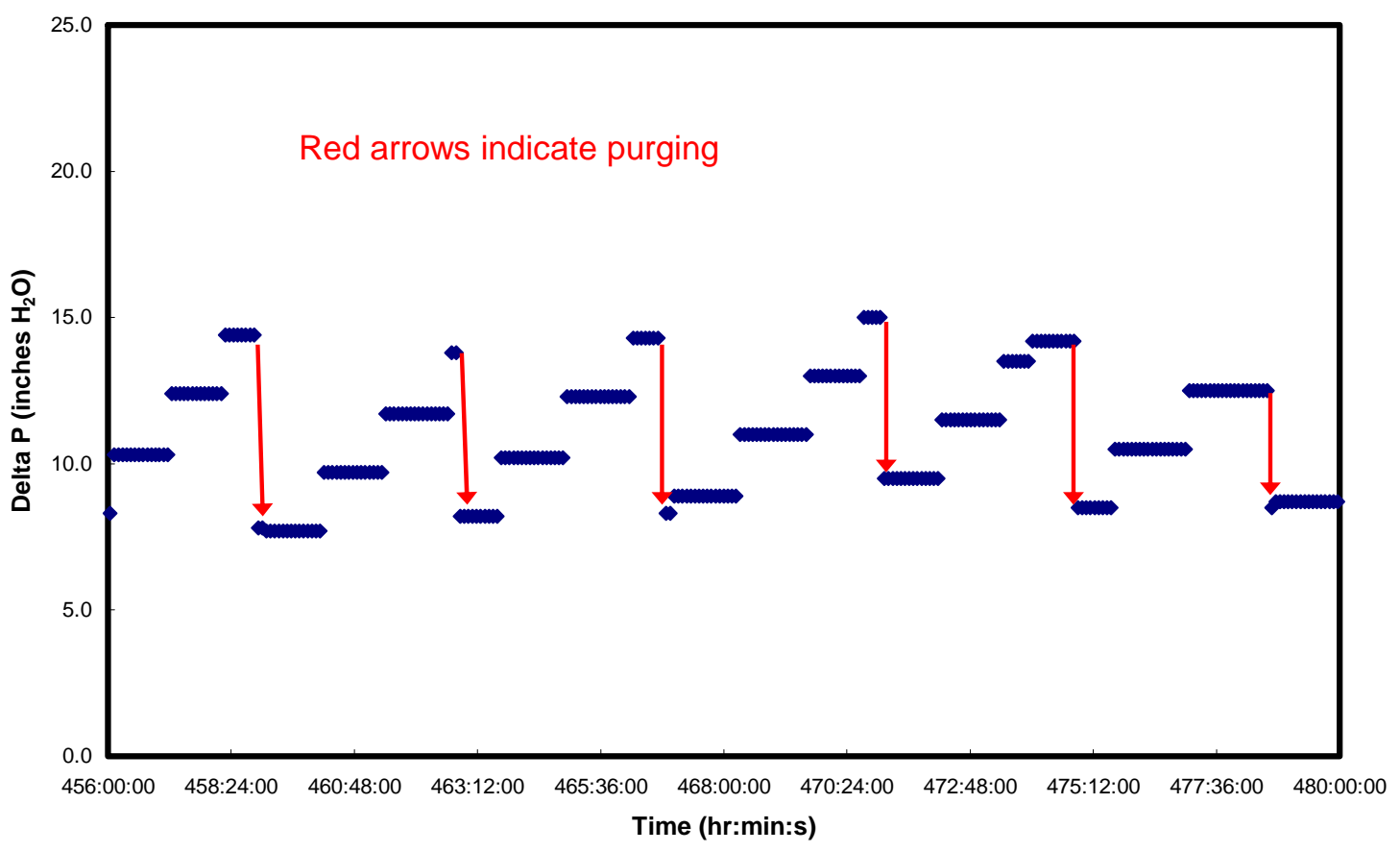

Figure 9: $\quad$ Pressure data for day 20 


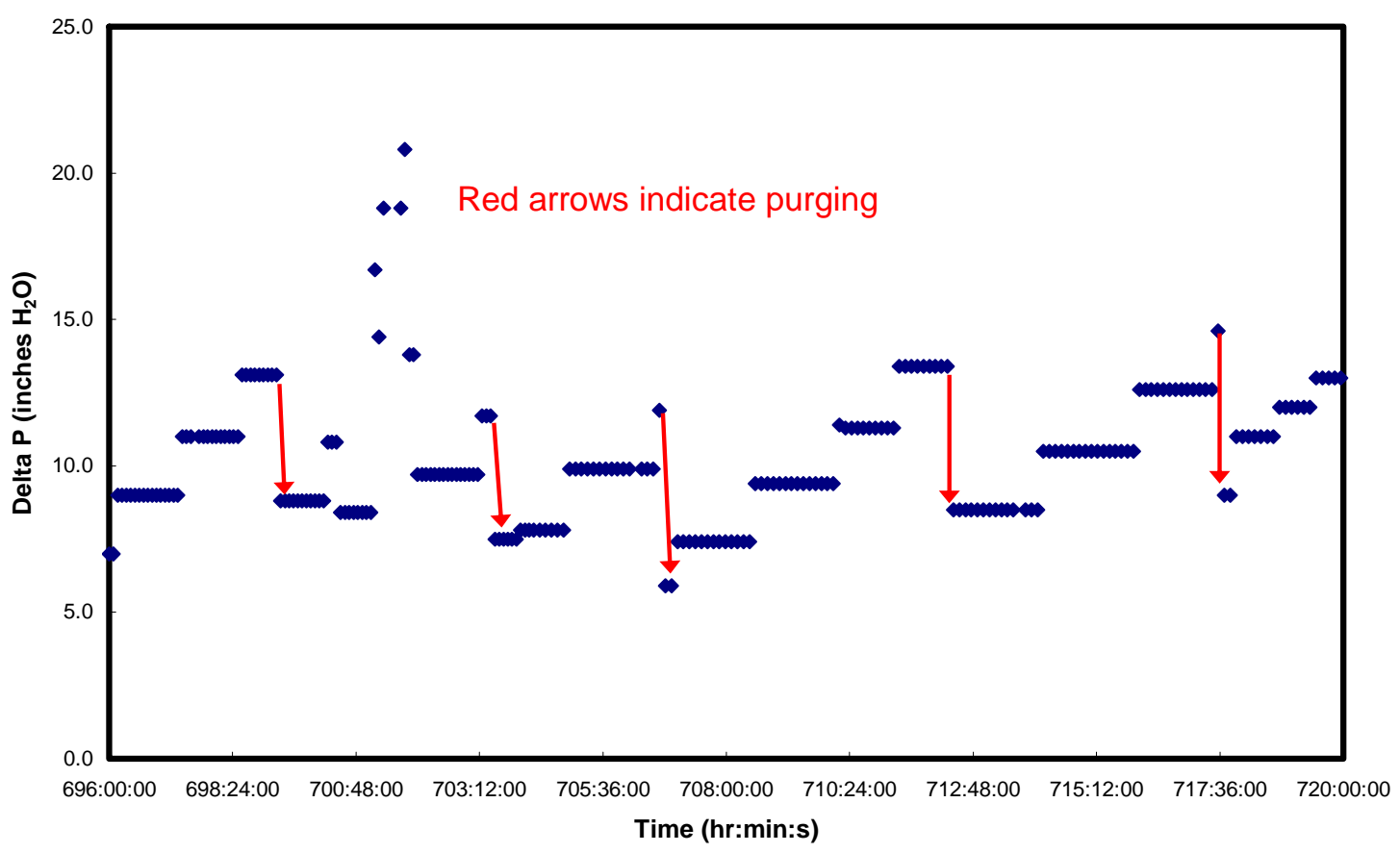

Figure 10: $\quad$ Pressure data for day 30

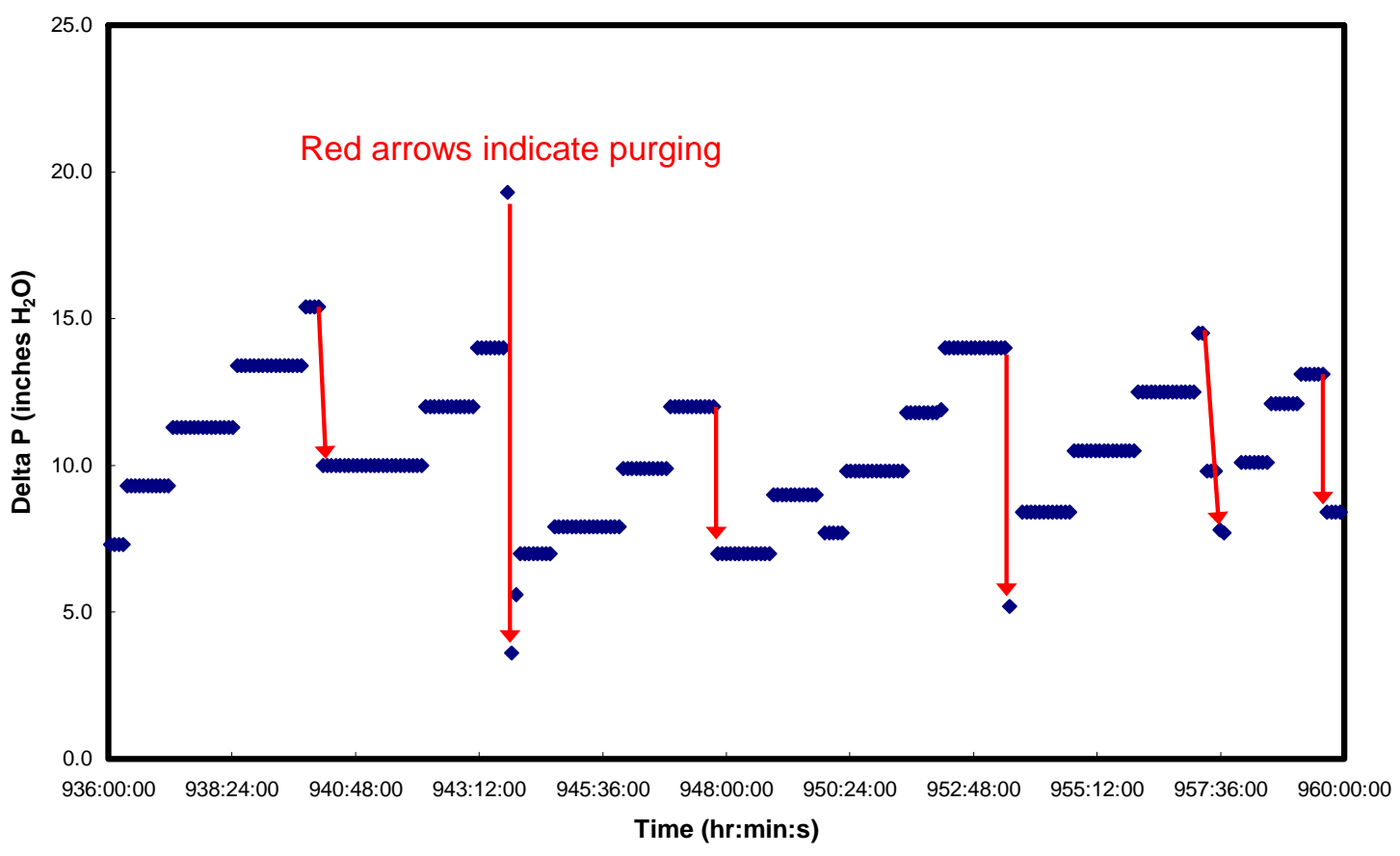

Figure 11: $\quad$ Pressure data for day 40

21 
As can be seen by comparing the figures above, no significant increase in differential pressure was observed during the test, indicating that the pulse cleaning method was effective and the filters are regenerative. Upon completion of the 45 day test, the slipstream system was dismantled. The parts were moved to the Coal Development Park at Carterville, IL.

\section{Task 5 — Filter Performance and Materials Assessment}

During removal and/or maintenance of the filter vessel and/or array, the candle filter elements were visually inspected. No damage was visible (i.e., cracking, chipping, bowing, etc., along the filter body; ash bridging, agglomeration, caking and/or inadequate removal). Typical problems reported in the literature are that filters are bending at high temperatures. The simple observation and comparison of the exact measurements of the filter before and after the testing (after 45 days) show that they do not show any bending.

After assessment by SWPC STC personnel, the removed elements were subjected to room temperature gas flow resistance measurements to address the physical state of the AFBC-exposed elements (i.e., reduced gas flow resistance - cracks, chips, etc.; increased gas flow resistance - adherence and/or inadequate removal of ash fines along the surface or within the filter matrix). The filter elements were characterized via SEM, BET, and permeability analyses to define possible changes that have occurred as a response to operation in the AFBC environment. The new and used (after 45 days) filters were examined. Two rings (about 1 inch long) were cut from the original filters. Figure 12 below shows those elements.

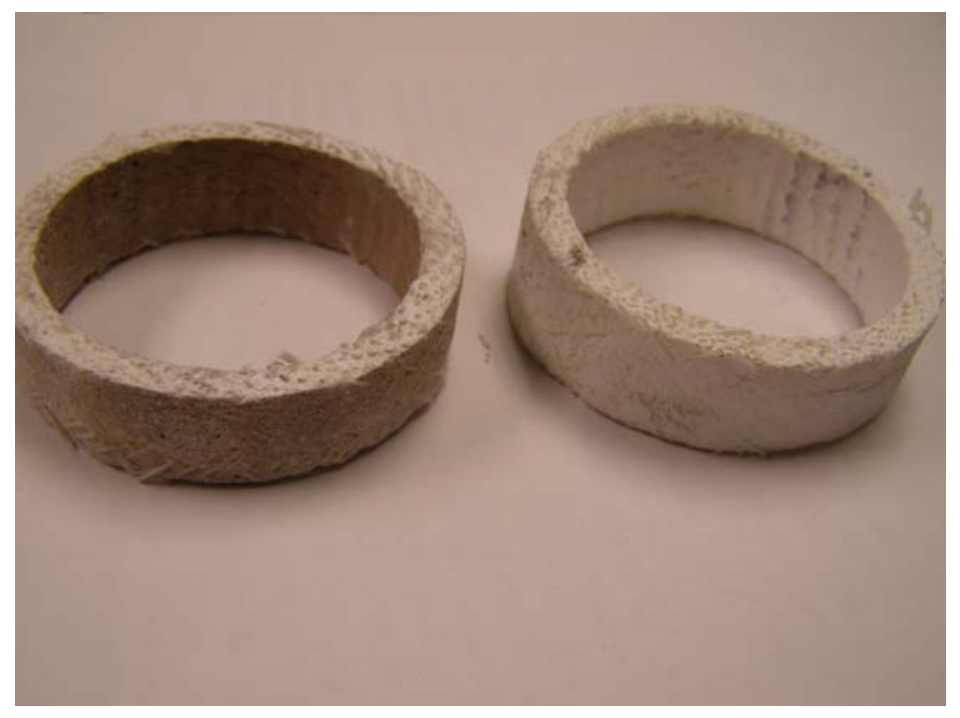

Figure 12: $\quad$ Photo of the rings of the new (right) and used (left) filter 


\section{$\underline{\text { SEM Analysis }}$}

Scanning electron microscopy was used to examine the surfaces of the filter at the magnifications higher than those achievable by optical microscopes. The micrographs of the filter samples (new and used) are shown on Figures 13 and 14. The micrograph of the used filter shows more fine particles, suggesting the sintering of the filter during the operation. The micrographs shown in Figures 15 and 16 (x1000) confirm this observation. Another confirmation of the formation of the fine particles at the filter is the permeability test that is reported in the next paragraph.

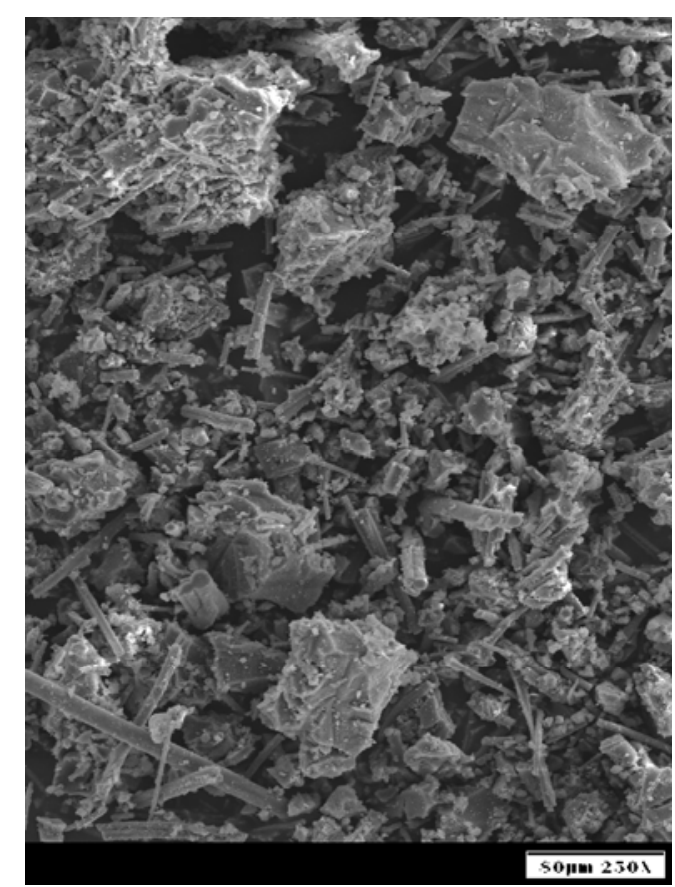

Figure 13: Scanning electron micrograph of the fresh filter (x250) 


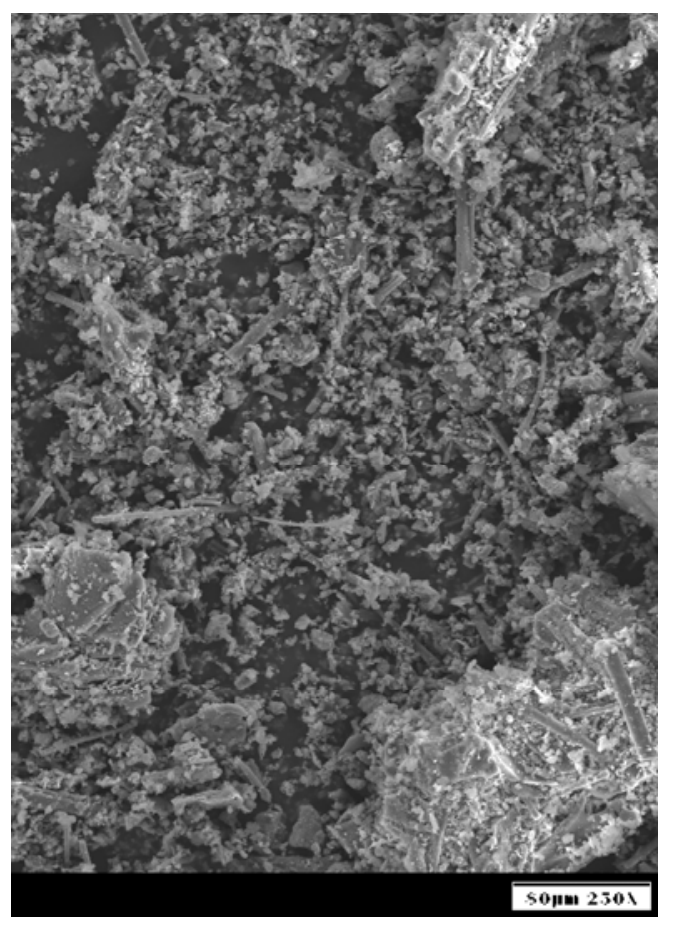

Figure 14: $\quad$ Scanning electron micrograph of the used filter (x250)

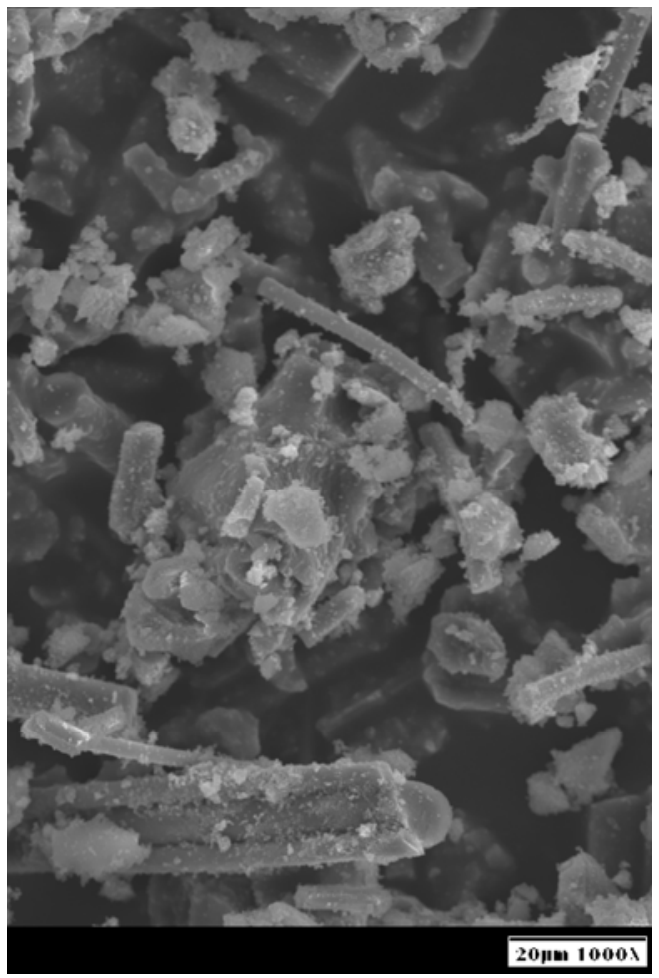

Figure 15: $\quad$ Scanning electron micrograph of the fresh filter (x1000) 


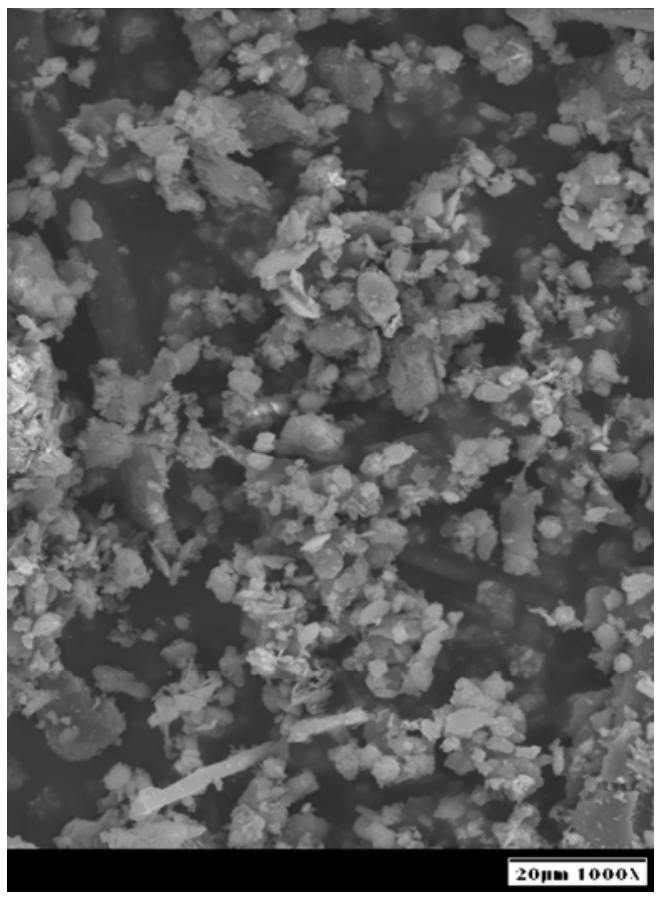

Figure 16: $\quad$ Scanning electron micrograph of the used filter (x1000)

\section{$\underline{\text { Permeability Calculation }}$}

The permeability of the filters was measured by recording the pressure drop across the porous specimen for different volumetric flows. The expression for permeability, $\beta$, is given by

$$
\beta=\frac{Q}{\Delta P} \frac{\mu T}{A}
$$

Where $Q$ is the volumetric flow rate, $T$ is the thickness of the filter, $A$ is the cross sectional area, $\mu$ is viscosity and $\Delta P$ is the pressure drop.

The data in Table 2 shows the permeability of the fresh and used (after 45 days of testing) filters at the beginning and after caking of the fly ash on the filter. It is seen that an increase in the flow rate increases the permeability. In addition it is also observed that the adherence of the fly ash onto the filter and subsequent caking results in the reduction of the permeability of the filter elements. The data shows that pulsing the air in the reverse direction sufficiently breaks off the cake and restores the original permeability of the filters. 
Table 2: $\quad$ The permeability $(\beta)$ values for fresh and 45 days used (before and after purge)

\begin{tabular}{|c|c|c|c|}
\hline $\begin{array}{c}\mathrm{Q} \\
\mathrm{gpm}\end{array}$ & $\begin{array}{c}\text { Fresh } \\
\mathrm{m}^{2}\left(\times 10^{3}\right)\end{array}$ & $\begin{array}{c}\text { After purge } \\
\mathrm{m}^{2}\left(\times 10^{3}\right)\end{array}$ & $\begin{array}{c}\text { Used } \\
\mathrm{m}^{2}\left(\times 10^{3}\right)\end{array}$ \\
\hline 0.15 & 2.96 & 1.71 & 0.19 \\
0.7 & 4.82 & 3.58 & 0.20 \\
1.3 & 6.22 & 5.10 & 0.20 \\
2.6 & 6.45 & 5.27 & 0.47 \\
3.4 & 6.57 & 5.29 & 1.25 \\
5 & 7.60 & 6.06 & 1.39 \\
7 & 7.71 & 6.15 & 1.76 \\
10 & 9.08 & 7.38 & 6.21 \\
\hline
\end{tabular}

\section{$\underline{\text { BET Results }}$}

The surface area and average pore size measurements were performed using the Quantachrome 2200e instrument. Tables 3 - 8 below show the BET results (pore size distribution, surface area, and pore volume information) of fresh and used after 45 days of operation. 
Table 3: $\quad$ BET measurement of the fresh filter (adsorption)

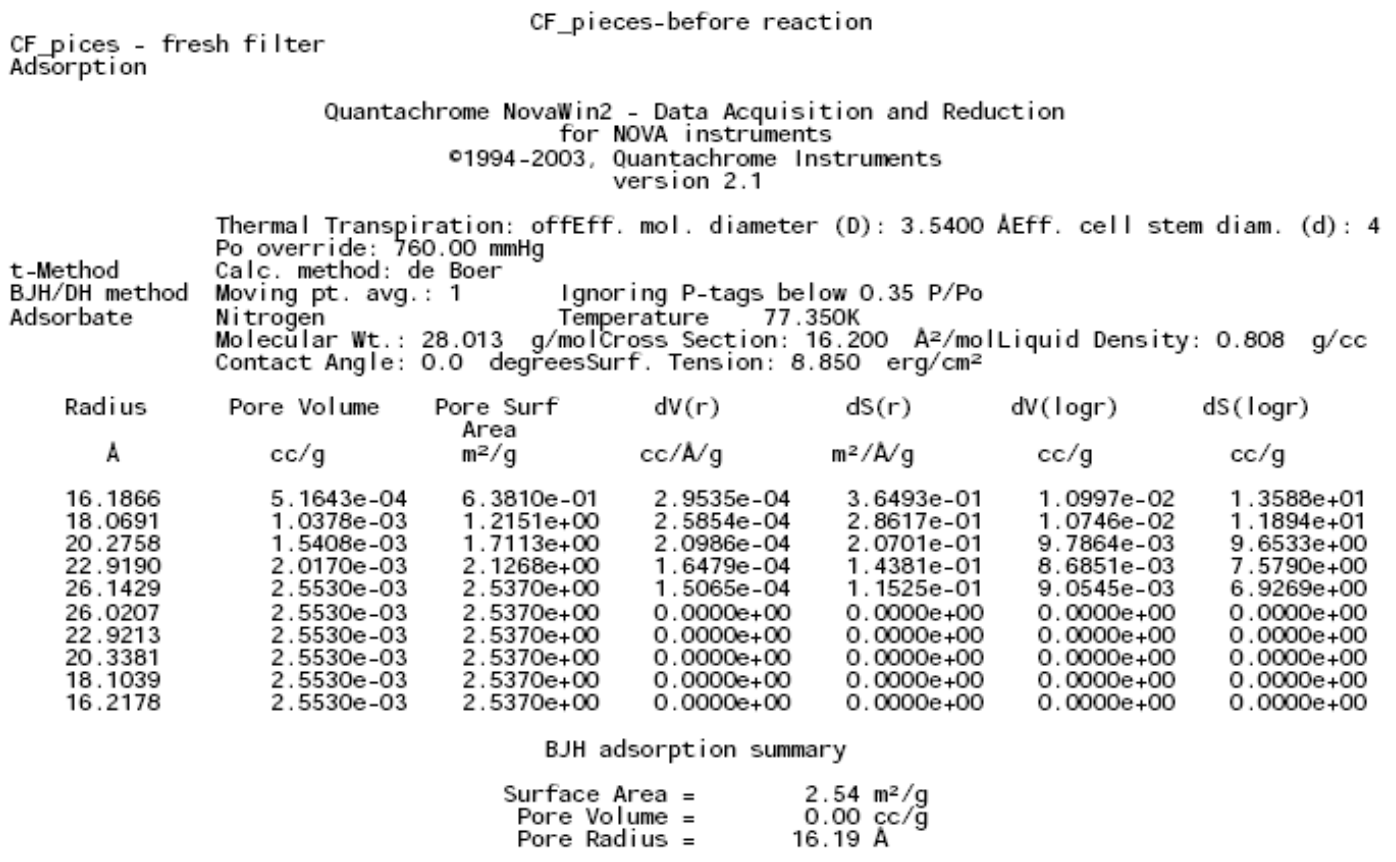

Table 4: $\quad$ BET measurement of the fresh filter (desorption)

Desorption

\begin{tabular}{|c|c|c|c|c|c|c|}
\hline \multirow[b]{2}{*}{$\begin{array}{l}\text { t-Method } \\
\text { BJH/DH method } \\
\text { Adsorbate }\end{array}$} & \multicolumn{6}{|c|}{$\begin{array}{l}\text { Quantachrome NovaWin2 - Data Acquisition and Reduction } \\
\text { for NOVA instruments } \\
01994-2003, \text { Quantachrome Instruments } \\
\text { version } 2.1\end{array}$} \\
\hline & \multicolumn{6}{|c|}{ 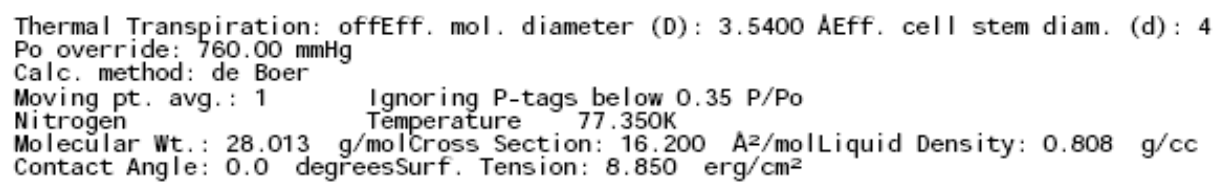 } \\
\hline Radius & $\begin{array}{l}\text { Pore Volume } \\
\mathrm{cc} / \mathrm{g}\end{array}$ & $\begin{array}{l}\text { Pore Surf } \\
\text { Area } \\
\mathrm{m}^{2} / \mathrm{g}\end{array}$ & $\mathrm{dV}(r)$ & $d S(r)$ & $\begin{array}{c}\mathrm{dV}(\log r) \\
\mathrm{cc} / \mathrm{g}\end{array}$ & $\begin{array}{l}\text { dS (logr) } \\
\mathrm{cc} / \mathrm{g}\end{array}$ \\
\hline $\begin{array}{l}16.2178 \\
18.1039 \\
20.3381 \\
22.9213 \\
26.0207 \\
26.1429 \\
22.9190 \\
20.2758 \\
18.0691 \\
16.1866\end{array}$ & $\begin{array}{l}5.8104 \mathrm{e}-04 \\
1.1129 \mathrm{e}-03 \\
1.8492 \mathrm{e}-03 \\
2.4873 \mathrm{e}-03 \\
3.3476 \mathrm{e}-03 \\
3.3476 \mathrm{e}-03 \\
3.3476 \mathrm{e}-03 \\
3.3476 \mathrm{e}-03 \\
3.3476 \mathrm{e}-03 \\
3.3476 \mathrm{e}-03\end{array}$ & $\begin{array}{l}7.1654 \mathrm{e}-01 \\
1.3041 \mathrm{e}+\infty \\
2.0281 \mathrm{e}+\infty \\
2.58500 \mathrm{e}+\infty \\
3.24611 \mathrm{e}+\infty \\
3.2461 \mathrm{e}+\infty \\
3.2461 \mathrm{e}+\infty \\
3.2461 \mathrm{e}+\infty \\
3.24611 \mathrm{e}+\infty \\
3.2461 \mathrm{e}+\infty\end{array}$ & $\begin{array}{l}2.8014 \mathrm{e}-04 \\
3.1321 \mathrm{e}-04 \\
2.6577 \mathrm{e}-04 \\
2.6635 \mathrm{e}-04 \\
2.2620 \mathrm{e}-04 \\
0.0000 \mathrm{e}+00 \\
0.0000 \mathrm{e}+\infty 0 \\
0.0000 \mathrm{e}+\infty \\
0.0000 \mathrm{e}+\infty 0 \\
0.0000 \mathrm{e}+\infty\end{array}$ & $\begin{array}{l}3.4547 \mathrm{e}-01 \\
3.4601 \mathrm{e}-01 \\
2.6135 \mathrm{e}-01 \\
2.3240 \mathrm{e}-01 \\
1.7387 \mathrm{e}-01 \\
0.0000 \mathrm{e}+00 \\
0.0000 \mathrm{e}+00 \\
0.0000 \mathrm{e}+00 \\
0.0000 \mathrm{e}+00 \\
0.0000 \mathrm{e}+00\end{array}$ & $\begin{array}{l}1.0447 \mathrm{e}-02 \\
1.3047 \mathrm{e}-02 \\
1.2427 \mathrm{e}-02 \\
1.4045 \mathrm{e}-02 \\
1.3529 \mathrm{e}-02 \\
0.0000 \mathrm{e}+00 \\
0.0000 \mathrm{e}+00 \\
0.0000 \mathrm{e}+00 \\
0.00000 \mathrm{e}+00 \\
0.0000 \mathrm{e}+00\end{array}$ & $\begin{array}{l}1.2883 \mathrm{e}+01 \\
1.4413 \mathrm{e}+01 \\
1.2220 \mathrm{e}+01 \\
1.2255 \mathrm{e}+01 \\
1.0399 \mathrm{e}+01 \\
0.0000 \mathrm{e}+00 \\
0.0000 \mathrm{e}+00 \\
0.0000 \mathrm{e}+00 \\
0.0000 \mathrm{e}+00 \\
0.0000 \mathrm{e}+00\end{array}$ \\
\hline \multicolumn{7}{|c|}{ BJH desorption summary } \\
\hline \multicolumn{7}{|c|}{$\begin{array}{rrr}\text { Surface Area } & = & 3.25 \\
\text { Pore Volume } & = & 0.00 \\
\text { Pore Radius } & = & 18.10\end{array}$} \\
\hline
\end{tabular}


Table 5: $\quad$ BET measurement of the fresh filter (surface area summary)

BET

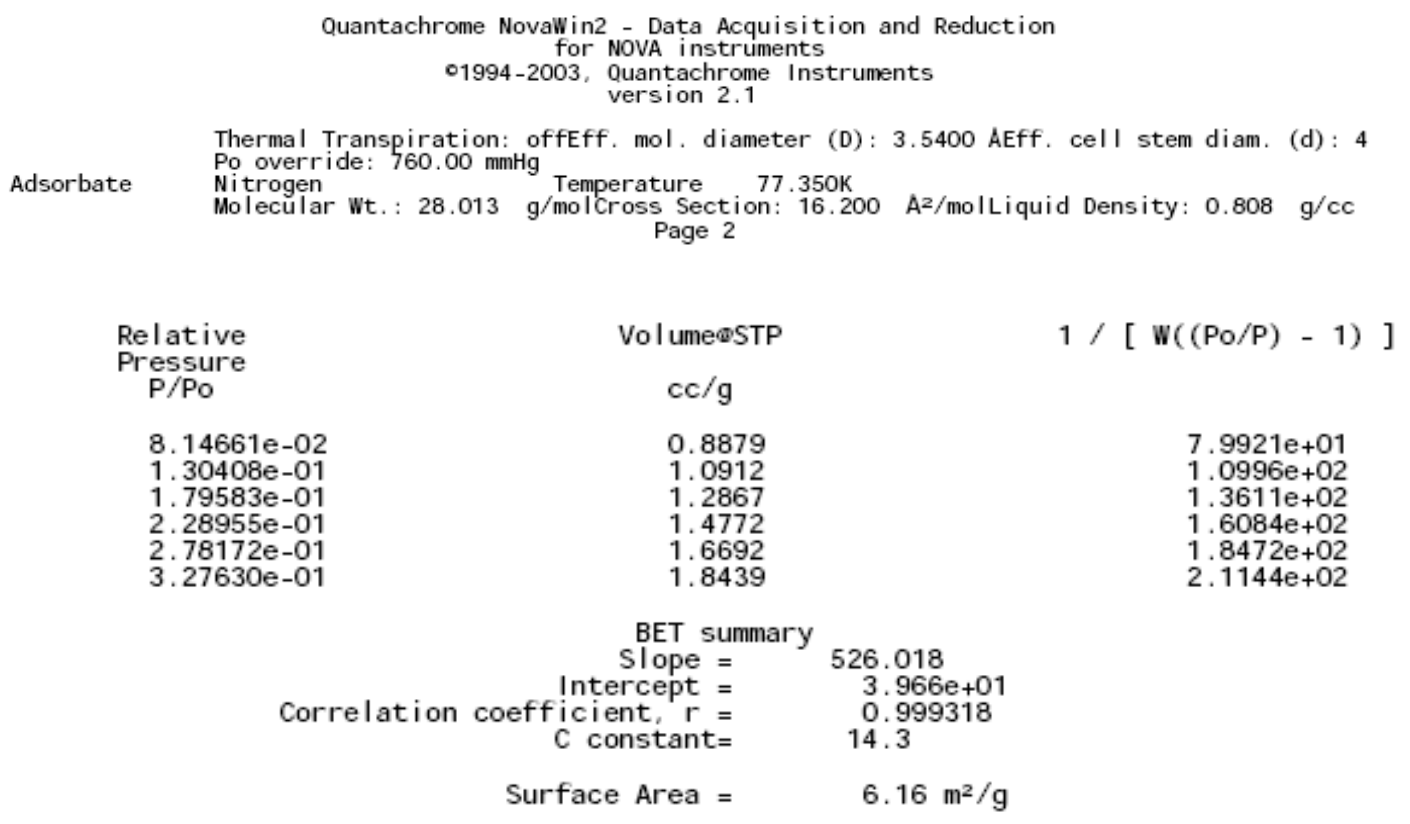

Table 6: $\quad$ BET measurement of the filter after 45 days (adsorption)

\begin{tabular}{|c|c|c|c|c|c|c|}
\hline \multicolumn{7}{|c|}{ CF_pieces-after reaction } \\
\hline $\begin{array}{l}\text { CF_pieces - a } \\
\text { Adsorption }\end{array}$ & reaction & _. & 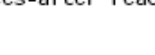 & (2) & & \\
\hline \multicolumn{7}{|c|}{$\begin{array}{l}\text { Quantachrome NovaWin2 - Data Acquisition and Reduction } \\
\text { for NOVA instruments } \\
\begin{array}{c}01994-2003, \text { Quantachrome Instruments } \\
\text { version } 2.1\end{array}\end{array}$} \\
\hline $\begin{array}{l}\text { t-Method } \\
\text { BJH/DH method } \\
\text { Adsorbate }\end{array}$ & \multicolumn{6}{|c|}{ 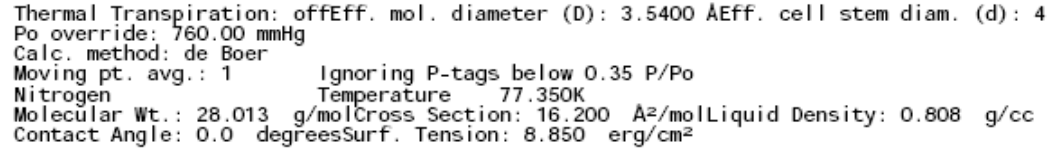 } \\
\hline Radius & \multirow{2}{*}{\multicolumn{2}{|c|}{$\begin{array}{cc}\text { Pore Volume } & \begin{array}{c}\text { Pore Surf } \\
\text { Area } \\
\mathrm{m}^{2} / \mathrm{g}\end{array}\end{array}$}} & $d v(r)$ & $d S(r)$ & $\mathrm{dV}(\log r)$ & ds (logr) \\
\hline A & & & $\mathrm{cc} / \mathrm{A} / \mathrm{g}$ & $\mathrm{m}^{2} / \mathrm{A} / \mathrm{g}$ & $\mathrm{cc} / \mathrm{g}$ & $\mathrm{cc} / \mathrm{g}$ \\
\hline $\begin{array}{l}10.5587 \\
12.0937 \\
13.9326 \\
16.1768 \\
18.7498 \\
18.7602 \\
16.0331 \\
13.8110 \\
12.0245 \\
10.4703\end{array}$ & $\begin{array}{l}7.9392 \mathrm{e}-05 \\
1.5690 \mathrm{e}-04 \\
2.1867 \mathrm{e}-04 \\
2.7669 \mathrm{e}-04 \\
2.9422 \mathrm{e}-04 \\
2.9422 \mathrm{e}-04 \\
2.9422 \mathrm{e}-04 \\
2.9422 \mathrm{e}-04 \\
2.9422 \mathrm{e}-04 \\
2.9422 \mathrm{e}-04\end{array}$ & $\begin{array}{l}1.5038 \mathrm{e}-01 \\
2.7856 \mathrm{e}-01 \\
3.6723 \mathrm{e}-01 \\
4.3897 \mathrm{e}-01 \\
4.5766 \mathrm{e}-01 \\
4.5766 \mathrm{e}-01 \\
4.5766 \mathrm{e}-01 \\
4.5766 \mathrm{e}-01 \\
4.5766 \mathrm{e}-01 \\
4.5766 \mathrm{e}-01\end{array}$ & $\begin{array}{l}5.6273 \mathrm{e}-05 \\
4.6717 \mathrm{e}-05 \\
3.0597 \mathrm{e}-05 \\
2.3497 \mathrm{e}-05 \\
6.5463 \mathrm{e}-06 \\
0.0000 \mathrm{e}+00 \\
0.0000 \mathrm{e}+00 \\
0.0000 \mathrm{e}+00 \\
0.0000 \mathrm{e}+00 \\
0.0000 \mathrm{e}+\infty 0\end{array}$ & $\begin{array}{l}1.0659 \mathrm{e}-01 \\
7.7258 \mathrm{e}-02 \\
4.3921 \mathrm{e}-02 \\
2.9051 \mathrm{e}-02 \\
6.9828 \mathrm{e}-03 \\
0.0000 \mathrm{e}+00 \\
0.0000 \mathrm{e}+00 \\
0.0000 \mathrm{e}+00 \\
0.0000 \mathrm{e}+00 \\
0.0000 \mathrm{e}+00\end{array}$ & $\begin{array}{l}1.3661 \mathrm{e}-03 \\
1.2989 \mathrm{e}-03 \\
9.7986 \mathrm{e}-04 \\
8.7354 \mathrm{e}-04 \\
2.8214 \mathrm{e}-04 \\
0.0000 \mathrm{e}+00 \\
0.0000 \mathrm{e}+00 \\
0.0000 \mathrm{e}+00 \\
0.0000 \mathrm{e}+00 \\
0.0000 \mathrm{e}+00\end{array}$ & $\begin{array}{l}2.5876 \mathrm{e}+00 \\
2.1480 \mathrm{e}+00 \\
1.4066 \mathrm{e}+00 \\
1.0800 \mathrm{e}+00 \\
3.0095 \mathrm{e}-01 \\
0.0000 \mathrm{e}+00 \\
0.0000 \mathrm{e}+00 \\
0.0000 \mathrm{e}+00 \\
0.0000 \mathrm{e}+00 \\
0.0000 \mathrm{e}+00\end{array}$ \\
\hline \multicolumn{7}{|c|}{ BJH adsorption summary } \\
\hline \multicolumn{7}{|c|}{$\begin{aligned} \text { Surface Area } & = \\
\text { Pore Volume } & = \\
\text { Pore Radius } & =\end{aligned}$} \\
\hline
\end{tabular}

Desorntion 


\section{Table 7: $\quad$ BET measurement of the filter after 45 days (desorption)}

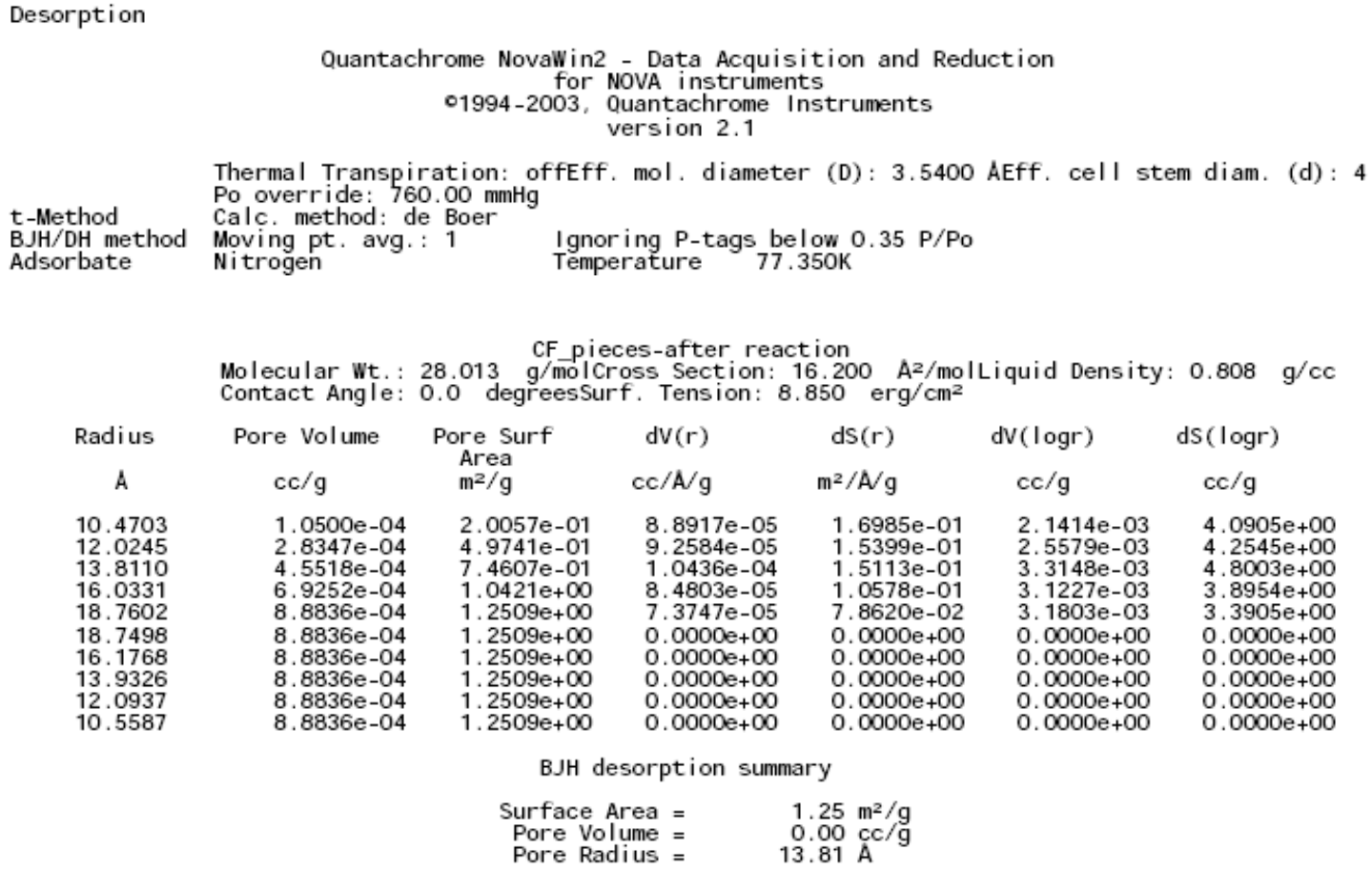

Table 8: $\quad$ BET measurement of the filter after 45 days (surface area summary)

BET

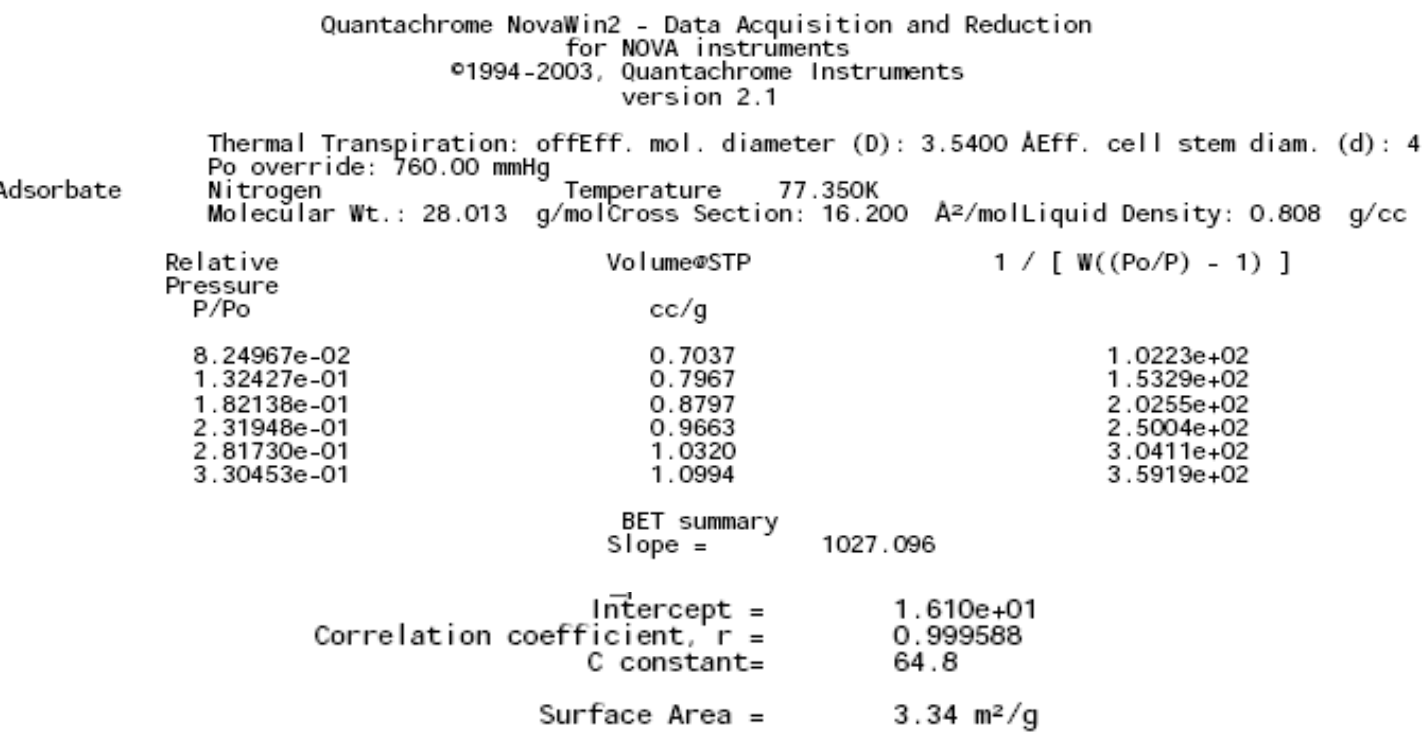


The BET measurements show that mean pore radius of the used (45 days) filter decreases from $18.10 \mathrm{~A}$ to $13.81 \mathrm{~A}$. This indicates that some of the pores are being plugged during the filtering process. This suggestion is corroborated by an observed decrease in the surface area from $6.16 \mathrm{~m}^{2} / \mathrm{g}$ for the fresh filter to $3.34 \mathrm{~m}^{2} / \mathrm{g}$ for the used filter after 45 days of operation.

\section{Pressure Drop Tests}

A pressure drop study was performed on a new candle filter and a used candle filter which was tested in a slipstream for the feasibility study at the SIUC steam plant. Figures 17 and 18 show the results of this pressure drop study on a new and used filter, respectively. By comparing the figures, it is evident that there is only a minimal increase in the pressure drop caused by the long-term use of the filter. This is true for all the tested temperatures and flow rates. Also visible in the figures is that the pressure drop for both the new and used filters increases with the air flow rate and temperature. Examining comparisons of the data at the highest tested flow rate and temperature (Figure 19) shows that the highest difference in pressure drop between the new and used filters was $<0.9$ inches $\mathrm{H}_{2} \mathrm{O}$. It can be concluded from this data that the pressure drop caused by the filter is only minimally affected by long-term use and the necessary purging was effective in cleaning the filter.

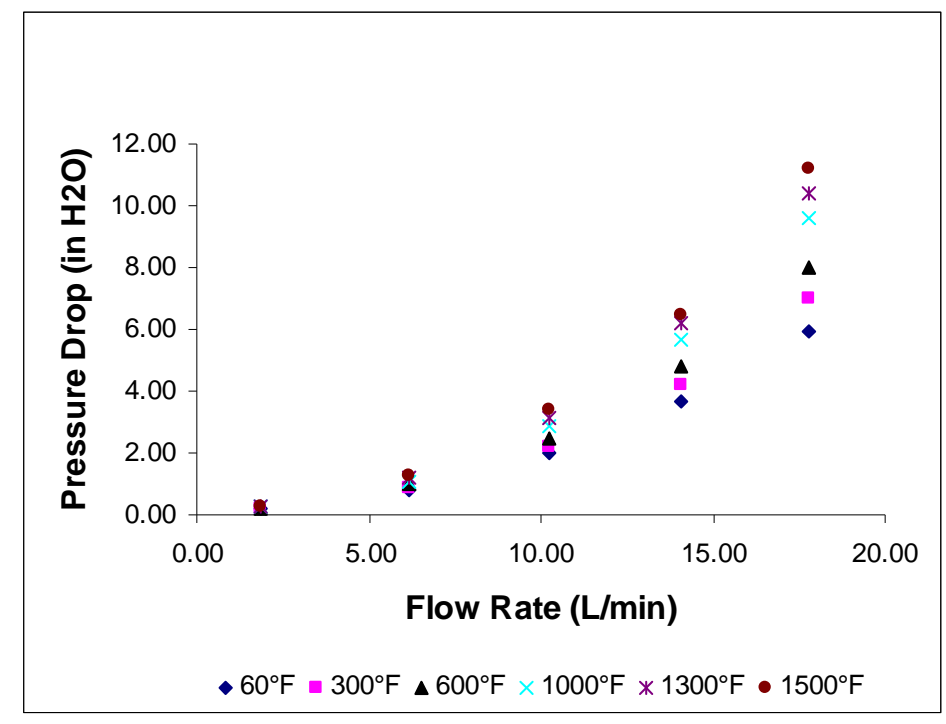

Figure 17: $\quad$ Plot of pressure drop across a new filter verses air flow rate at different temperatures. 


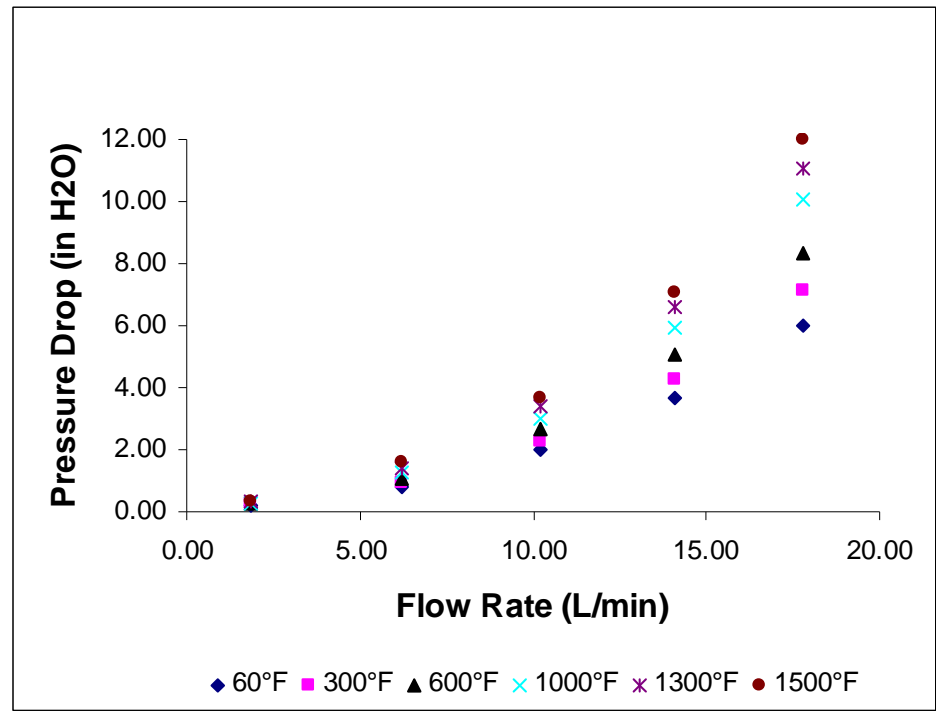

Figure 18: $\quad$ Plot of pressure drop across a used filter verses air flow rate at different temperatures.

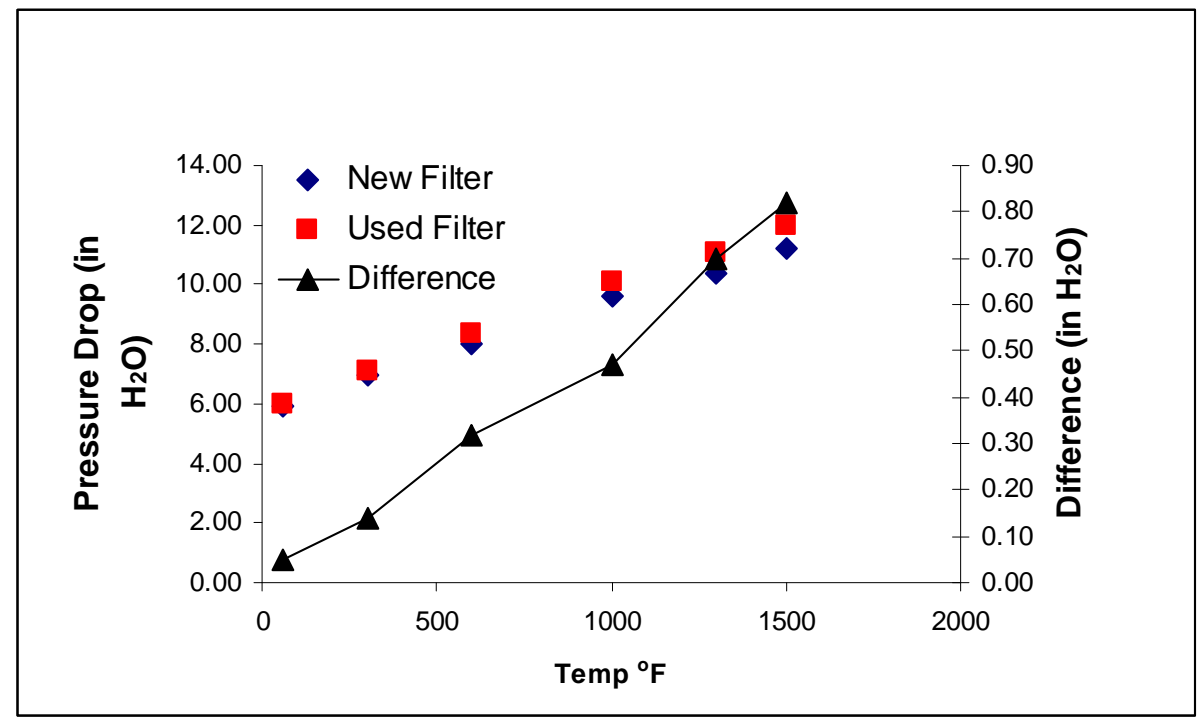

Figure 19: $\quad$ Plot of pressure drop across new and used filters verses temperature

\section{Task 6 - Thermal Shock Tests in a Single-Filter Reactor}

It is well known that rapid temperature changes can cause serious structural damage to ceramic filters. Thermal shock is the term used to describe detrimental effects (i.e. cracking) which occur in a material as a result of being subjected to rapid temperature changes. Ceramic materials are particularly vulnerable to this form of failure, due to their low toughness, low thermal conductivity, and high thermal expansion coefficients. 
Thermal shock occurs when a thermal gradient causes different parts of a filter to expand by different amounts. This differential expansion can be understood in terms of stress or of strain, equivalently. At some point, this stress overcomes the strength of the material, causing a crack to form. If nothing stops this crack from propagating through the material, it will cause the filter's structure to fail.

The first thermal shock experiment was performed for 225 hours with only air flowing through the reactor system. The temperature of the reactor was varied between $180{ }^{\circ} \mathrm{F}$ and $1200{ }^{\circ} \mathrm{F}$. This was done by turning the heater off and opening the furnace once 1200 ${ }^{\circ} \mathrm{F}$ was reached. The pressure drops were monitored and plotted against time and temperature (Figure 20). The data clearly indicate that rapid cooling and heating in this temperature range did not destroy the filter element. The differential pressure increase from 3.8 inches $\mathrm{H}_{2} \mathrm{O}$ to 7 inches $\mathrm{H}_{2} \mathrm{O}$ was due to increased temperature only.

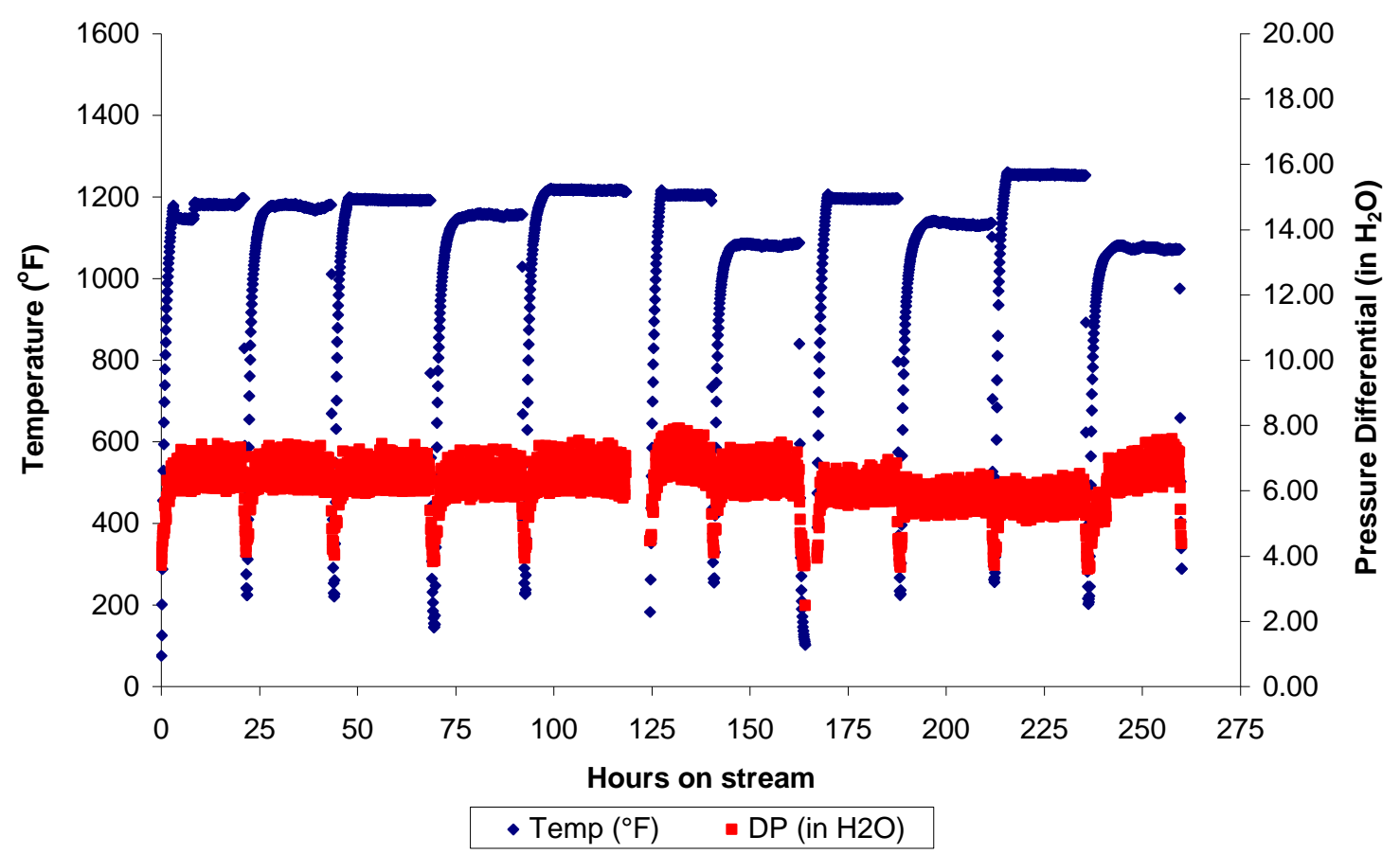

Figure 20: Thermal shock (used filter, air only, flow=14 L/min)

Next, a mixture of air $(14 \mathrm{~L} / \mathrm{min})$ with flyash $(0.3-0.35 \mathrm{~g} / \mathrm{min}$, obtained from the SIUC steam plant) was passed through the single-filter chamber for 250 hours. Figure 21 shows that at temperatures above $1400{ }^{\circ} \mathrm{F}$, a heavy loading of flyash on the filter surface did not contribute to any sizeable increase in differential pressure (DP) across the filter. Therefore, with air and flyash only, the flyash collected on the filter remains as permeable as the filter itself. 


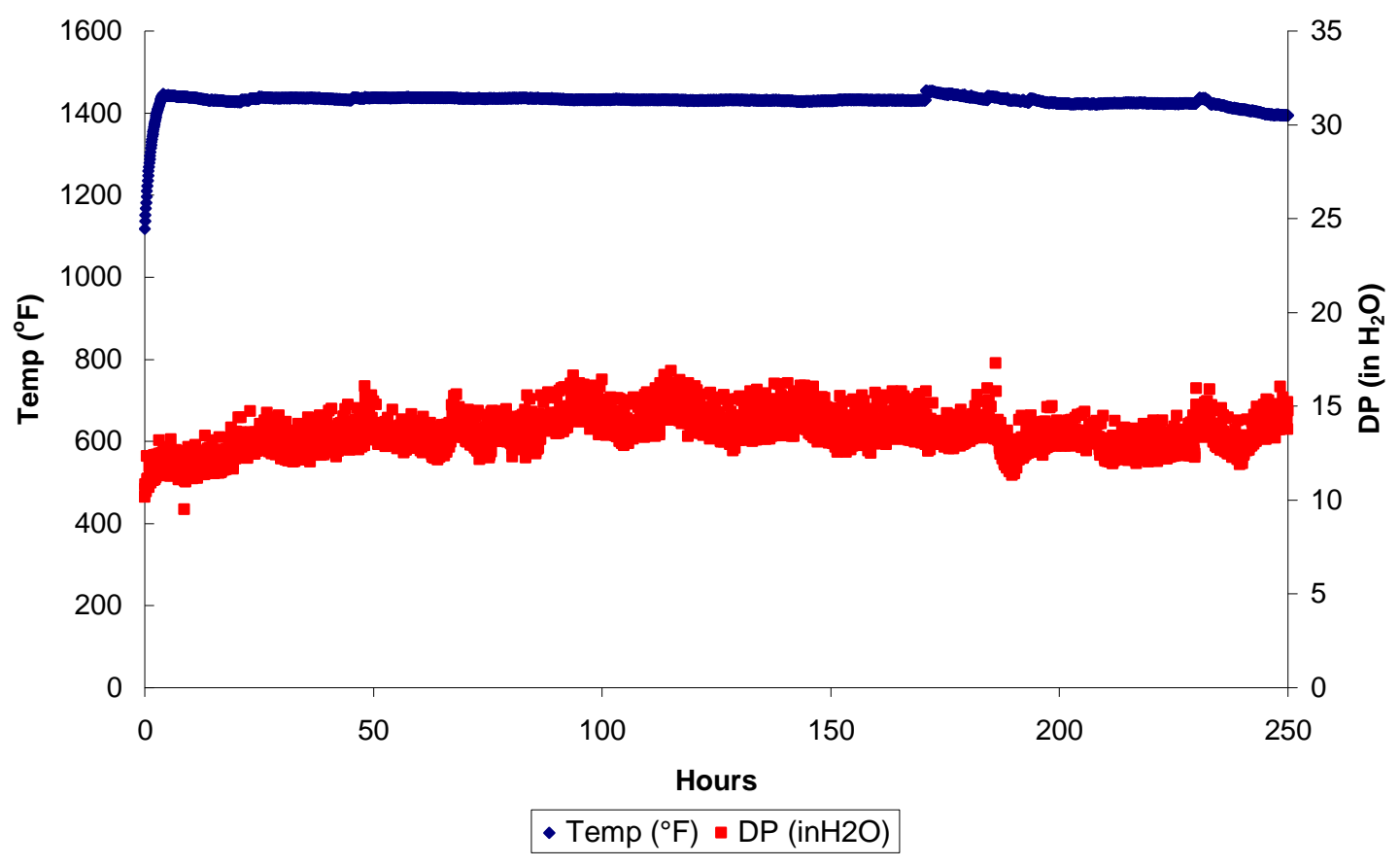

Figure 21: $\quad$ Used filter with $14 \mathrm{~L} / \mathrm{min}$ air and 0.3-0.35 g/min flyash

For a better representation of the conditions seen by the filters in coal plants, steam was added to the inlet mixture in the amount of approximately $0.7 \mathrm{~L} / \mathrm{min}$ (roughly $5 \%$ of the total flow. The results of loading the filter with an air/flyash/steam mixture are shown in Figure 22. It is visible that the differential pressure increased from approximately 10 to 14 inches $\mathrm{H}_{2} \mathrm{O}$ during the test with steam and the one without steam. The conclusion that can be made from this data is that moisture in the flue gas does not greatly contribute to compaction of the flyash on to the filter. Pictures of the filter with flyash caked on from this experiment are shown in Figure 23. The center of the filter had the greatest depth of flyash measured to be 1.12 inches. The thickness of the layer then decreases as you move away from the center in either direction, with bare spots on the filter located at both ends. This was due to the flyash falling off upon removal from the reactor. As is apparent in Figure 23, the filter was thoroughly caked with flyash and only a relatively small increase in DP was seen given the duration of the experiment. 


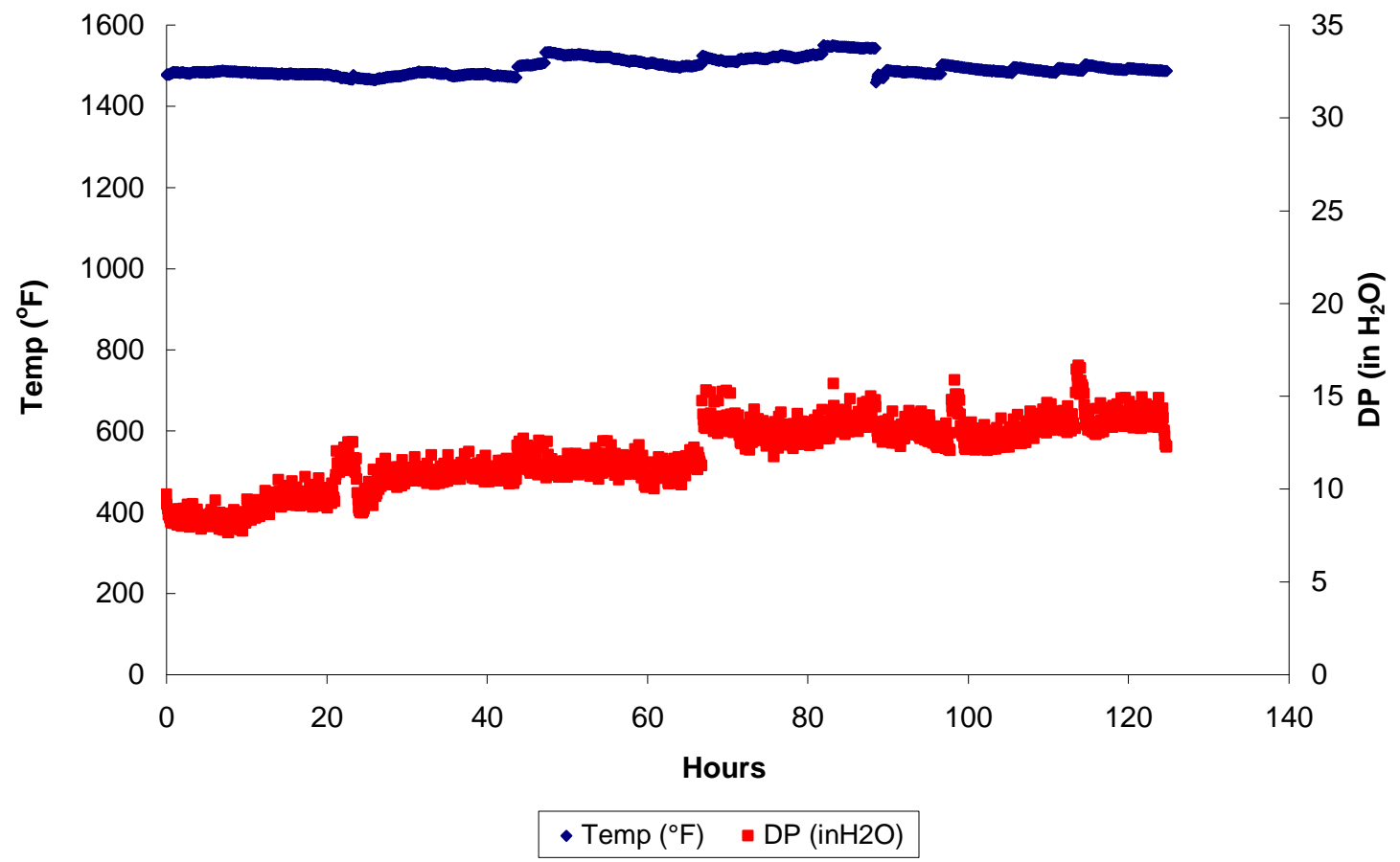

Figure 22: Used filter with $14 \mathrm{~L} / \mathrm{min}$ air, $0.3-0.35 \mathrm{~g} / \mathrm{min}$ flyash, and $0.7 \mathrm{~L} / \mathrm{min}$ steam 


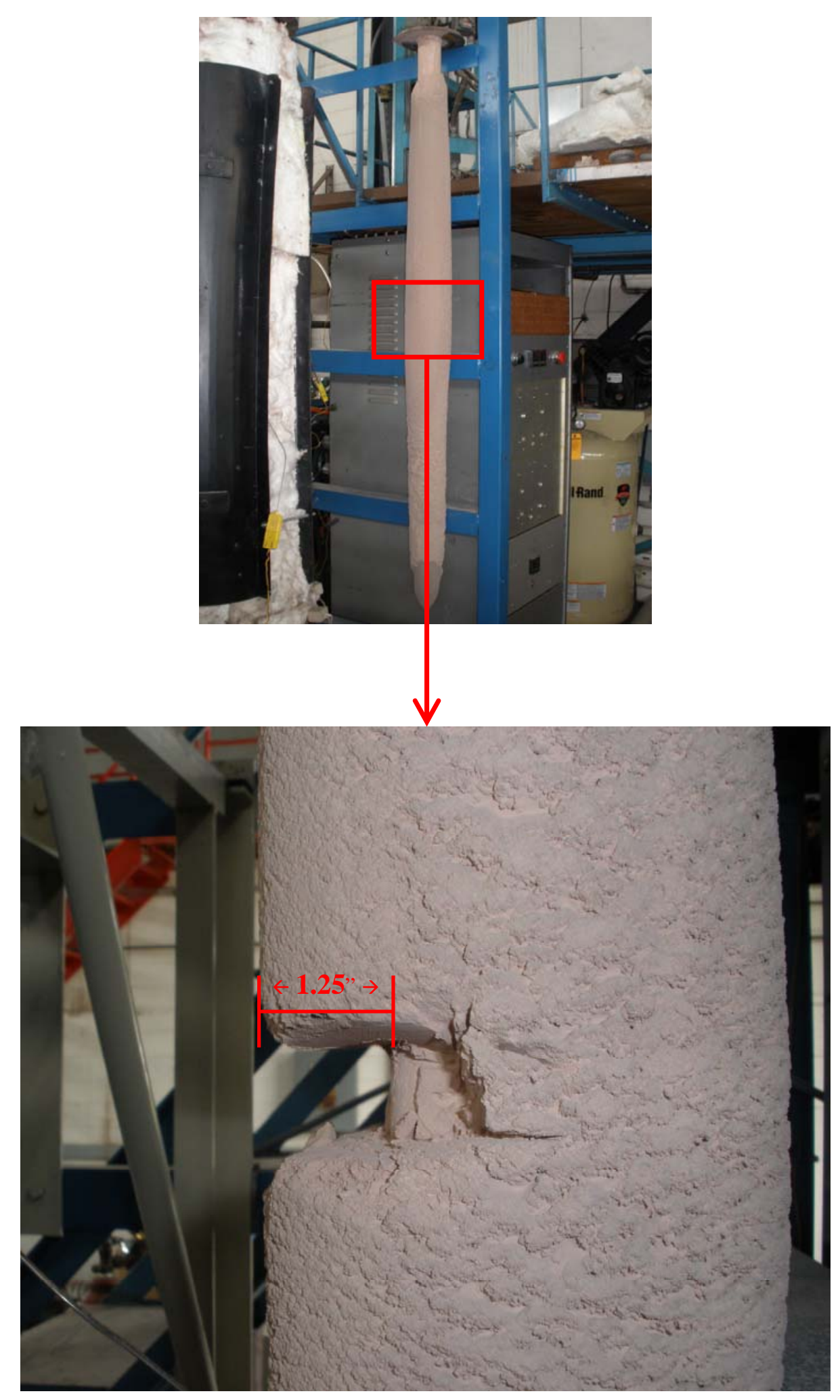

Figure 23: Pictures of the filter loaded with flyash after being subjected to an air/flyash/steam mixture for nearly 130 hours. 
Ten thermal shocks were then performed on the flyash-loaded filter from Figure 23 in the temperature range from below 400 to over $1500{ }^{\circ} \mathrm{F}$. The flyash and steam flows were stopped for this time, leaving only air to flow through the reactor system. The shocks were performed by ramping the heater up (on average $4{ }^{\circ} \mathrm{F} / \mathrm{min}$ ) and then turning the heater off and opening the furnace. The filter was cooled at a rate averaging $12.5^{\circ} \mathrm{F} / \mathrm{min}$. The results from the thermal shock experiment are shown in Figure 24. The pressure drops were monitored and plotted against time and temperature. The data clearly indicates that rapid heating and cooling in this temperature range did not destroy the filter element. The differential pressure increase from as low as 5 to over 11 inches $\mathrm{H}_{2} \mathrm{O}$ was again due to increased temperature only.

Lastly, after cleaning the filter from the previous experiment, a flow of $17.8 \mathrm{~L} / \mathrm{min}$ air, $0.3-0.35 \mathrm{~g} / \mathrm{min}$ flyash, and $0.9 \mathrm{~L} / \mathrm{min}$ steam was passed through the single-filter reactor for 150 hours. By comparing the results of this test (Figure 25) with the results of the previous filter loading test (Figure 22), it can be observed that only a negligible increase in differential pressure was caused by the higher flow rate. Similarly, upon running thermal shock tests with this higher flow rate (air only), no significant changes in the filter performance could be identified from the data (Figure 26).

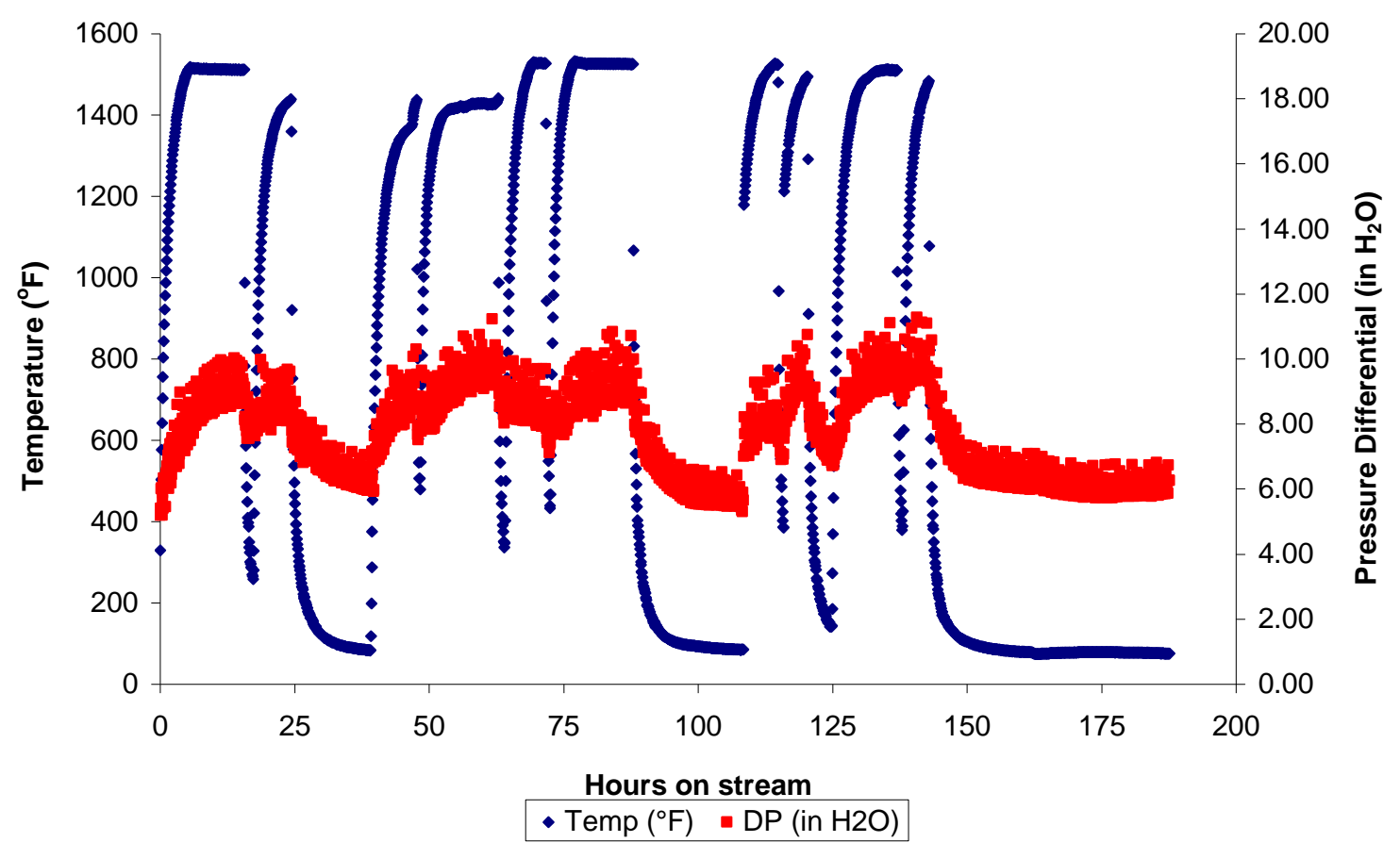

Figure 24: Thermal shock (used filter with flyash caked on, air flow=14 L/min) 


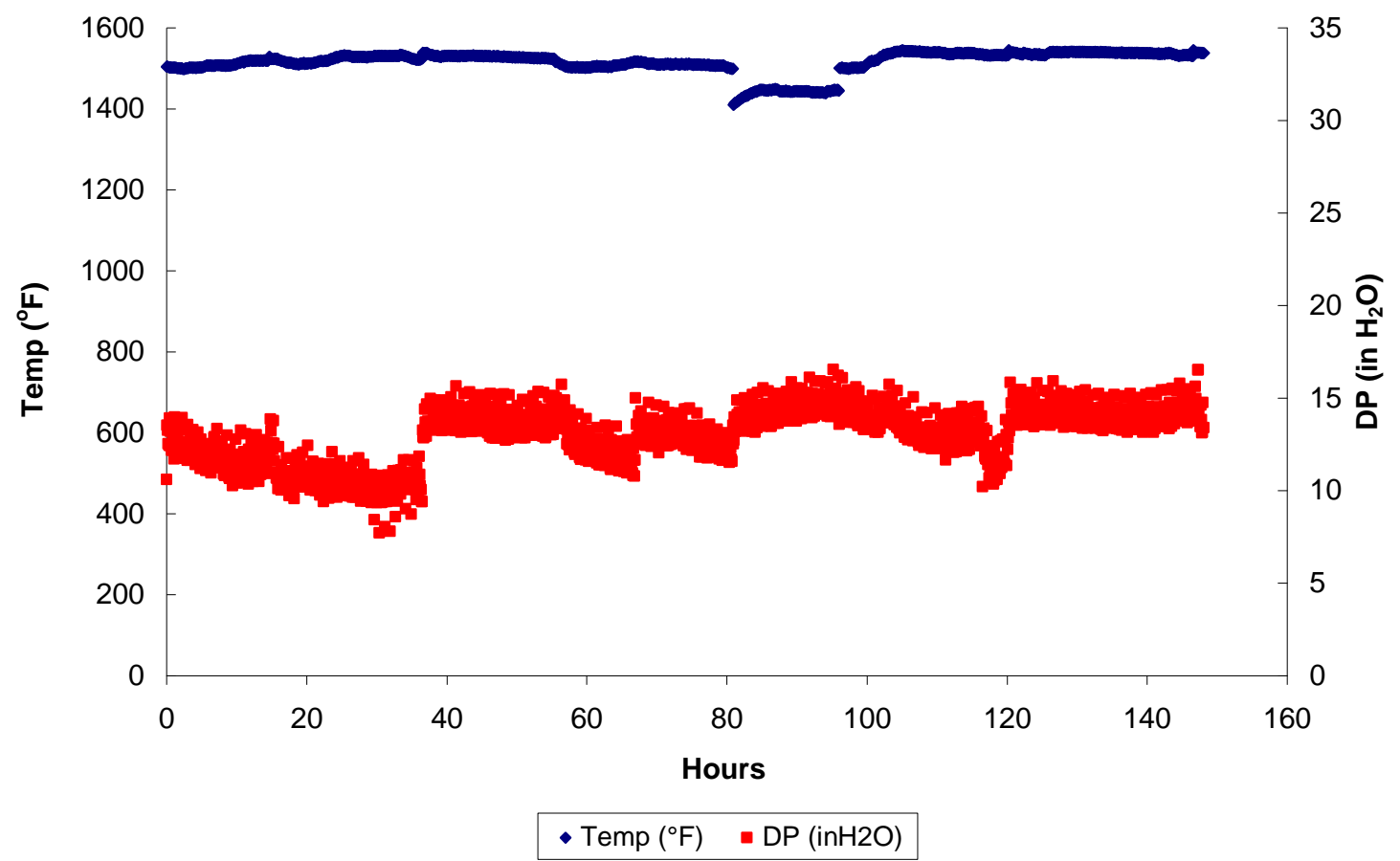

Figure 25: $\quad$ Used filter with $17.8 \mathrm{~L} / \mathrm{min}$ air, $0.3-0.35 \mathrm{~g} / \mathrm{min}$ flyash, and $0.9 \mathrm{~L} / \mathrm{min}$ steam

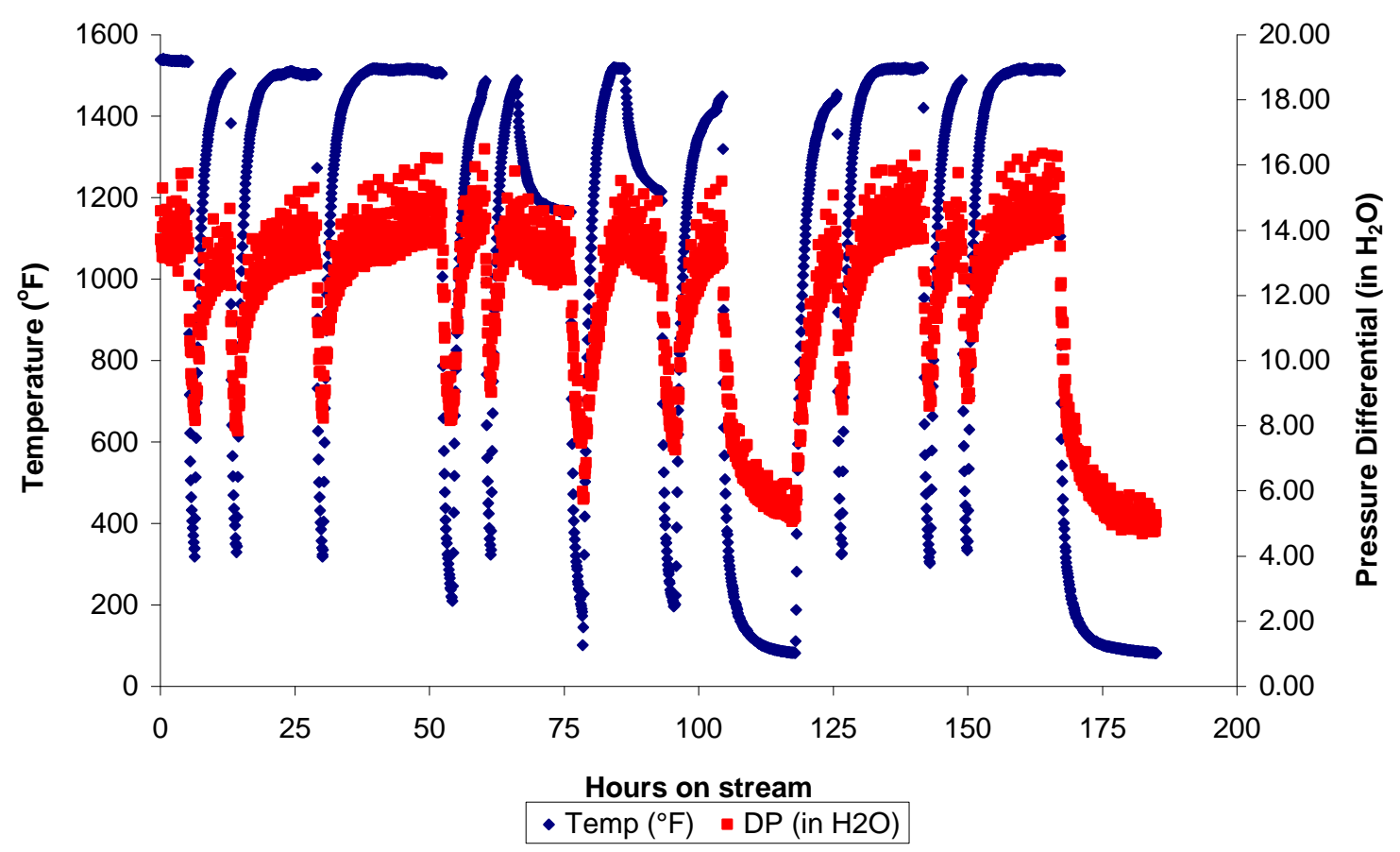

Figure 26: Thermal shock (used filter with flyash caked on, air flow $=17.8 \mathrm{~L} / \mathrm{min}$ ) 


\section{Task 7. “Single Filter” Long Term Experiments}

These experiments were carried out for 276 days using the "single-filter" system described in Experimental and present in Figures 3 and 4. The gas flow was setup for 14.7 L/min and the fly ash loading was $1.92 \mathrm{~g} / \mathrm{min}$. The fly ash used in this test came from SIUC's Steam Plant and was the same that was used in the "12-filter" Slip stream test.

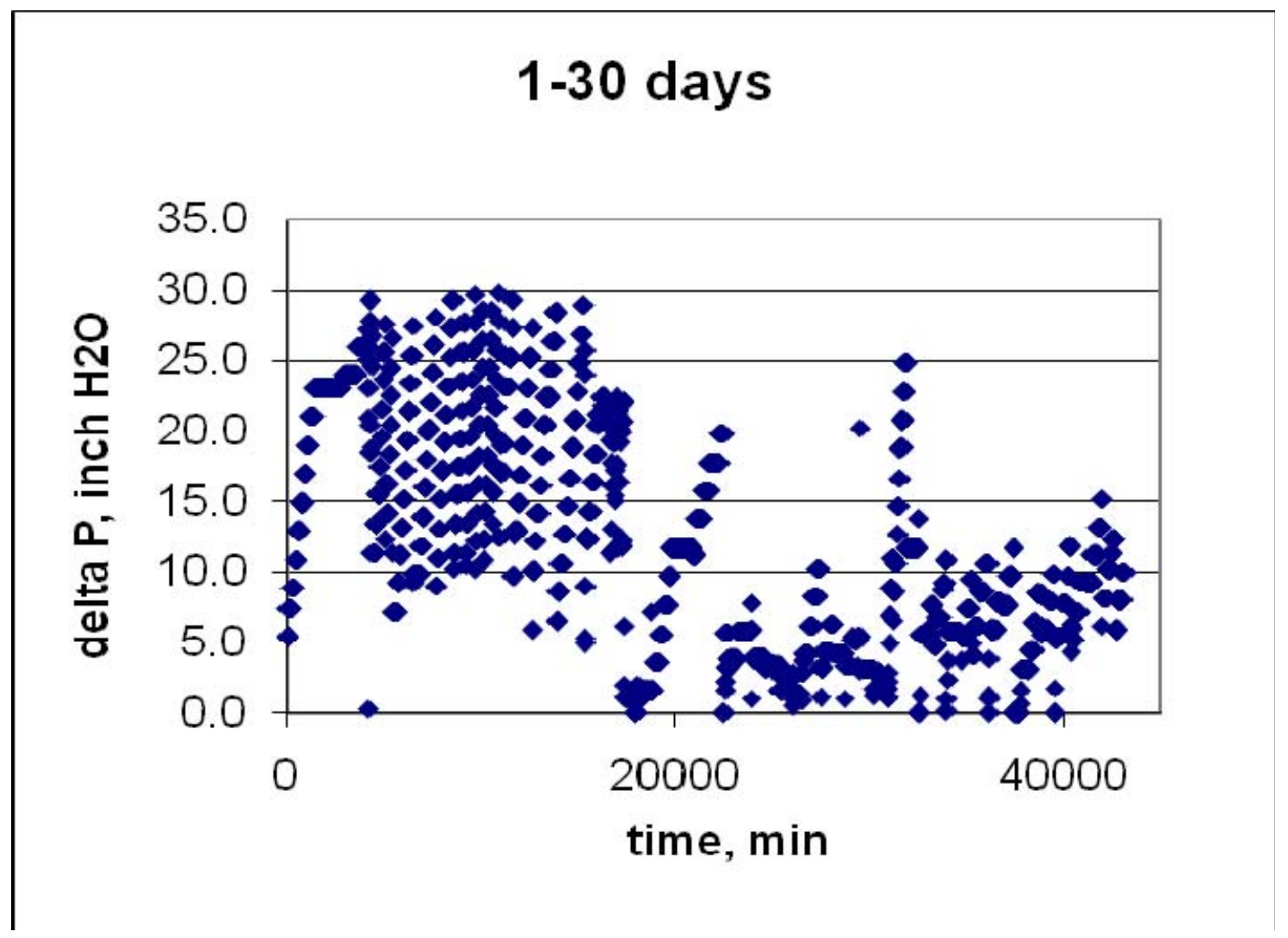

Figure 27 “Single Filter” Experiments 1-30 days 


\section{$31-60$ days}

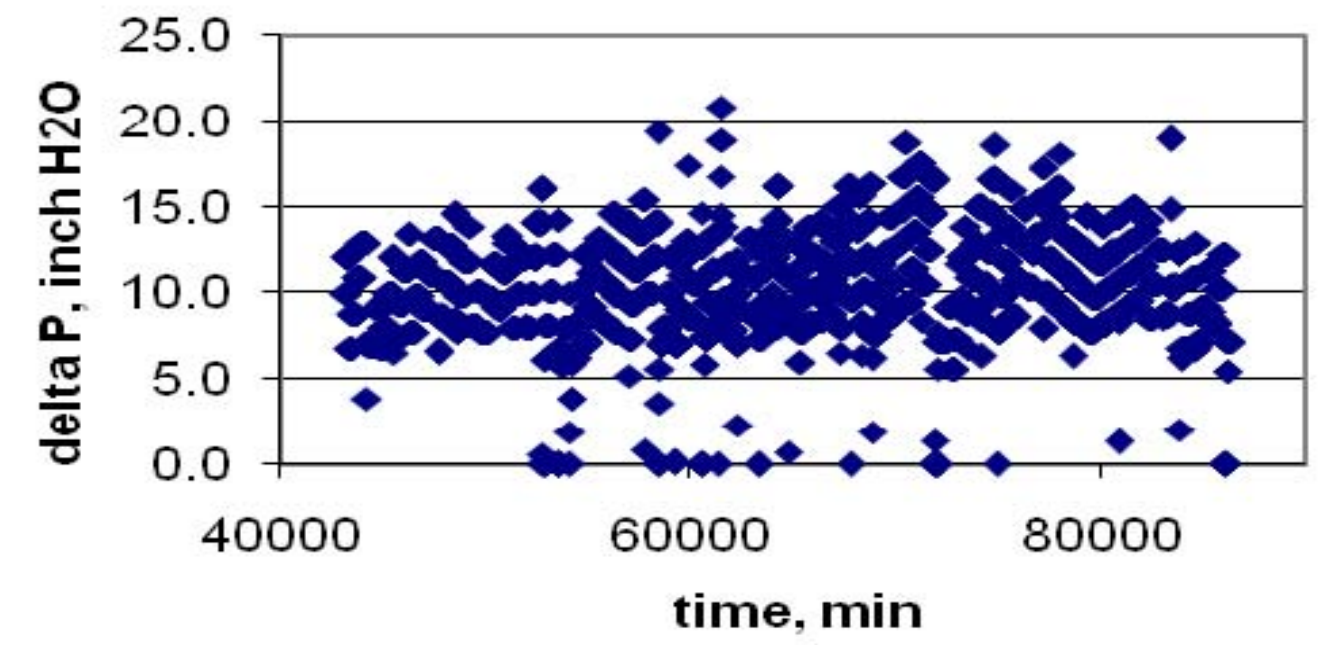

Figure 28: “Single Filter” Experiments 31-60 days

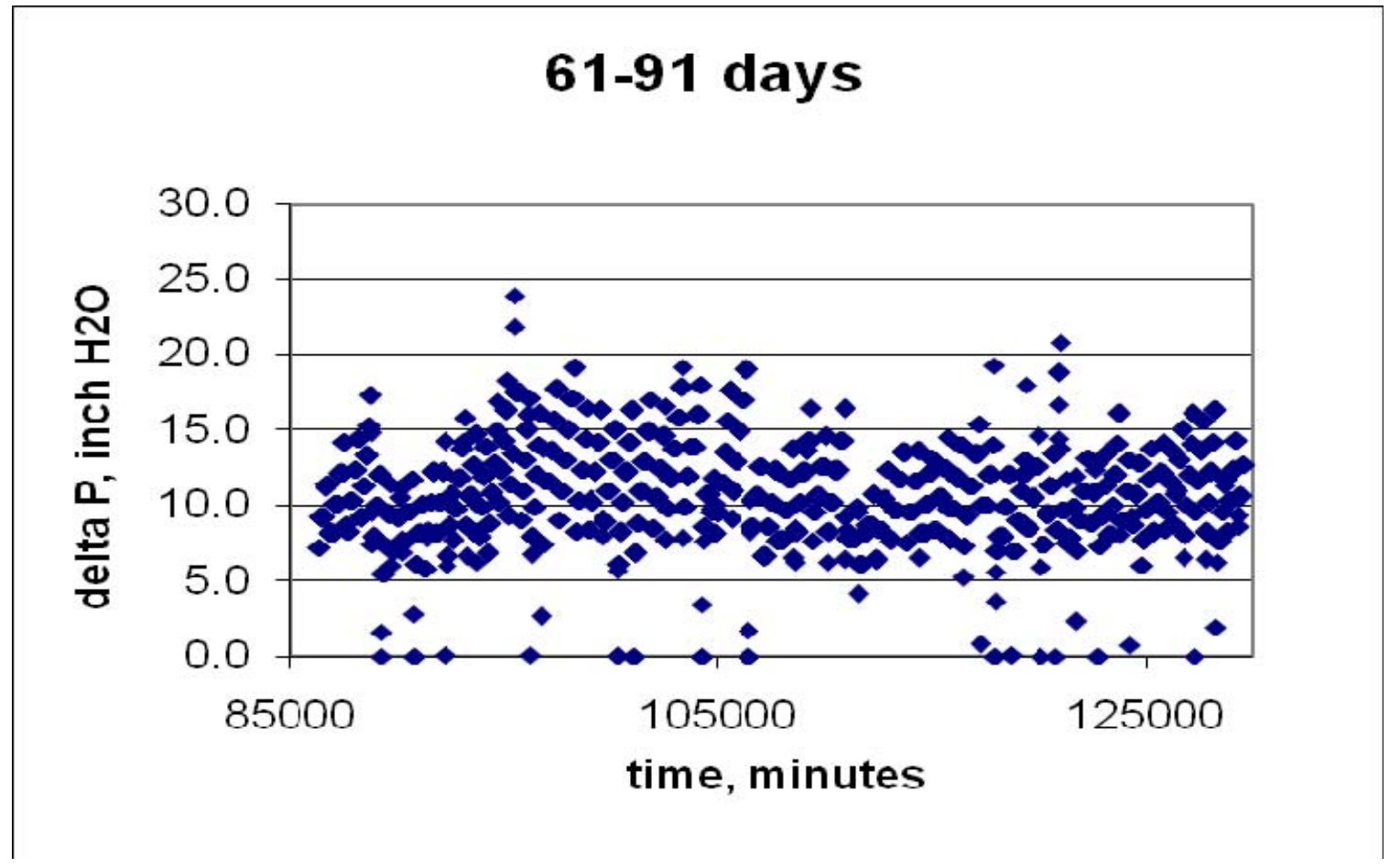

Figure 29: “Single Filter” Experiments 61-91 days 


\section{2-115 days}

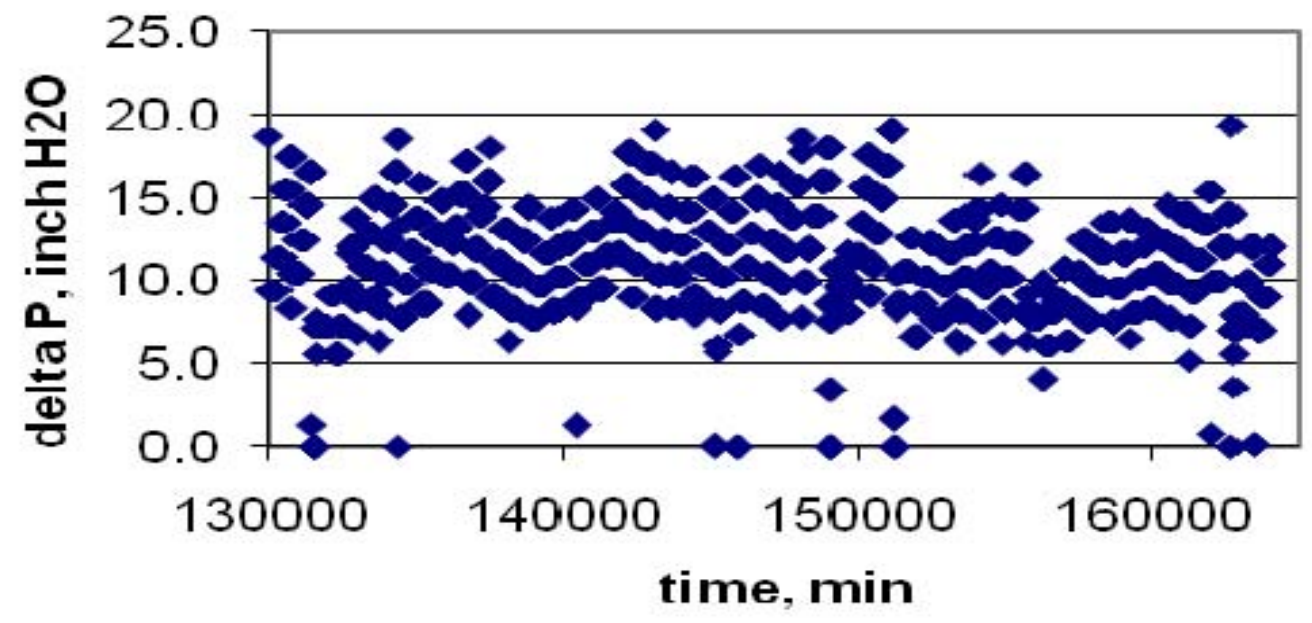

Figure 30: “Single Filter” Experiments 92-115 days

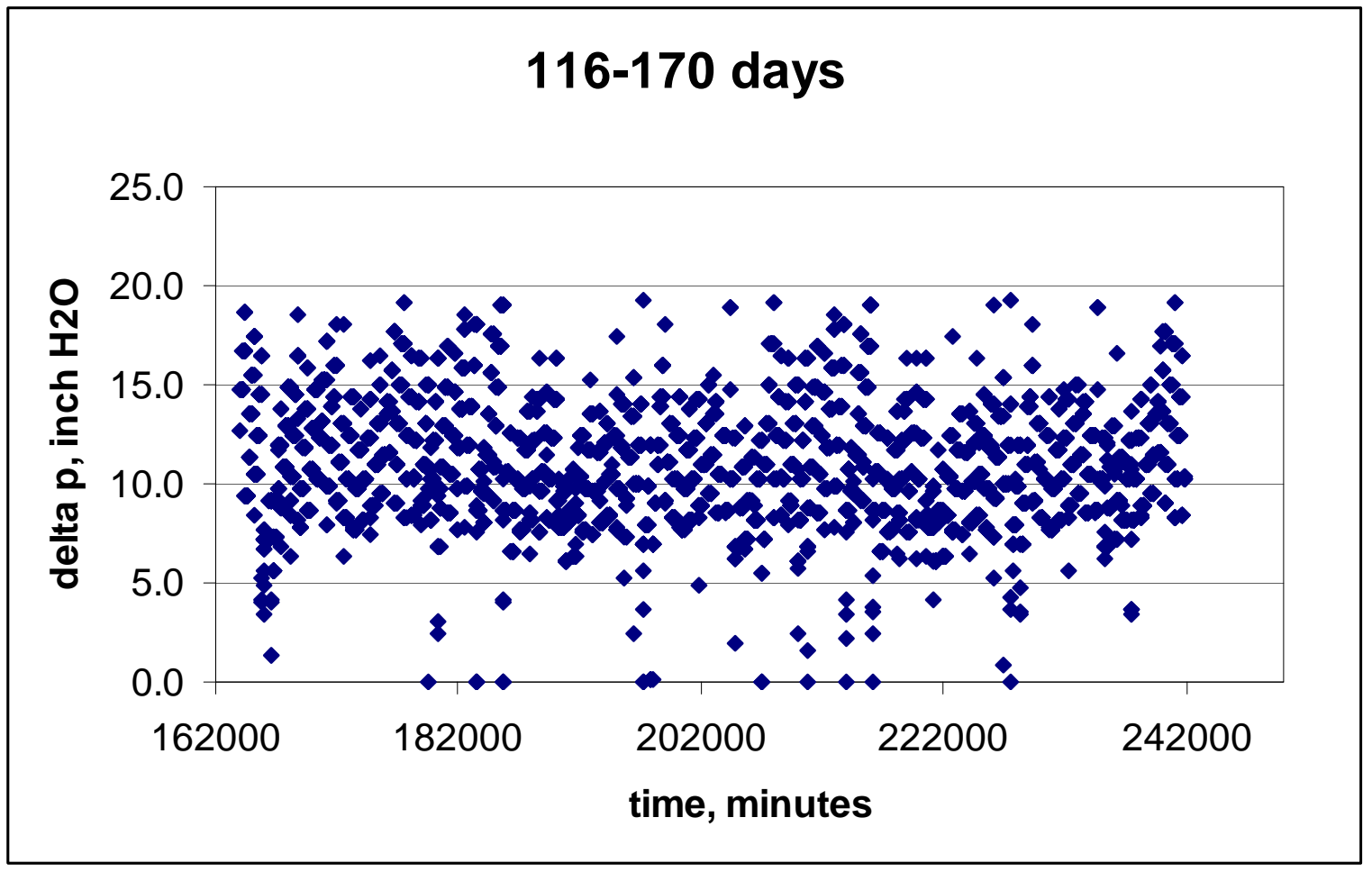

Figure 31: “Single Filter” Experiments 116-170 days 


\section{$171-220$ days}

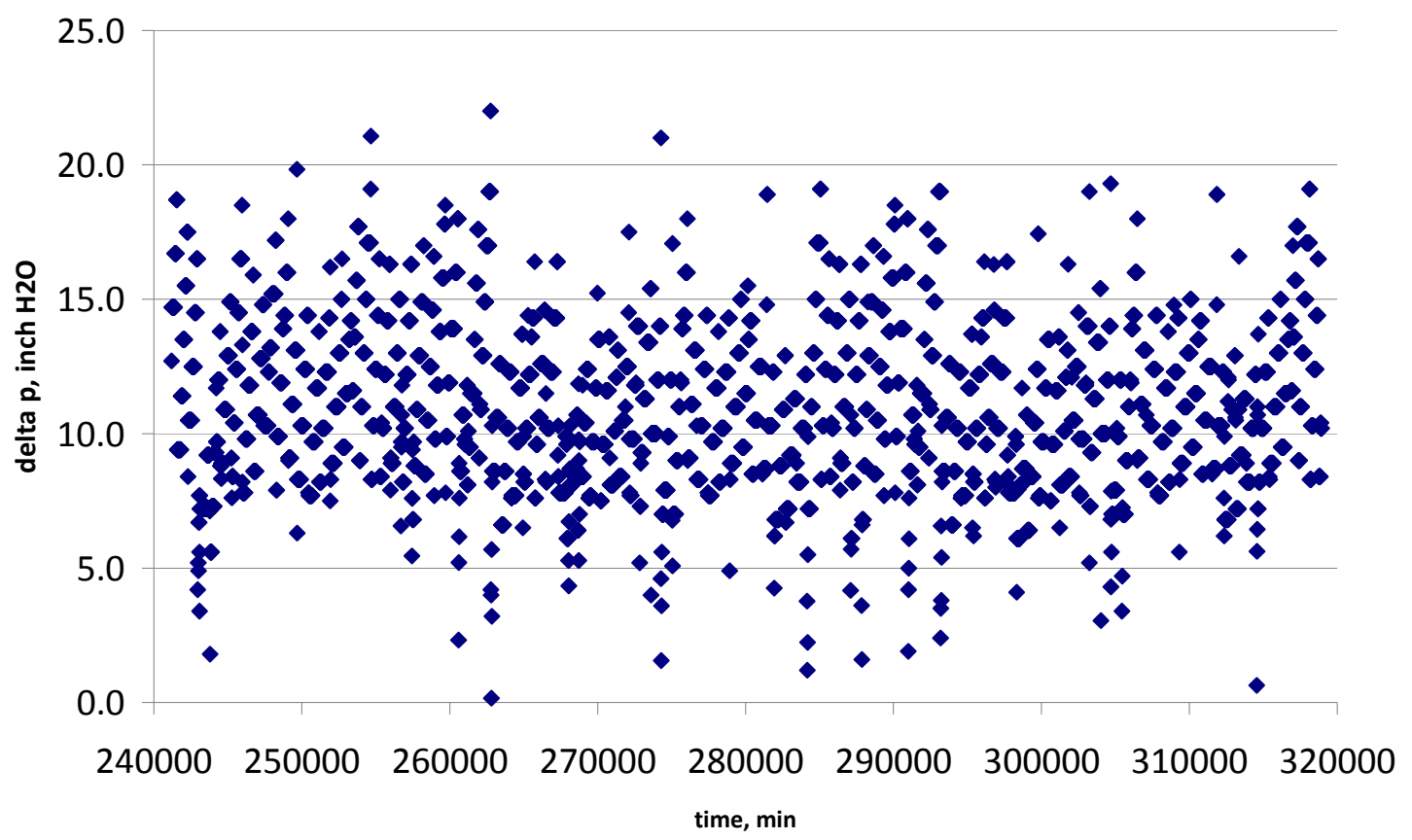

Figure 32: “Single Filter” Experiments 171-220 days

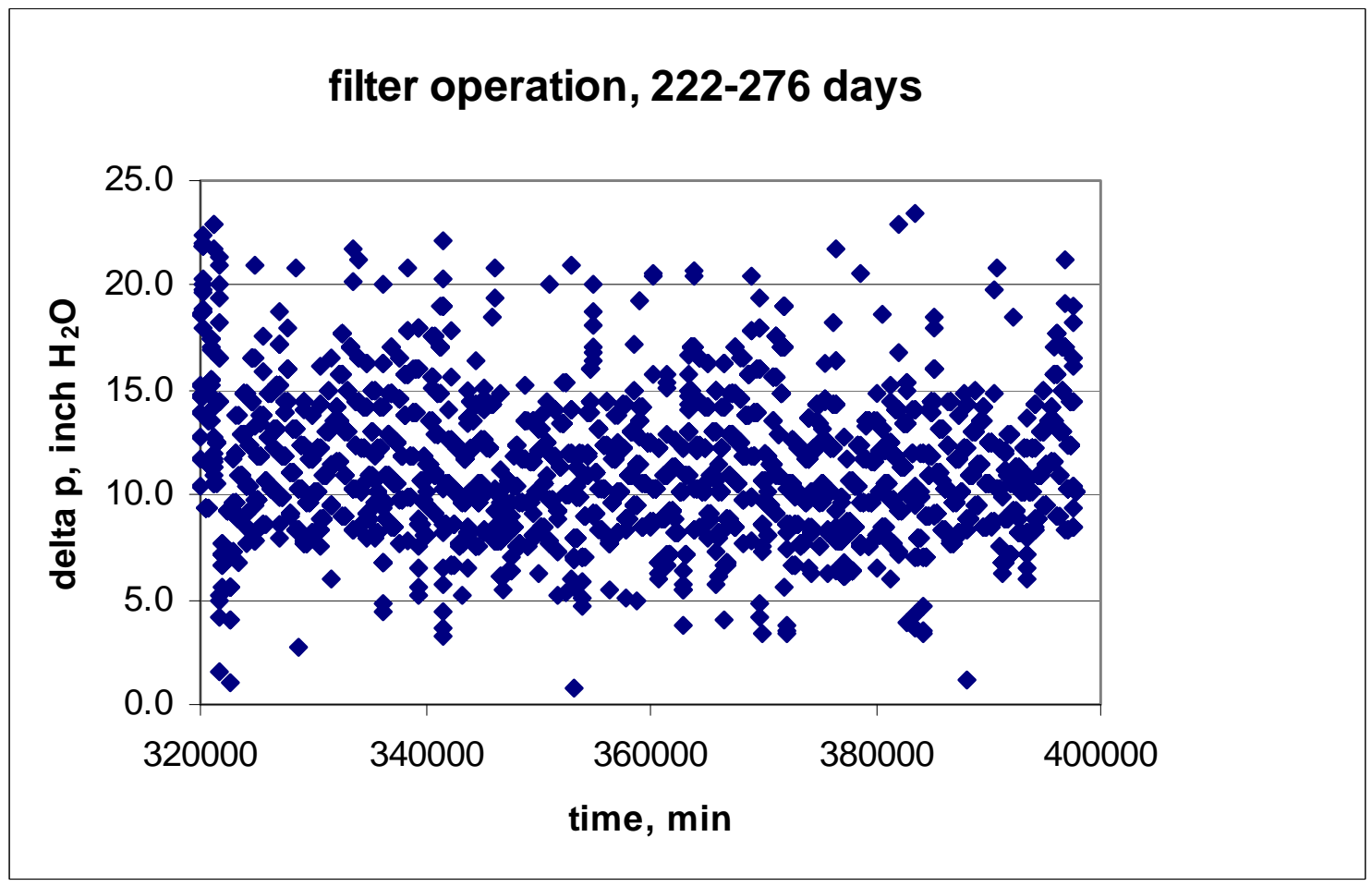

Figure 33: “Single Filter” Experiments 222-276 days 


\section{CONCLUSION}

Ceramic filters used in hot flue gas cleaning applications were tested in the slipstream long-term operation (Steam Plant-SIUC) and also tested in the different experiments using a so called "single-filter" unit located in the SIUC Coal Development Park. Based upon the test and analyses of this project, the following conclusions can be stated.

\section{$\underline{\text { Slipstream Steam Plant Testing }}$}

- The used filter elements were visually inspected and no cracks were found along the outer surface of the filter body.

- The simple observation and comparison of the exact measurements of the filter before and after the 45 days operation show no bending.

- The long term operation with real flue gas in a slipstream indicates no changes in the differential pressure between the cleaning air pulses.

\section{$\underline{\text { SEM Micrographs Analysis }}$}

- The micrograph of the used filter shows more fine particles, suggesting the sintering of the filter during the operation.

$\underline{\text { Permeability Analysis }}$

- The calculation of the permeability of the filters shows that the adherence of the fly ash onto the filter and subsequent caking results in the reduction of the permeability of the filter elements.

- The data also shows that an increase in the gas flow rate increases the permeability.

- Pulsing the air in the reverse direction sufficiently breaks off the cake and restores the original permeability of the filters.

\section{$\underline{\text { BET Surface Area Measurements }}$}

- The BET measurements show that mean pore radius of the used filter decreases from 18.10 A to $13.81 \mathrm{~A}$. This indicates that some of the pores are being plugged during the filtering process.

- The above conclusion is corroborated by a decrease in the surface area from 6.16 $\mathrm{m}^{2} / \mathrm{g}$ for the fresh filter to $3.34 \mathrm{~m}^{2} / \mathrm{g}$ for the used filter.

\section{$\underline{\text { Pressure Drop Tests }}$}

- There was only a minimal increase in the pressure drop caused by the long-term use of the filter, despite the results from the SEM, permeability, and BET tests.

- The pressure drop for both the new and used filters increases with the air flow rate and temperature. 
- Purging the filters was effective in restoring low pressure drop and therefore, cleaning the filter.

\section{Thermal Shock Tests in a Single-Filter Reactor}

- The differential pressure increases during the thermal shock tests were due to increased temperature only.

- Rapid cooling and heating in the temperature range of $180{ }^{\circ} \mathrm{F}-1500{ }^{\circ} \mathrm{F}$ did not destroy the filter.

- Thermal shocks of the filter heavily covered by the thick layer the fly ash cake show the pressure variation in the range of $5-17$ inches $\mathrm{H}_{2} \mathrm{O}$.

\section{RECOMMENDATIONS}

The results of both the single-filter reactor and Steam Plant 12-filter vessel testing indicated a high collection efficiency, high permeability and no cracks or other structural defects. However, opportunities for future studies still remain. At the conclusion of this project, the following recommendations can be made for future research:

- The filters maintained functionality throughout all of the efforts in this work, therefore, it is recommended that more experiments be performed in a higher temperature range (above $1500{ }^{\circ} \mathrm{F}$ ) to determine the minimum failure temperature.

- The separate detailed studies should be performed to determine the alkali effect on the chemical reactions between the filters and flue gas alkali components.

- Additional research should be carried out on the effect of the alkali on the fly ash cake properties. This should be helpful in the determination of the pulsing period (based not only on the differential pressure increase). The frequency at which pulsing is applied to the system should depend not only on the maxim differential pressure but also on the properties of the cake. Cake is being formed because of (a) barrier of the filter wall and also (b) the agglomeration of the fly ash particles. This agglomeration is the function of the surface properties of the fly ash that are modified in the contact with alkali.

- Tests should be performed in which filters are be impregnated with SCR catalysts for simultaneous removal of $\mathrm{NO}_{\mathrm{x}}$ and particulates. 
APPENDIX 


\section{$\underline{\text { Schematics of Filter Vessel Location at SIUC Steam Plant }}$}
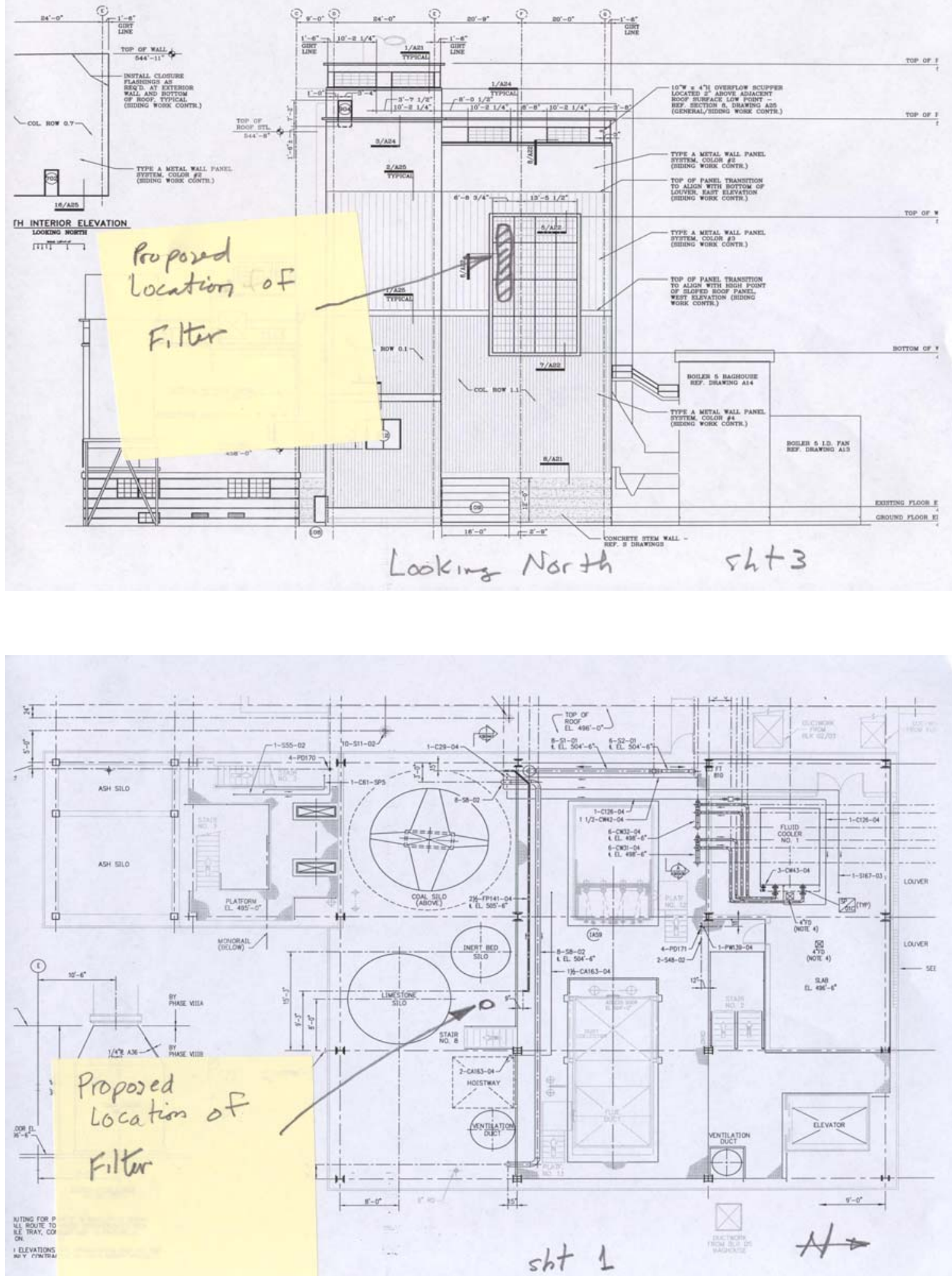


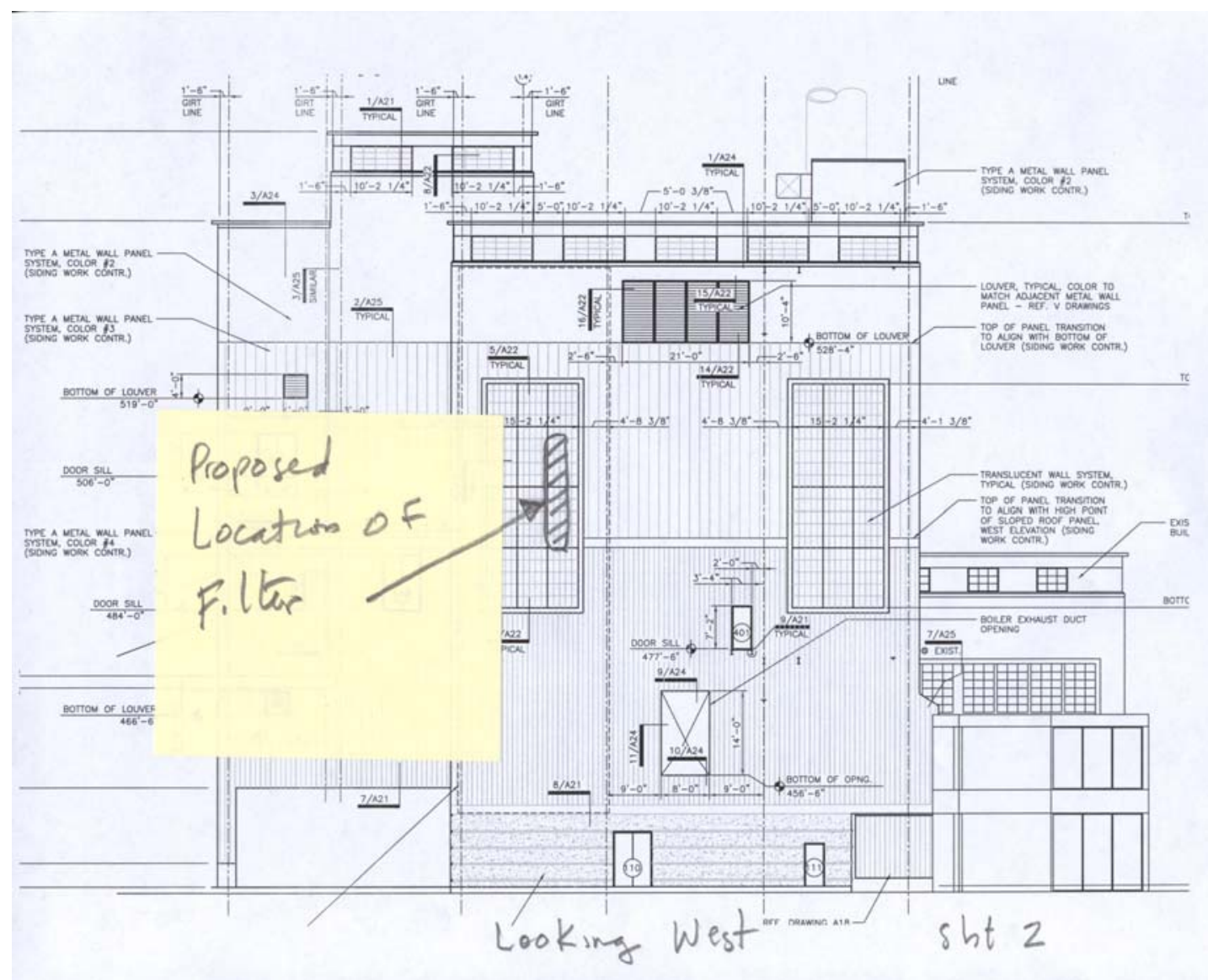


Filter Array Vessel Schematics

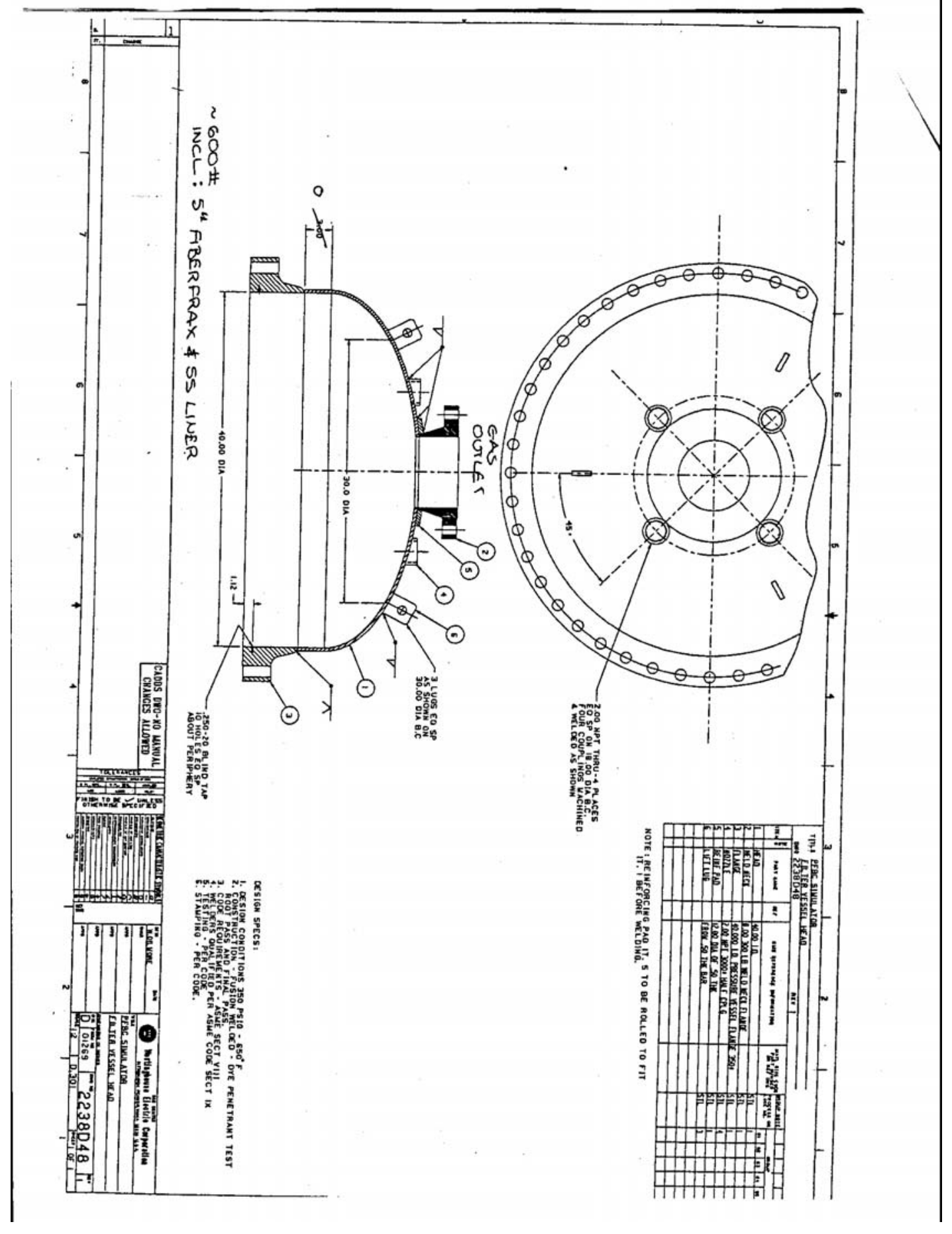




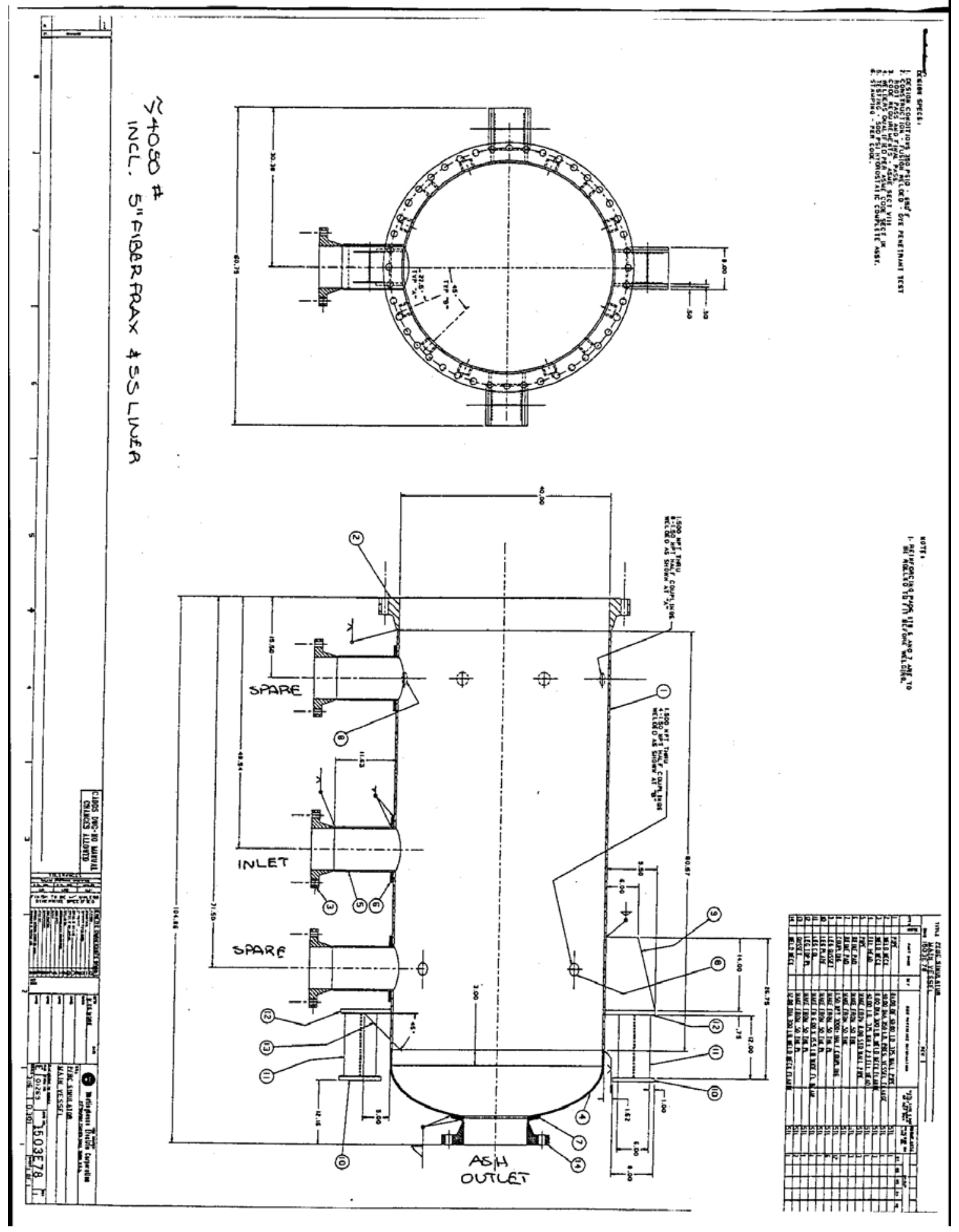




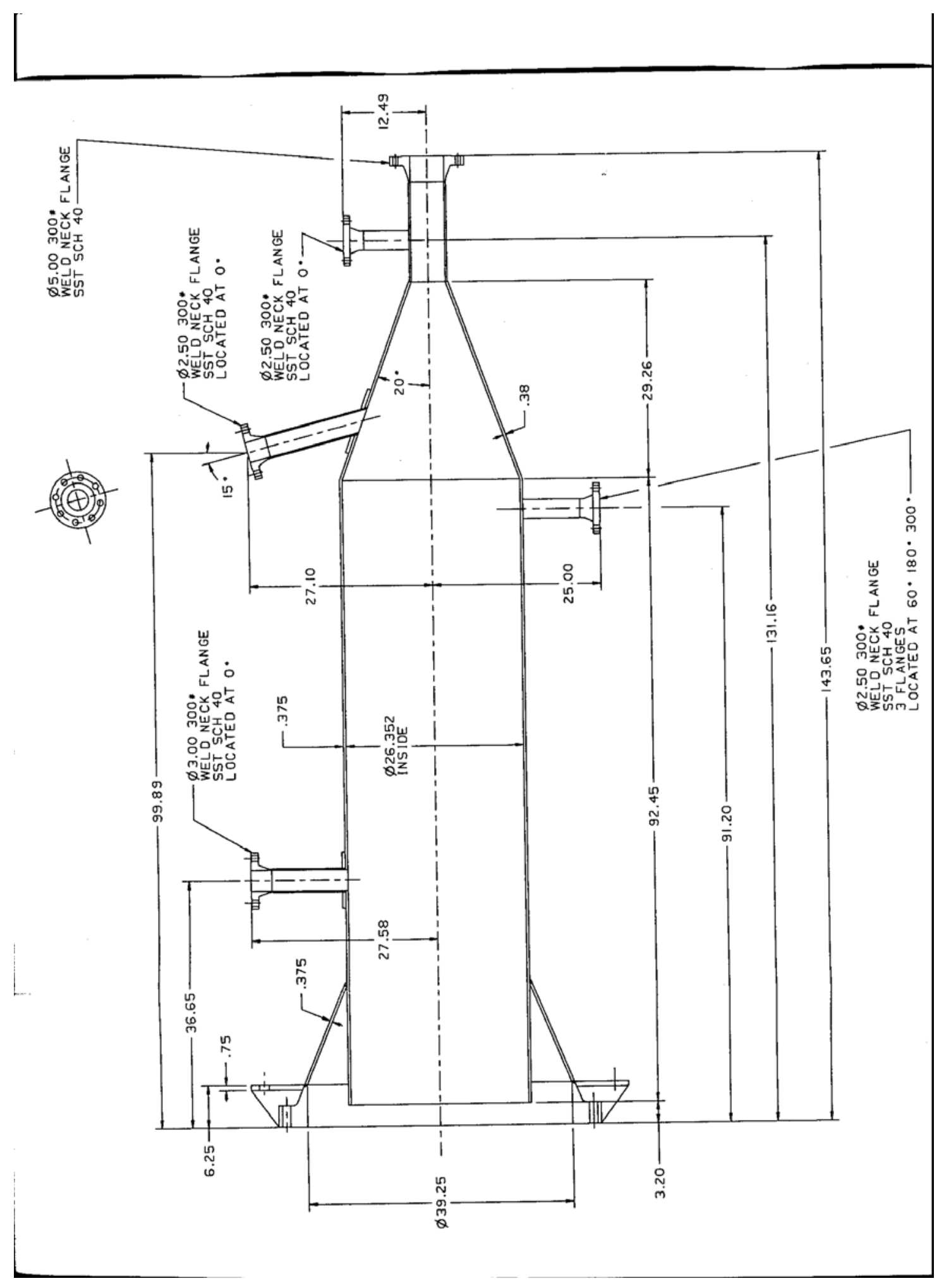




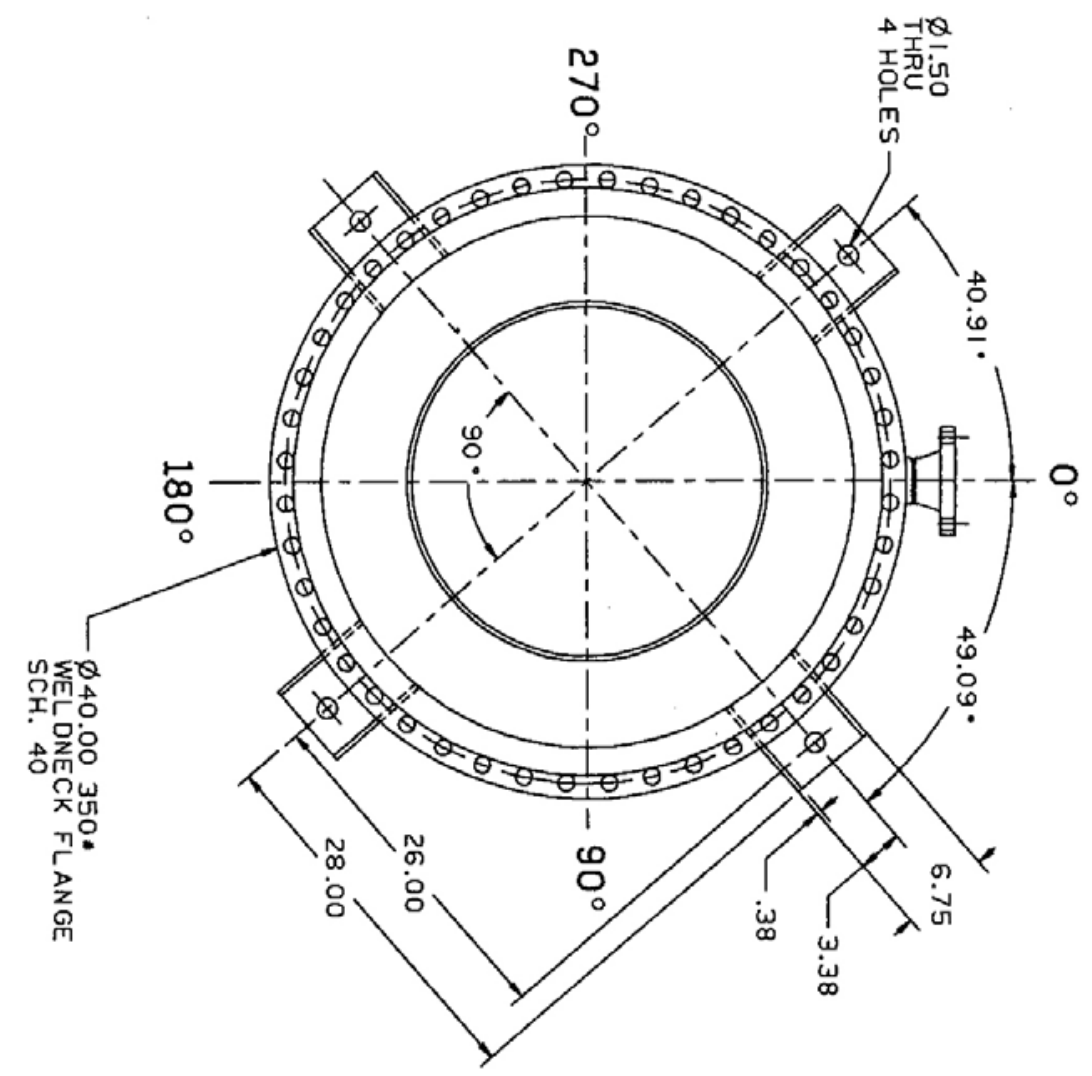




\section{HGF SLIPSTREAM}

VESSEL FOR SIU

PRELIMINARY

HEAD SKETCH

903531.VESSEL -PREL IM INARY

W.E.K. $2004,02,25$

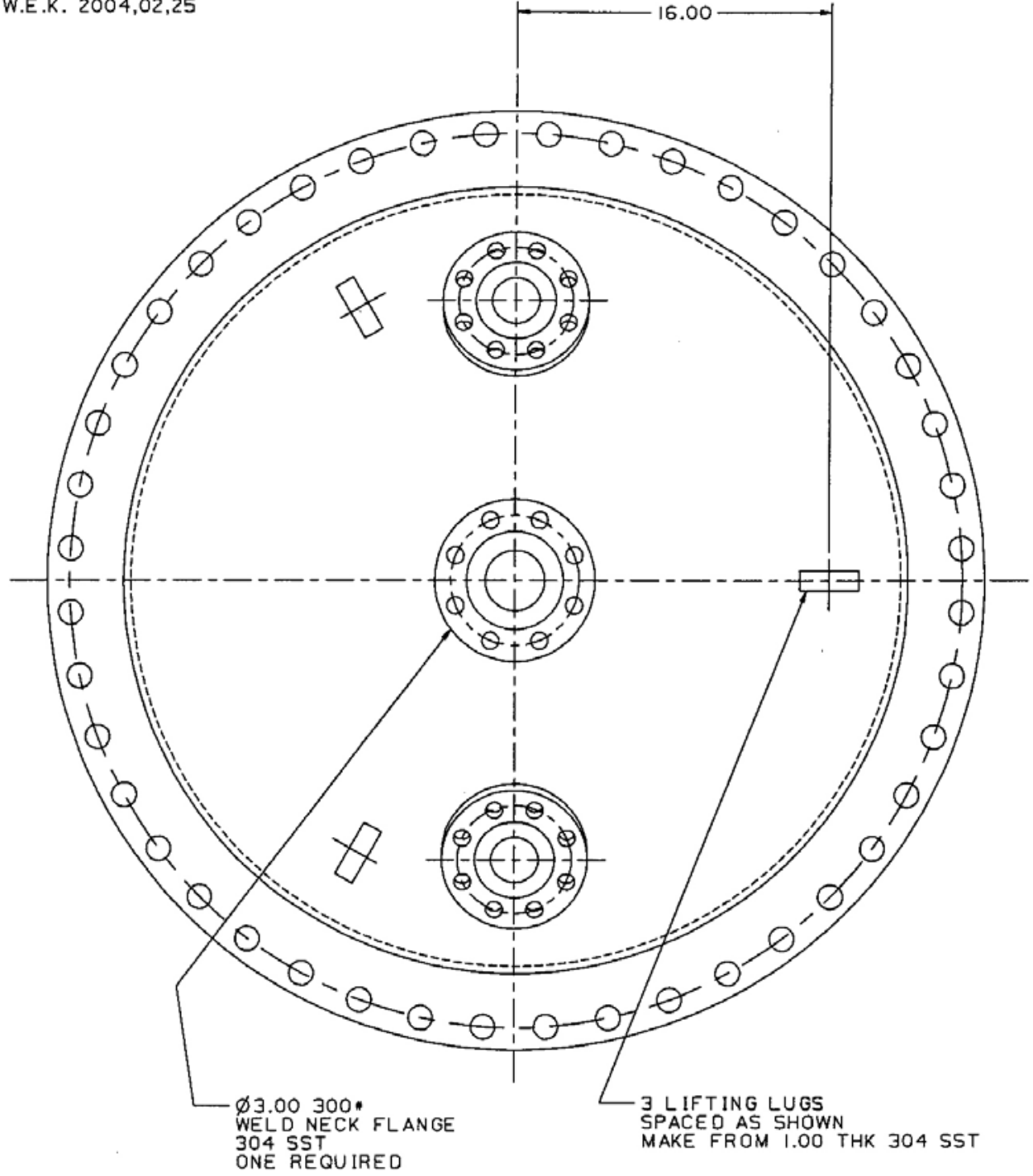




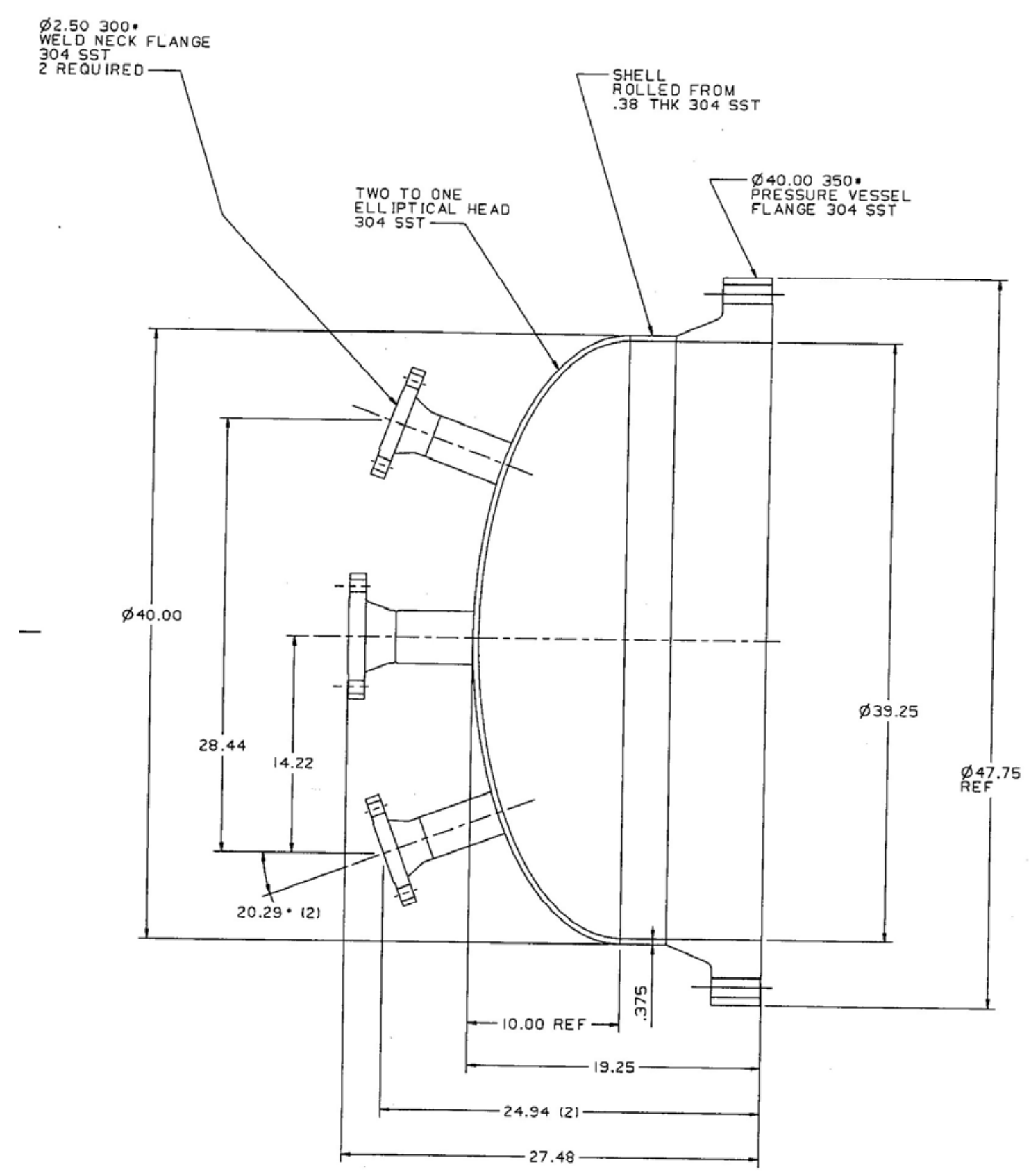




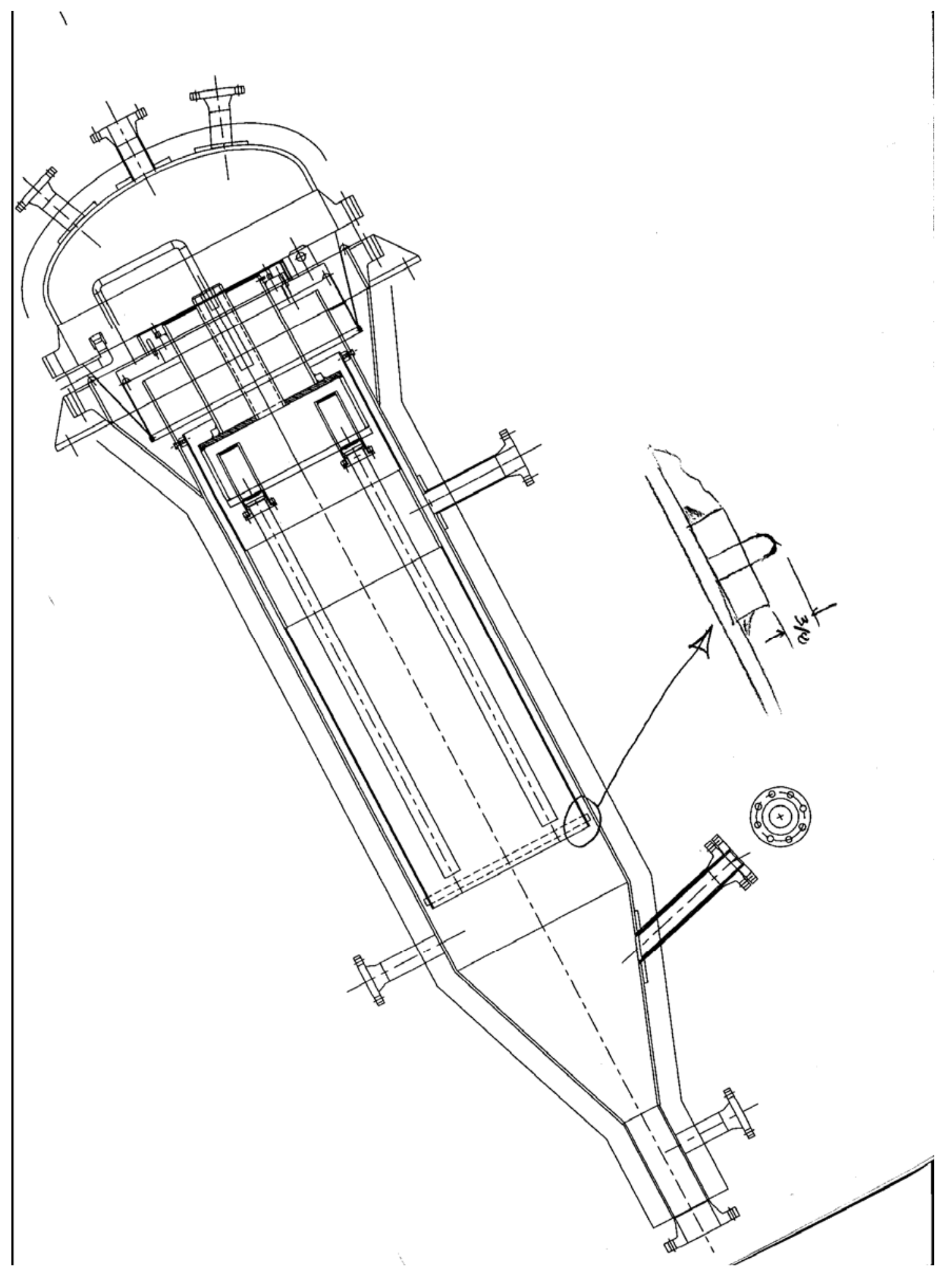




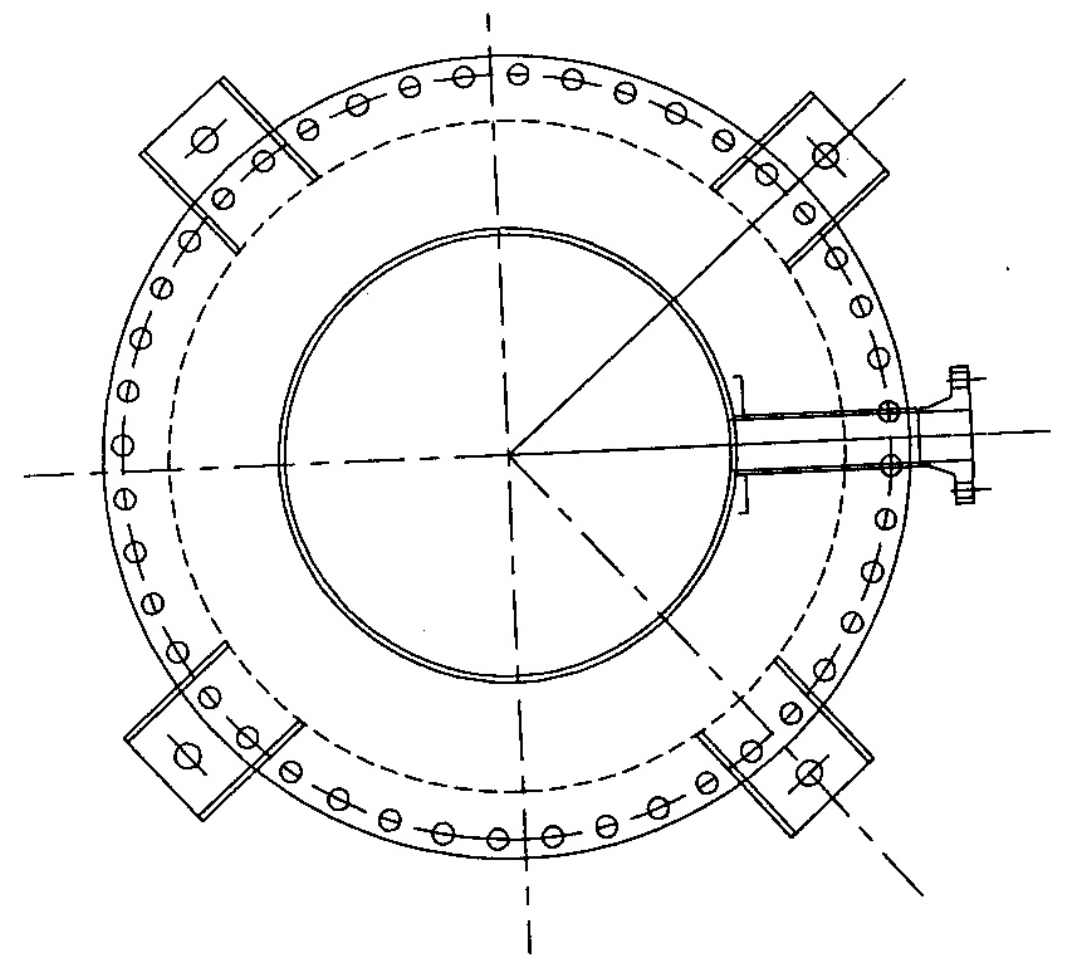

Filter Array Vessel Photos

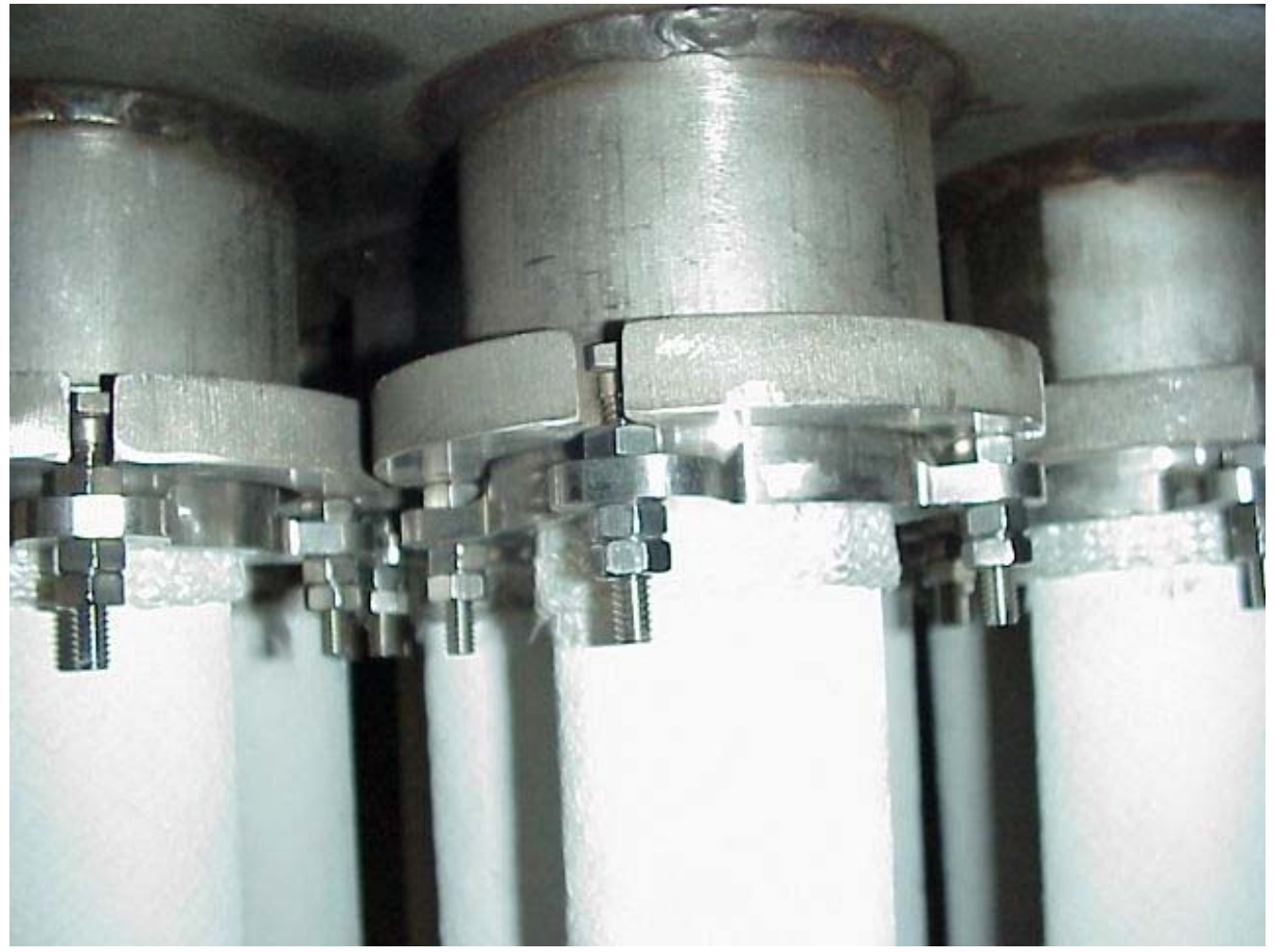




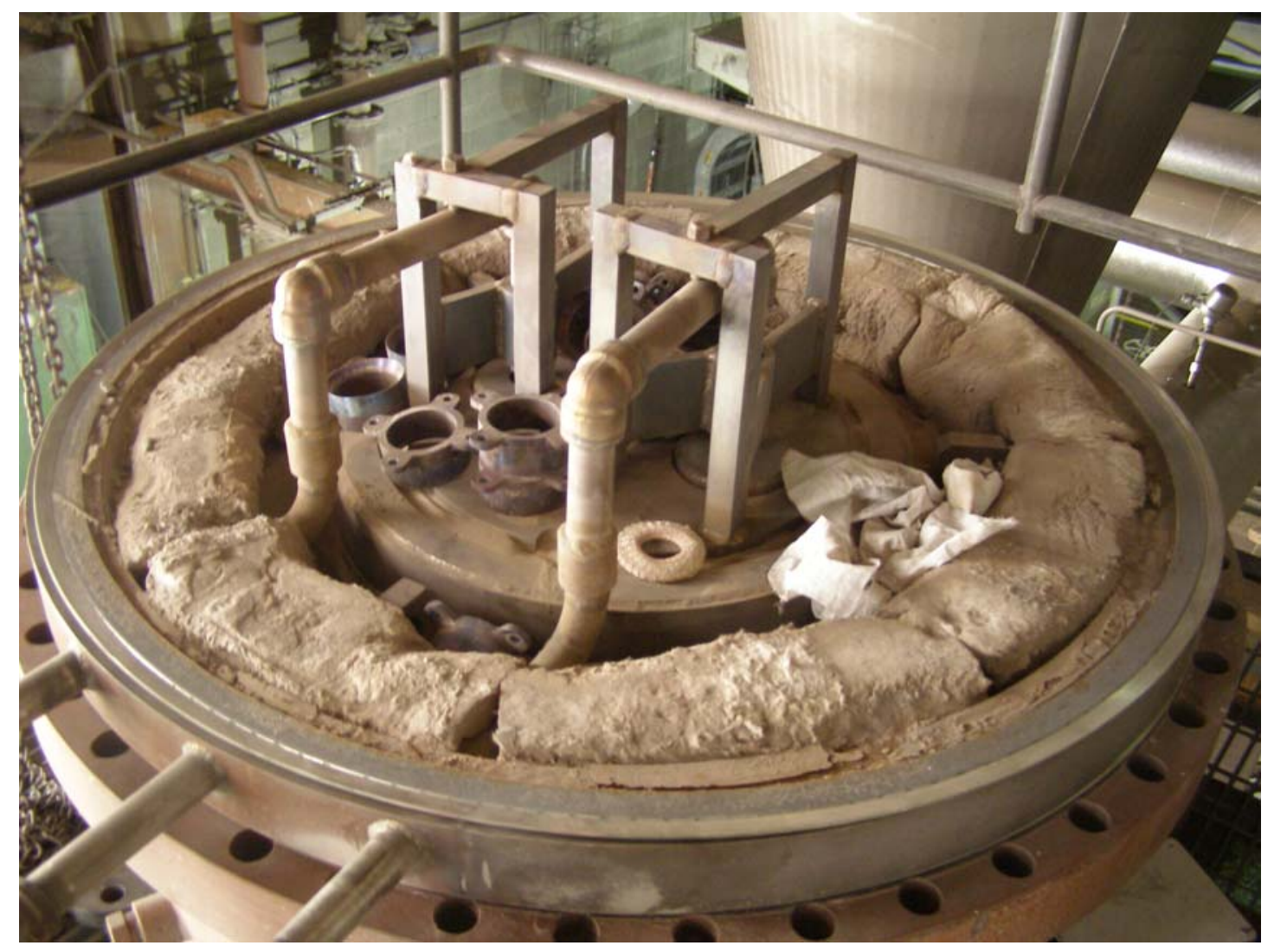

